\title{
Carbon Nanotube-Based Electrochemical Sensors: Principles and Applications in Biomedical Systems
}

\author{
Chengguo $\mathrm{Hu}^{1,2}$ and Shengshui $\mathrm{Hu}^{1,2}$ \\ ${ }^{1}$ Key Laboratory of Analytical Chemistry for Biology and Medicine (Ministry of Education), \\ College of Chemistry and Molecular Sciences, Wuhan University, Wuhan 430072, China \\ ${ }^{2}$ State Key Laboratory of Transducer Technology, Chinese Academy of Sciences, Beijing 100080, China
}

Correspondence should be addressed to Shengshui Hu, sshu@whu.edu.cn

Received 20 December 2008; Accepted 18 March 2009

Recommended by Michele Penza

Carbon nanotubes (CNTs) have received considerable attention in the field of electrochemical sensing, due to their unique structural, electronic and chemical properties, for instance, unique tubular nanostructure, large specific surface, excellent conductivity, modifiable sidewall, high conductivity, good biocompatibility, and so on. Here, we tried to give a comprehensive review on some important aspects of the applications of CNT-based electrochemical sensors in biomedical systems, including the electrochemical nature of CNTs, the methods for dispersing CNTs in solution, the approaches to the immobilization of functional CNT sensing films on electrodes, and the extensive biomedical applications of the CNT-based electrochemical sensors. In the last section, we mainly focused on the applications of CNT-based electrochemical sensors in the analysis of various biological substances and drugs, the methods for constructing enzyme-based electrochemical biosensors and the direct electron transfer of redox proteins on CNTs. Because several crucial factors (e.g., the surface properties of carbon nanotubes, the methods for constructing carbon nanotube electrodes and the manners for electrochemical sensing applications) predominated the analytical performances of carbon nanotube electrodes, a systematical comprehension of the related knowledge was essential to the acquaintance, mastery and development of carbon nanotube-based electrochemical sensors.

Copyright () 2009 C. Hu and S. Hu. This is an open access article distributed under the Creative Commons Attribution License, which permits unrestricted use, distribution, and reproduction in any medium, provided the original work is properly cited.

\section{Introduction}

Carbon nanotubes (CNTs) have become the subject of intense researches in the last decades because of their unique properties and the promising applications in any aspect of nanotechnology. Because of their unique one-dimensional nanostructures, CNTs display fascinating electronic and optical properties that are distinct from other carbonaceous materials and nanoparticles of other types. CNTs are widely used in electronic and optoelectronic, biomedical, pharmaceutical, energy, catalytic, analytical, and material fields. Particularly, the properties of small dimensions, functional surfaces, good conductivity, excellent biocompatibility, modifiable sidewall, and high reactivity make CNTs ideal candidates for constructing sensors with high performances. As an example, CNTs have been extensively employed in constructing various electrochemical sensors. Compared with the conventional scale materials and other types of nanomaterials, the special nanostructural properties make
CNTs have some overwhelming advantages in fabricating electrochemical sensors, including

(i) the large specific area producing high sensitivity;

(ii) the tubular nanostructure and the chemical stability allowing the fabrication of ultrasensitive sensors consisting of only one nanotube;

(iii) the good biocompatibility that is suitable for constructing electrochemical biosensors, especially for facilitating the electron transfer of redox proteins and enzymes;

(iv) the modifiable ends and sidewalls providing a chance for fabricating multifunctioned electrochemical sensors via the construction of functional nanostructures;

(v) the possibility of achieving miniaturization;

(vi) the possibility of constructing ultrasensitive nanoarrays. 
In fact, since the first application of CNTs in electrochemistry by Britto et al. [1], numerous works have dealt with the construction of electrochemical sensors by CNTs and the subsequent applications. Generally, the replacement of ordinary materials by CNTs can effectively improve the redox currents of inorganic molecules, organic compounds, macrobiomolecules or even biological cells and reduce the redox overpotentials. The electron transfer and the direct electrochemistry of redox proteins at CNT-based electrochemical sensors were also widely reported. Due to the well-defined structure, the chemistry stability and the electrocatalytic activity toward many substances, CNTs are also extensively used as the carrier platforms for constructing various electrochemical sensors. The promising applications of CNTs have been reviewed by several authors [2-6]. Instead of covering all aspects of CNT applications in electrochemistry, this review is restricted to electrochemical sensors based on tradditional electrochemical methods (e.g., voltammetry and amperommetry), and does not cover other methods like potentiometry, impedance spectroscopy and piezoelectricity. It not only pays attention to the principle, the fabrication and the biomedical applications of various CNT-based electrochemical sensors but also attempts to focus on the fundamental electrochemical knowledge of CNTs.

\section{Electrochemical Properties of Carbon Nanotubes}

The electrochemical qualities of carbon material-based electrodes are significantly dependent on the surface properties as the creation of specific surface functional groups (especially oxygen-containing groups) can considerably increase the rate of electron transfer (ET) [7]. Based on their specific structures, two distinct surface regions exist in carbon nanotubes (CNTs): the sidewalls and the ends. Since carbon nanotubes can be seen as the graphene sheets rolled into tubes, the electrochemical properties of carbon nanotubes are comparable to the basal planes of pyrolytic graphite (bppg). For intact carbon nanotubes, the defectfree structure makes the whole tubes possess almost the same properties to that of bppg except that the cap regions may be more reactive due to the much higher curve strain than the sidewall. The opening of the ends by physical/chemical treatments on carbon nanotubes produces a variety of oxygen-containing groups, which possess the properties similar to the edge places of bppg [8].

Due to the simple and well-defined responses at carbon materials, the $\mathrm{Fe}(\mathrm{CN})_{6}{ }^{3-} / \mathrm{Fe}(\mathrm{CN})_{6}{ }^{4-}$ couple has been widely used to characterize the surface properties of all kinds of carbon electrodes. Similarly, the electrochemical properties of carbon nanotube-based electrodes are generally investigated by $\mathrm{Fe}(\mathrm{CN})_{6}{ }^{3-} / \mathrm{Fe}(\mathrm{CN})_{6}{ }^{4-}$ as the probe. Nugent et al. [9] compared the electrochemical behaviors of aligned bundles of carbon nanotubes with other carbon electrodes of similar structures. The results indicated that $\mathrm{Fe}(\mathrm{CN})_{6}{ }^{3-} / \mathrm{Fe}(\mathrm{CN})_{6}{ }^{4-}$ showed an ideal redox peak separation $\left(\Delta E_{p}\right)$ of $59 \mathrm{mV}$ at the aligned multiwalled carbon nanotubes (MWNTs). In comparison, they reported $\Delta E_{p}$ of more than $100 \mathrm{mV}$ and $700 \mathrm{mV}$ for the basal planes of highly oriented pyrolytic graphite (HOPG) with and without electrochemical pretreatments, respectively. Whereas, $\Delta E_{p}$ of about $70 \mathrm{mV}$ was observed at the edge planes of HOPG. In contrast to the ideal response reported by Nugent et al. [9], Li et al. [8] observed much larger $\Delta E_{p}$ at single-walled carbon nanotube $(\mathrm{SWNT})$ papers $\left(\Delta E_{p}=96 \mathrm{mV}\right)$ and at aligned MWNTs with heat pretreatment to remove impurities like amorphous carbon and catalyst $\left(\Delta E_{p}=230 \mathrm{mV}\right)$. Particularly, for aligned MWNTs, the apparent electron transfer rate (as indicated by $\Delta E_{p}$ ) was found to correlate with both the area of the exposed sidewalls (with graphite basal-planelike properties) and the density of graphite edge-planelike defects, that is, the electrochemistry of the probe was also influenced by the sidewalls of the nanotubes. They attributed the small $\Delta E_{p}$ at the SWNT paper to the promoted electron transfer by the oxygen-containing defects produced during the acid purification step for preparing the papers. Recently, the fundamental electrochemical properties of inherently hydrophobic MWNT electrodes and acid-treated MWNTs were reported by Papakonstantinou et al. using AC impedance spectroscopy and cyclic voltammetry (CV) [10]. Slow electron transfer kinetics with $\Delta E_{p}$ larger than $200 \mathrm{mV}$ and an electron transfer resistance of about $370 \Omega$ were observed on pristine MWNTs, close to the results reported by Li et al. at aligned MWNTs [8]. However, acid treatment was found to significantly improve the electron transfer kinetics of $\mathrm{Fe}(\mathrm{CN})_{6}{ }^{3-} / \mathrm{Fe}(\mathrm{CN})_{6}{ }^{4-}$ redox couple, approaching almost reversible ET kinetics. They believed that the acid treatment modified the charge carrier density at the surface by introducing surface states and served to facilitate electron transfer. The better wetting properties of functionalized CNTs and the higher local density of states as compared with untreated MWNTs were regarded responsible for favoring faster ET kinetics. In a word, the intact CNT sidewalls resemble the basal planes of pyrolytic graphite and can be regarded electrochemically inert to electroactive species. The apparent improved electron transfer at the intact nanotube sidewalls is attributed to the higher stains than the basal planes. As for the opened caps, the presence of defects and oxygen-containing functional groups makes them possess similar electrochemical properties to those of edge planes of pyrolytic graphite. The introduction of edge-like defect sites and oxygen-containing functional groups at both the caps and the sidewalls by chemical or physical treatments can significantly improve the electrochemical properties of CNTs by changing the electronic structures, the surface states and the wettability of the sidewall, reflected by the apparently facilitated electron transfer kinetics.

The critical roles of defect sites and oxygen-containing groups on the electrochemical performances of CNT-based electrodes have been proved by several fundamental research works [11-14]. Compton et al. [12] compared the oxidative behaviors of reduced $\beta$-nicotinamide adenine dinucleotide $(\mathrm{NADH})$, epinephrine $(\mathrm{EP})$ and norepinephrine $(\mathrm{NE})$ that were widely used to verify the so-called "electrocatalytical properties" of CNTs at CNT- and graphite powdermodified basal plane pyrolytic graphite electrodes. They 


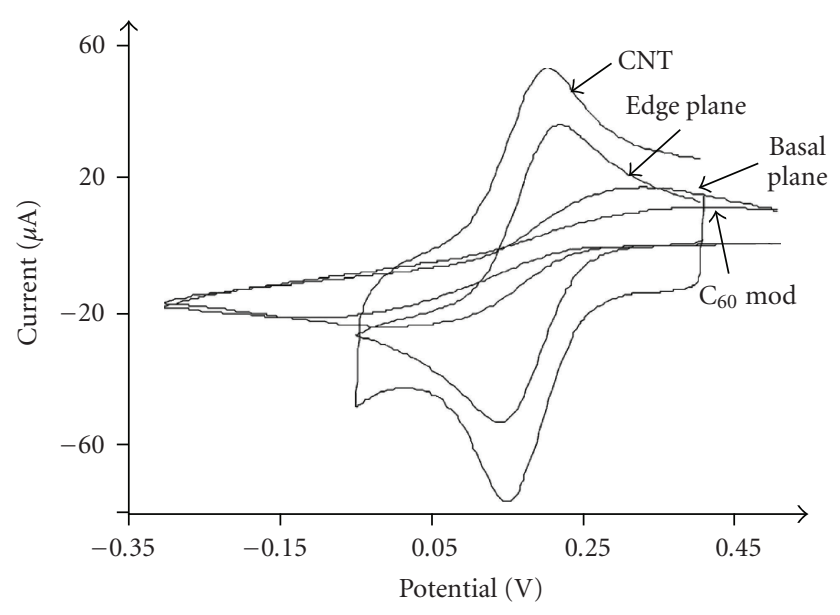

Figure 1: Cyclic voltammograms for the reduction of $1 \mathrm{mM}$ ferricyanide for CNT- and $\mathrm{C}_{60}$ film-modified bppg electrodes. Also shown is the response of a bare bppg electrode and an edge plane pyrolytic graphite electrode. All scans at a rate of $100 \mathrm{mV} / \mathrm{s}$. [Reprinted with permission from Banks et al. [11], Chem. Commun., 16, 1804 (2004). Copyright 2004, Royal Society of Chemistry.]

found both the nanotube- and graphite powder-modified electrodes show that electrocatalytical activities toward these species, with enhanced currents and reduced peak-to-peak separations in comparison with the naked basal plane pyrolytic graphite. Moreover, the electrocatalytic activity of CNTs toward hydrogen peroxide was approvded to arise from the residual catalyst of iron instead of CNTs themselves [15]. Based on this, they recommended that the catalytic properties should be cautiously assigned to carbon nanotubes. Further, they explored the origin of catalytic properties of CNTs by comparing the voltammetric behaviors of ferricyanide and epinephrine at different chemically modified pyrolytic graphite electrodes $[11,13]$. The results indicated that these species exhibited similar behaviors at the $\mathrm{C}_{60}$ film-modified bppg electrode and at the naked bppg electrode [13]. Whereas, the response at the CNT film-modified electrode was close to that at the edge plane pyrolytic graphite electrode [11, 13] (Figure 1). They concluded that the basis of the electrocatalytic nature of MWNTs was suggested to reside in electron transfer from the edge-plane-like defect sites at the open ends of nanotubes, which structurally resembled the behavior of edge plane (as opposed to basal plane) graphite. Latter, Gooding et al. [14] demonstrated the critical role of oxygencontaining groups on the electrochemical properties of CNT-based electrodes using randomly orientated nanotube films by a simple casting method and vertically aligned nanotubes by a self-assembled method. In fact, a pair of redox couple located at around $0.0 \mathrm{~V}$ in neutral media was usually observed at acid-treated CNT-based electrodes, which was attributed to the redox of the carboxyl groups by Li. et al. using XPS and infrared spectra (IR) [16]. In addition, the electrode process involved four electrons while the rate-determining step was a one-electron reduction. Our recent work indicated that both the hydrophobic structural defect sites and the hydrophilic oxygen-containing groups were the electroactive sites of CNTs [17]. That is to say, the surface property of CNTs could be conveniently designed by simple pretreatments for optimizing the adsorption and the electrochemical response of analytes. For instance, the hydrophobic defect sites created during the growth or the workup of CNTs were favorable to the adsorption and the electrochemical response of hydrophobic analytes, while the hydrophilic oxygen-containing groups produced by acid treatments facilitated the stable adsorption and the direct electrochemistry of redox proteins.

As a result of the strong intertube interactions, CNTs generally existed as highly tangled ropes and were insoluble in almost all solvents, which greatly hindered their practical applications. In addition, as-produced SWNTs, regardless of the production procedure, usually contain amorphous carbon, carbon nanoparticles and residues from the metal catalysts. To overcome these limitations and to create defect-like sites and oxygen-containing groups on CNTs that favored the electrochemical properties of CNTs, as-received CNTs were usually treated by chemical methods using oxidative, such as refluxing in dilute nitric acid or refluxing/sonication in a concentrated $\mathrm{H}_{2} \mathrm{SO}_{4} / \mathrm{HNO}_{3}$ mixture [19]. These treatments, by generating surface defects and sometimes resulting in tube shortening, can provide abundant carboxylated sites along the nanotube surface and the shortened tube ends [1921]. During these processes, nitric acid molecules or $\mathrm{NO}_{x}$ residues can intercalate SWNTs [22] and lead to changes in the Raman spectra of SWNTs by doping [23], which can be deintercalated by thermal annealing treatments in vacuum or argon along with the removal of most defect-like sites on CNTs [24]. A typical example of the annealing treatment effect on the defect sites of CNTs was reported by Kuznetsova et al. using transmission IR spectra (Figure 2) [18]. It is clear that the oxygen-containing groups on the defect sites can be effectively eliminated with annealing treatment. Whereas, the defect sites are not removed by this method, that is, the annealing treatment cannot restore the perfect structure of CNTs. The annealing effects on the electrochemical properties of CNT-based electrodes were investigated by Barisci et al. $[25,26]$. They found that thermal annealing produced significant changes in a range of properties of the material including increased hydrophobicity and elimination of electroactive surface functional groups. The activation of CNTs was also achieved by electrochemical methods. Wang et al. [27] explored the electrochemical activation of MWNTs from different sources by anodization treatment. They found that while the anodic pretreatment resulted in a dramatic improvement in the electrochemical reactivity of the ARCproduced CNTs, CNTs produced by chemical vapour deposition (CVD) appeared to be resistant to the anodic activation. These differences in the effect of the electrochemical pretreatment were attributed to the anodic preanodization effectively "breaking" the basal-plane end caps of ARC-CNTs thereby exposing edge plane defects, similar to those already present in the open-end caps of CVD-CNTs. The electrochemical activation of as-grown CNTs ensembles in $1.0 \mathrm{M} \mathrm{NaOH}$ was also achieved by Lin et al. [28] by applying a bias at 


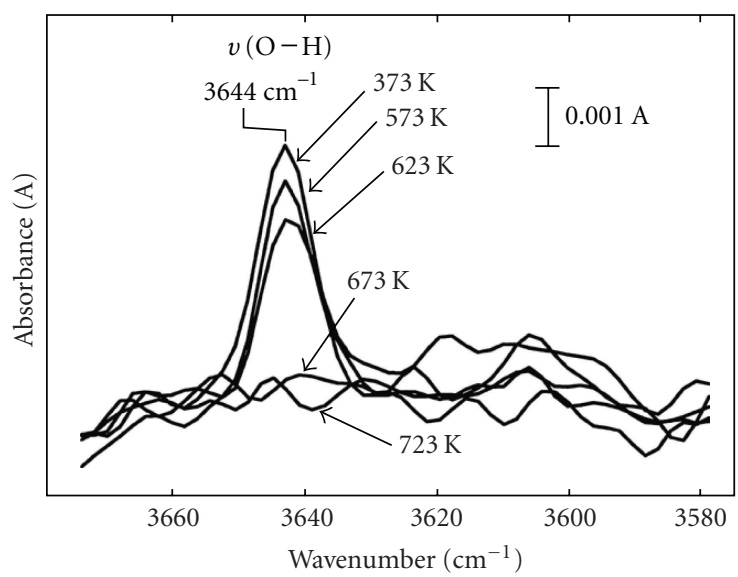

(a)

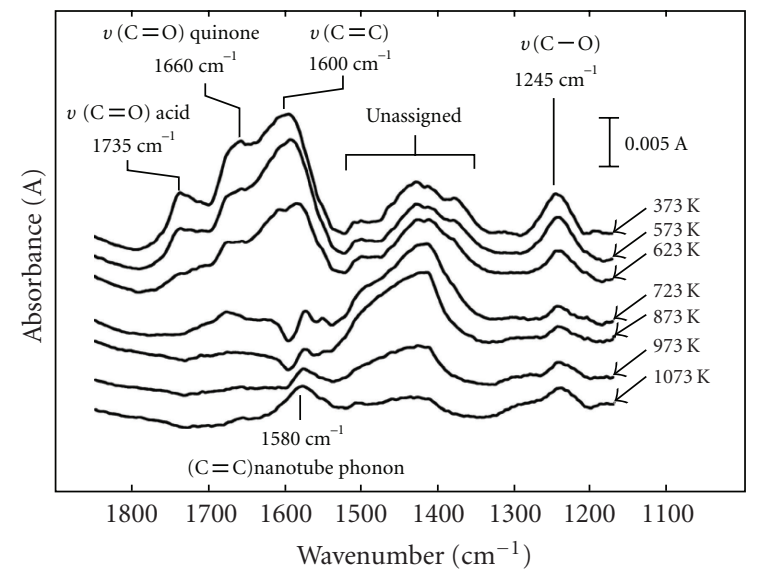

(b)

FIGURE 2: Decomposition of oxygen related functionalities on o-SWNTs. Transmission IR spectra of o-SWNTs following heating in vacuum to the indicated temperatures. The spectra indicate that carboxylic acid and quinone groups are thermally destroyed in vacuum above about $600 \mathrm{~K}$. Other unassigned surface functionalities are also observed to disappear upon heating. Removal of these functionalities reveals the IR transition associated with a $1580 \mathrm{~cm}^{-1}$ phonon mode of nanotubes. [Adapted with permission from Kuznetsova et al. [18], Chem. Phys. Lett., 321, 292 (2000). Copyright 2000, Elsevier Science.]

$1.5 \mathrm{~V}$ for 90 seconds. After electrochemical treatment, some functional groups (e.g., carboxylic acid) were created at the CNTs ends, which were further utilized to immobilize proteins using standard water-soluble coupling agents 1ethyl-3-(3-dimethylaminopropyl)carbodiimide (EDC) and $\mathrm{N}$-hydroxysulfo-succinimide (sulfo-NHS) by forming amide linkages between their amine residues and the carboxylic acid groups on the CNTs ends.

\section{Fabrication of Carbon Nanotube-Based Electrochemical Sensors}

Since their first application in electrochemistry by Britto et al. [1], numerous papers dealing with the use of CNTs as electrodes have been reported. The major problem on the promising applications of CNTs in electrochemical sensors is the immobilization of activated CNTs on the electrode surface because CNTs generally exist as highly tangled ropes and are insoluble in almost all solvents, which greatly hinder their capacity of forming uniform and stable films. To overcome this deficiency, CNTs are firstly dispersed or dissolved in various solutions or suspensions and immobilized on the surfaces of various substrates by physical or chemical methods. This section focuses on the introduction of some typical immobilization methods of CNTs on electrode surfaces that are widely used in constructing CNT-based electrochemical sensors.

3.1. Solvent Dispersion and Casting Immobilization. The most widely used methods for fabricating CNT-based electrochemical sensors are the approaches that involve the dispersing of CNTs in a certain solvent with sonication after their purification and activation pretreatments, followed by dropping the resultant suspensions on the electrode surfaces and allowing to dry (i.e., the casting methods). Among the reported solvents, $\mathrm{N}, \mathrm{N}$-dimethylformamide (DMF) is the most extensively used polar solvent and more than half of the papers deal with CNT-based electrochemical sensors using DMF as the dispersing solvent [16, 29-42]. There are also some other solvents used to prepare CNT suspensions, including water [43-48], acetone [49-53], ethanol [54$56]$ and even toluene [57, 58]. However, compared with these solvents, DMF has some overwhelming advantages for dispersing CNTs, for example, much higher solubility, stability and exfoliation efficiency. The debundling and dissolution of SWNTs in DMF and N-methyl-2-pyrrolidone (NMP) have been systematacially investigated by Furtado et al. [59]. Compared with other approaches, the solventdispersing methods of CNTs inevitably suffer from some disadvantages, such as low solubility, low stability and low exfoliation efficiency, due to the rather weak interactions between these solvents and CNTs. The predominance of these methods is their simplicity, convenience and no need of other additives, which makes them suitable for using as the foregoing step in multistep fabrications of complex CNTbased electrochemical sensors.

3.2. Additive-Assisted Dispersion and Immobilization. To improve the solubility and stability of CNTs in their suspensions, various additives are added into solvents to assist the dispersion of CNTs, such as surfactants and polymers. The structures of these species are shown in Figure 3.

3.2.1. Nafion. As a typical cationic ion exchange resin, Nafion has been used extensively for the modification of electrode surfaces and for the construction of amperometric biosensors, due to the unique ion-exchange, discriminative, and biocompatibility properties $[60,61]$. It is clear from Figure 3(a) that Nafion contains two different regions: the hydrophobic polymer backbone and the ionized hydrophilic 


$$
\begin{aligned}
&+\mathrm{CF}_{2}-\mathrm{CF}_{2}+{ }_{x}+ \underset{\mid}{\mathrm{CF}}-\mathrm{CF}_{2}+ \\
&\left(\mathrm{O}-\mathrm{CF}_{2}-\underset{\mathrm{CF}_{3}}{\mathrm{CF}}+_{m} \mathrm{O}-\mathrm{CF}_{2}-\mathrm{CF}_{2}-\mathrm{SO}_{3}-\mathrm{H}^{+}\right.
\end{aligned}
$$

(a) Nafion<smiles>CCCCCCCCCCCCOS(=O)(=O)[O-]</smiles>

(b) SDS

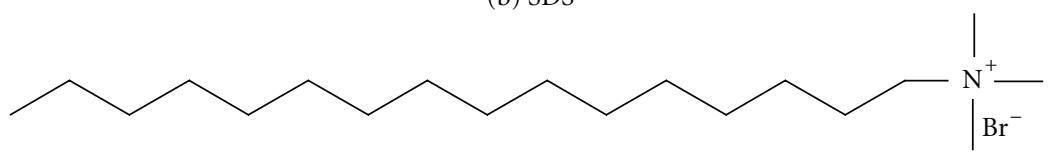

(c) $\mathrm{CTAB}$

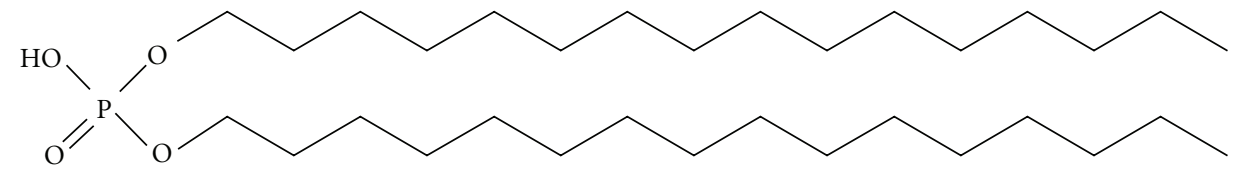

(d) DHP

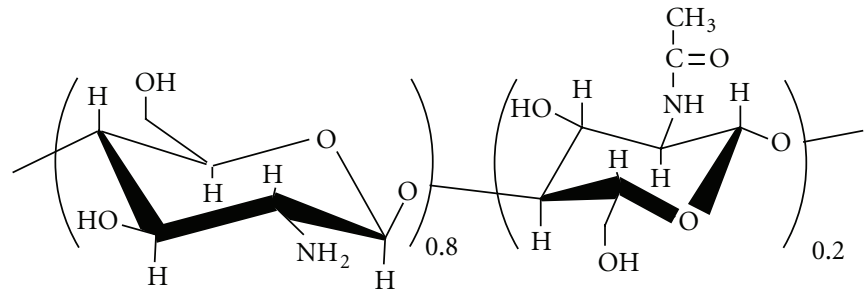

(e) CHIT

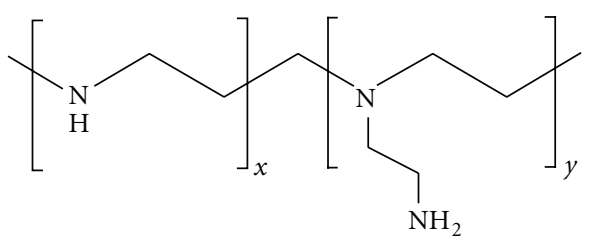

(f) PEI<smiles></smiles>

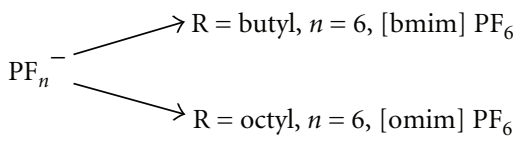

(g) RTIL<smiles>Nc1c(N=Nc2ccc(-c3ccc(N=Nc4cc([N+](=O)[O-])c5ccccc5c4N)cc3)cc2)cc(OS(N)(=O)=O)c2ccccc12</smiles>

(h) Congo red

FIGURE 3: Molecular structures of various additives for dispersing CNTs in solutions. 
sulfonate groups outside the hydrophobic region. This special amphiphilic structure makes Nafion bear the capacity of combining with CNTs by hydrophobic interactions between the hydrophobic backbone of Nafion and the sidewall of CNTs as well as dispersing them in solutions by the hydrophilic groups. The dispersion of CNTs in Nafion solutions with sonication was firstly reported by Wu et al. and used for the selective determination of dopamine (DA) via the elimination of potential interferences from negatively charged uric acid (UA) and ascorbic acid (AA) by the Nafion film [62]. Later, Wang et al. systematacially studied the dispersion of CNTs in Nafion solutions and used this system to construct glucose electrochemical biosensors based on the electrocatalytic action toward hydrogen peroxide $\left(\mathrm{H}_{2} \mathrm{O}_{2}\right)$ [63]. Since then, many works focused on the construction of CNT-based electrochemical sensors by this method, including the direct determination of DA $[64,65]$, nitrophenol [66, 67], cadmium ion [68], carbohydrates [69] and homocysteine (HcySH) [70], and the fixation of glucose oxidase $(\mathrm{GOx})[71]$, copper $(\mathrm{Cu})[72]$ and platinum $(\mathrm{Pt})$ nanoparticles [73] for constructing glucose electrochemical sensors as well as the electrodeposition of nickel (Ni) for analysis of amino acids in flow injection analysis (FIA) [74].

\subsubsection{Surfactants}

(1) Water-Soluble Surfactants. Since the report by Abatemarco [75], sodium dodecyl sulphate (SDS) (Figure 3(b)) has been widely used to prepare stable suspensions of purified SWNTs in water with the aid of sonication. The mechanism for the dissolution of SWNTs in SDS aqueous solutions is well investigated. The common agreement is that the encapsulation of SWNTs in SDS micelles and the repulsive interactions between negatively charged SDS micelles account for the stable suspension of SWNTs in solution. The reports on the applications of SDS-dispersed CNTs in electrochemical sensors are rare, due to the rather weak adsorption of SDS-CNT composites on the smooth surfaces of conventional solid electrodes and the unstable films prepared from this suspension. However, Chen et al. prepared a SWNT modified carbon fiber nanoelectrode (CFNE) for the sensitive determination of DA from the suspension of SWNTs in SDS aqueous solution [76]. The achievement of this successful preparation might arise from the strong adsorption of SWNTs on the porous and hydrophilic surface of CFNE. The interaction between the oxygen-containing groups on acid treated SWNTs and on the CFNE pretreated by burning in air might also contribute to the strong attachment of SWNTs on CFNE. The suspension of CNTs in cetyltrimethylammonium bromide (CTAB) (Figure 3(c)) aqueous solution was used by Cai et al. to prepare CNT-based hemoglobin $(\mathrm{Hb})$ electrochemical biosensors [77]. The suspension of CNTs was mixed with the phosphate buffer solution (PBS) containing $\mathrm{Hb}$ and fixed on the surface of a glassy carbon electrode (GCE) by a Nafion coating, resulting in the direct electrochemistry of $\mathrm{Hb}$. Similary, the direct electrochemistry of GOx was achieved at similar electrochemical biosensors and used for the determination of glucose [78].
(2) Water-Insoluble Surfactants. Besides the Nafion dispersing system of CNTs, Wu et al. also developed another CNT dispersing system on the basis of the stable dispersion of CNTs in the aqueous solution of dihexadecyl hydrogen phosphate (DHP) (Figure 3(d)) [79]. Different from SDS and $\mathrm{CTAB}, \mathrm{DHP}$ consists of two hydrophobic tails and a dissociable phosphate group. This special structure enables DHP to form stable and homogeneous suspensions in water, which can be cast on the electrode surfaces to prepare stable and uniform films. Based on the hydrophobic interactions between the hydrophobic tails of DHP and the sidewall of the nanotubes as well as the possible interactions between the phosphate groups on DHP and the oxygen-containing groups on acid-treated CNTs, MWNTs were dispersed in the aqueous suspension of DHP with sonication, resulting in the formation of a stable and homogeneous aqueous suspension of DHP and CNTs. The casting of the suspension of DHP and MWNTs on the electrode surface produced CNT-based electrochemical sensors that showed excellent electrochemical activity toward many species, such as hormone [80-82], drugs [83-93], biomolecules [79, 94-99], and heavy metal ions $[100,101]$.

3.2.3. Chitosan. Chitosan (CHIT) is a polysaccharide biopolymer (Figure 3(e)), which displays excellent filmforming ability, high water permeability, good adhesion, and susceptibility to chemical modifications due to the presence of reactive amino and hydroxyl functional groups. Jiang et al. firstly reported the stable dispersion of CNTs in the acidic aqueous solutions of CHIT with sonication and used to the simultaneous determination of DA and UA [102]. The special interaction between CHIT and CNTs was characterized by Zhang et al. [103]. They demonstrated by thermogravimetric analysis (TGA) that CHIT might be adsorbed onto CNTs and form a special CHIT-CNT system, which can be precipitated from the solutions by the addition of concentrated salts or the adjustment of solution acidity. The selective interaction between CHIT and CNTs also provided a possible approach for separating CNTs from carbonaceous impurities. Based on the derivation of the reactive groups on CHIT, they developed a CNT-based glucose electrochemical biosensor, which might be applied to a large group of dehydrogenase enzymes for the designing of a variety of bioelectrochemical devices (e.g., sensors, biosensors, biofuel cells). In fact, the solubilization of CNTs in aqueous solutions by polysaccharides has been reported previously by Star et al. using starch as the dispersing agent [104]. They found that common starch, provided it is activated toward complexation by wrapping itself helically around small molecules, would transport SWNTs competitively into aqueous solutions, and that the process was sufficiently reversible at high temperatures to permit the separation of SWNTs in their supramolecular starch-wrapped form by a series of physical manipulations from amorphous carbon. Based on their previous work [102], Jiang et al. applied the CHIT-CNT system for the direct determination of nitrite [38], the simultaneous detection of UA and NE [105], and the selective determination of DA in the presence of 
AA [106]. Another marvelous work on the simultaneous electrodeposition of CHIT-CNTs on gold electrodes was reported by Chen et al. [107]. The typical electrodeposition procedure was expressed as follows: a pair of polished and cleaned gold electrodes (diameter $2.0 \mathrm{~mm}$, separation of about $0.5 \mathrm{~cm}$ ) was connected to a direct current power supply $(3.0 \mathrm{~V})$ and dipped into the CNT-CHIT solution ( $\mathrm{pH} 5.0)$; $\mathrm{H}^{+}$in the solution was reduced to $\mathrm{H}_{2}$ at the cathode, and the $\mathrm{pH}$ near the cathode surface gradually increased; as the solubility of CHIT was $\mathrm{pH}$-dependent, when the $\mathrm{pH}$ exceeded the pKa of CHIT (about pH 6.3), CHIT became insoluble and the CHIT entrapped CNTs would deposit onto the cathode surface as a result. Based on this, they developed a glucose electrochemical biosensor through the codeposition of GOx with CHIT-CNTs. This simple and controllable electrodeposition method overcomes the major obstacle for preparing CNT-based biosensor systems and expands the scope of electrochemical devices based on CNTs. However, this method might suffer from some inevitable disadvantages, for example, the using of high potential bias $(3.0 \mathrm{~V})$ might influence the quality of the substrate electrodes and the bubbling of $\mathrm{H}_{2}$ produced during the electrolysis process might influence the uniformity of the deposited films.

3.2.4. Polyethyleneimine. As a positively charged polyelectrolye, polyethyleneimine (PEI) (Figure 3(f)) was also extensively employed as an efficient additive for the dispersion of CNTs in aqueous solutions. The resulting PEI-CNT composite was proved to have good stability and biocompatibility [108]. Based on the reactivity of amino groups on PEI, the noncovalent or covalent modification of CNTs by PEI provides a simple approach to the further surface functionalization of CNTs by quantum dots [109], metal nanoparticles $[110,111]$. PEI-functionlized CNTs are a useful nanocomposite in electromistry and electroanalytical chemistry. For instance, based on the interactions between PEI and GOx as well as the strong adsorption of PEI on MWNTs, Ivnitski et al. proposed a GOx anode for biofuel cell by using PEI as the binder for grafting Gox on the surface of MWNTs [112]. Similarly, Rivas et al. developed an electrochemical sensor for the sensitive determination of ascorbic acid, dopamine, 3,4dihydroxyphenylacetic acid (dopac) and hydrogen peroxide [113], on the basis of the stable suspension of CNTs in PEI aqeous solution and the surface modification of a glassy carbon electrode (GCE) by the PEI-MWNT composite. Later, they employed this electrochemical sensor as the detector in flow systems to achieve highly sensitive detections of hydrogen peroxide, different neurotransmitters (dopamine (D) and its metabolite dopac, epinephrine (E), norepinephrine $(\mathrm{NE})$ ), phenolic compounds (phenol $(\mathrm{P})$, 3-chlorophenol (3-CP) and 2,3-dichlorophenol (2,3CP)) and herbicides (amitrol), with sensitivities enhancements of 150 and 140 folds compared to GCE for hydrogen peroxide and amitrol, respectively [114]. One of the most remarkable properties of this sensor was the antifouling effect of the CNT/PEI layer. This unique property was further demonstrated by Chicharro et al. by examining the analytical

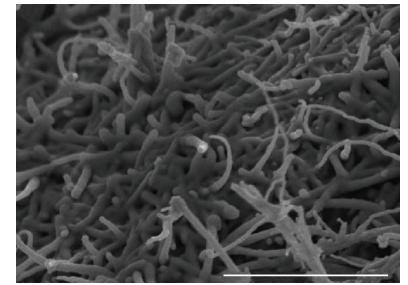

(a)

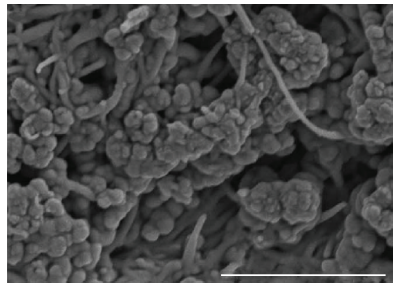

(b)
FIGURE 4: SEM pictures of the surface of the CNTs sol-gel composite (a) without and (b) with $0.25 \mathrm{mg}$ colloidal silica particles per mg of MWNTs. Bar, $5 \mu \mathrm{m}$. [Reprinted with permission from Gavalas et al. [118], Anal. Biochem., 329, 247 (2004). Copyright 2004, Elsevier Science.]

performance of PEI-CNT composite modified electrodes as electrochemical sensors in capillary electrophoresis for the MEKC separations of phenolic pollutants (phenol, 3chlorophenol, 2,3-dichlorophcnol, and 4-nitrophenol) and herbicides (amitrol, asulam, diuron, fenuron, monuron, and chlortoluron) [115]. A recent work of Rivas revealed that the highly selective and sensitive voltammetric dopamine quantification in the presence of ascorbic acid and serotonin could be obtained at glassy carbon electrodes modified with PEI-MWNT composite [116]. On the other hand, Qiu et al. developed a sensitive electrochemical system for the selective determination of ascorbic acid by incorporating a mediator, ferrocenyl group $(\mathrm{Fc})$, into the MWNT composite by using PEI as a binder [117].

3.2.5. Sel-Gels. The sol-gel and hydrogel have been widely used in recent years to immobilize biomolecules (e.g., enzymes) for constructing electrochemical biosensors because of their easy fabrication, chemical inertness, thermal stability and good biocompatibility. However, the lack of electrochemical reactivity and the poor conductivity of these materials, especially for silica sol-gel, greatly hinder their promising applications. A typical procedure for preparing CNT-based sol-gel consists of the dispersion of CNTs in solvents, the mixing of the CNT suspensions with the sols and finally the casting of the resultant mixture on the electrode surfaces. Recently, Gavalas et al. prepared CNT aqueous sol-gel composites as enzyme-friendly platforms for the development of stable biosensors [118] (Figure 4). These CNT-based sol-gel electrochemical biosensing platforms were demonstrated to possess both the electrochemical characteristics of CNTs and the role of sol-gel for eliminating by-products. Tan et al. reported a new type of amperometric cholesterol biosensor based on sol-gel CHIT/silica and MWNT organic-inorganic hybrid composite materials [119]. They found that MWNTs acted as both nanometer conducting wires and catalysts, which can effectively promote electron transfer between enzymes and the electrode surface. Gong et al. developed a new kind of ceramic-carbon nanotube nanocomposite electrodes (CCNNEs) prepared by doping MWNTs into silicate gel [120]. In contrast to the conventional sol-gel or CNT-based 


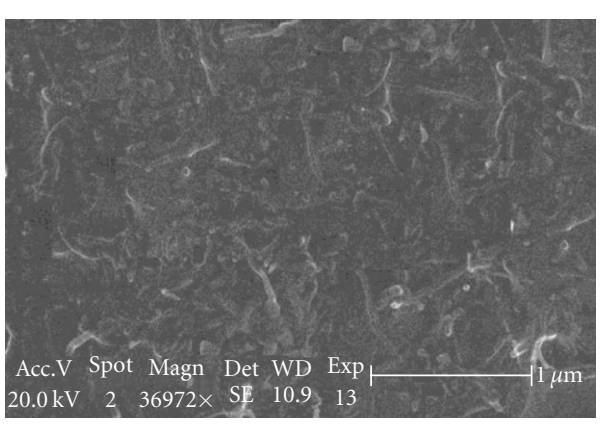

(a)

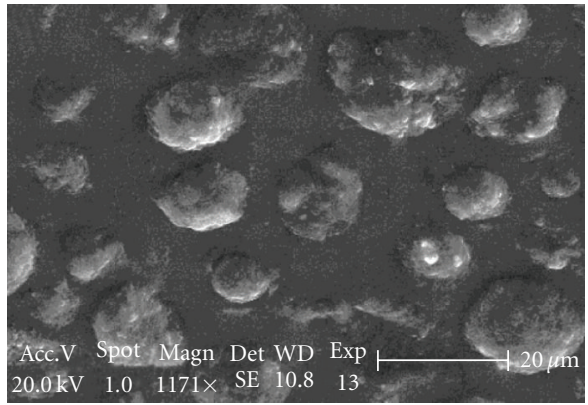

(b)

FIGURE 5: Environmental scanning electron microscopic (ESEM) images of (a) MWNT/[bmim]PF6 and (b) MCMB/[bmim]PF6, the scale bar is $1 \mu \mathrm{m}$ in (a) and $20 \mu \mathrm{m}$ in (b). The accelerating voltage is $20 \mathrm{kV}$. [Adapted with permission from Zhao et al. [122], Anal. Chem., 76, 4960 (2004). Copyright 2004, American Chemical Society.]

electrochemical sensors, the electrochemical response of these electrodes can be conveniently tuned from that of conventional scale electrodes to that of microelectrodes by just varying the content of MWNTs in the composites. Besides silica-based sol-gel, the preparation of CNT-redox polymer hydrogel composite films was also reported recently by Joshi et al. [121]. By incorporating enzyme modified SWNT into PVP-Os polymer hydrogel, the sensor's current output was increased for 2-3 times.

3.2.6. Room-Temperature Ionic Liquids. Room-temperature ionic liquids (RTILs) are thermally stable salts, liquid at room temperature, constituted by an organic cation and either an organic or an inorganic anion. Unlike traditional inorganic molten salts such as $\mathrm{NaCl}, \mathrm{NaAlF}_{6}$, or the eutectic mixture $\mathrm{LiCl}-\mathrm{KCl}$, room temperature ionic liquids present a high degree of asymmetry that inhibits crystallisation at room temperatures. RTILs have some marvelous properties, including nonvolatile nature or nonmeasurable vapour pressure, low melt point (even as low as $-90^{\circ} \mathrm{C}$ ), wide liquidus range (up to $200^{\circ} \mathrm{C}$ ), strong electrostatic field, wide electrochemical potential range (i.e., RTILs remain stable at potentials even higher than $5 \mathrm{~V}$ ), relative air and water stability, high polarity, favorable viscosity and density as solvents, high thermal stability (i.e., decomposition temperature might be higher than $400^{\circ} \mathrm{C}$ ), and the ability of solvating a wide range of species including organic, inorganic, and organometallic compounds by varying the $\mathrm{R}$ group in RTILs. These special properties make them have promising applications in green chemistry (including synthesis, catalysis and biocatalysis), functional materials (e.g., photoelectrical materials and lubricate materials), energy science, environment science, and so on. Recently, Zhao et al. [122] proposed a novel strategy for investigating the electrical-ionic properties of RTILs and carbon composite materials formed by mixing a water-insoluble RTILs (1-butyl-3-methylimidazolium hexafluoro- phosphate, [bmim] $\mathrm{PF}_{6}$ ) $($ Figure $3(\mathrm{~g}))$ and carbon materials of two types: one was MWNTs with a tube shape and the other was mesocarbon microbeads (MCMBs) with a bead shape (Figure 5). The hybrid MWNT/RTIL and MCMB/RTIL materials showed a different conductivity mechanism determined by ac impedance technology. The RTIL and carbon composite materials can also be used to act as modifiers in the direct electrochemistry of protein and to catalyze the reduction of $\mathrm{O}_{2}$ and $\mathrm{H}_{2} \mathrm{O}_{2}$. Later, Zhang et al. [123] developed an RTILs supported three-dimensional network SWNT electrode. In that work, large quantities of SWNTs were considerably untangled in RTILs so as to greatly increase the effective area of the electrode. Nsuccinimidyl acrylate (NSA), as a model monomer, was dissolved in the supporting RTILs and was electrografted onto SWNTs (SWNT-poly-NSA). Then, GOx was directly covalently anchored on the SWNT-poly-NSA assembly. More recently, Zhao et al. [124] prepared an RTIL-CNTmodified GCE by grinding the mixture of an RTILs (1-octyl3-methyl imidazolium hexafluorophosphate, $\mathrm{OMIMPF}_{6}$ ) (Figure 3(f)) and MWNTs on a certain weight ratio and casting the resulting black gel on the electrode surface, which was successfully used to the selective determination of DA in the presence of UA and AA.

3.2.7. Proteins. The employement of proteins as functional biomaterials has been widely reported due to the excellent biocompatibility and the abundant derativie surface groups. As a kind of special amphiphilic biomacromolecues, proteins are proved to be capable of dispersing CNTs in water. Lin et al. firstly discovered that SWNTs are naturally proteinaffinitive in an aqueous ferritin solution, resulting in significant ferritin-SWNT conjugation and the solubilization of the nanotubes [126]. The conjugation can be further enhanced and stabilized in the presence of a coupling agent for amidation to promote the formation of covalent linkages. Later, Karajanagi et al. reported that a variety of proteins differing in size and structure, for example, bovine serum albumin (BSA), peroxidases from soybean and horseradish, trypsin, ferritin, and mucor javanicus lipase (MJL), were able to generate individual nanotube solutions by a noncovalent functionalization procedure [127]. Our recent work also demonstrated that glucose oxidase (GOx) can be grafted on the surface of MWNTs by a simple noncovalent functionalization to achive both the solubilization of MWNTs in water and the direct electrochemistry of GOx 

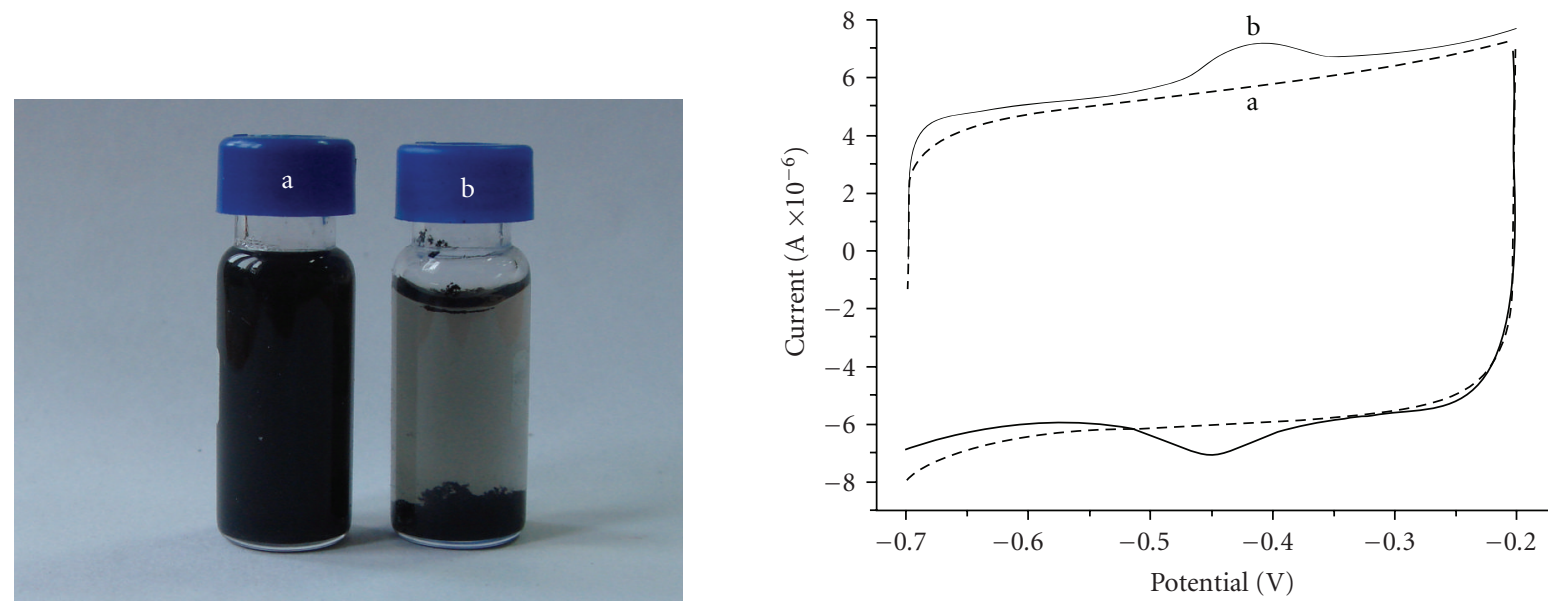

Figure 6: Photos of GOx-grafted MWNTs (a) and MWNTs (b) in water (left), and cyclic voltammograms of the MWNT- (a) and GOxgrafted MWNT- (b) modified glass carbon electrode in $0.1 \mathrm{M}$ phosphate buffer solution (pH 6.9) (right) [125].

(Figure 6) [125]. Morevoer, the oxygen-containing groups on MWNTs produced by acid treatments are crucial to the stable adsorption of GOx on MWNTs [128]. Since the protein-CNT hybride has the properities of both proteins and CNTs, it might have promising applications in various fileds like biomedical, material and analytical sciences.

3.2.8. Cyclodextrins. Cyclodextrins (CDs) are crystalline, water soluble, and cyclic oligosaccharides built up of glucopyranose units (glucose units) and contain a relatively hydrophobic central cavity and hydrophilic outer surface. The soft cutting of SWNTs by CDs was firstly reported by Chen et al. [129] and then characterized by Chambers et al. [130] using adsorption and Raman spectra as well as differential scanning calorimetery (DSC). The results confirmed conclusively that $\gamma$-CDs and SWNTs did interact with each other in a fashion similar to that originally suggested by Chen et al. [129], who proposed that CDs were absorbed at the surface of nanotube ropes by van der Waals forces. This result foretold the use of CDs for the chemical manipulation and processing of CNTs. Based on this, Luo et al. developed CD-CNT composite film-modified electrodes by dispersing CNTs in the aqueous solutions of either $\alpha$ - [131-133] or $\beta$-CD $[134,135]$ with sonication, which was used for the determination of NE [135], UA [134] and thymine [131], the selective determination of $p$ nitrophenol [132], and the simultaneous determination of DA and EP [133].

3.2.9. Organic Dyes. Different from the above weak Van der Waals interactions between the dispersing agents and $\mathrm{CNTs}$, conjugated organic compounds, especially organic dyes containing amino groups, can combine with CNTs via stronger $\pi-\pi$ interactions to form much stabler hybrides, which leads to a much higher stability and solubility of CNTs in solution. Chen et al. firstly reported the strong adsorption of an amino-derivative pyrene on the sidewall of SWNTs via $\pi-\pi$ interactions for the surface modification of SWNTs
[137]. They foresaw that this noncovalent method might also hold the key to forming stable suspensions of functionalized SWNTs in solutions and open up the possibility of selfassembly of nanotubes with unperturbed $\mathrm{sp}^{2}$ structures and electronic properties. Based on the strong $\pi-\pi$ interactions between methylene blue and SWNTs, Yan et al. developed a simple noncovalent method for the dissolution of SWNTs in water [138]. The MB-functionalized SWNTs were positively charged and utilized to construct an electroactive multilayer of $\mathrm{MB}$ and SWNTs through a layer-by-layer assembling method, which showed excellent electrocatalytic activity toward the reduction of oxygen. Our group also proposed a simple noncovalent method for dissolving CNTs in water by Congo red (CR) (Figure 3(h)), a negatively charged organic dye, based on the strong $\pi-\pi$ interactions between CR and CNTs [136, 139-141]. This method had the merit of high solubility, stability and selectivity, and was able to dissolve a variety of CNTs, for example, pristine or acid-treated SWNTs or MWNTs. The resulting CR-functionalized CNTs (CNT$\mathrm{CR}$ ) had a unique property of forming uniform, compact but stable CNT films on various substrates when completely dried (Figure 7), which had been proven to possess excellent electrochemical performances toward various substances, such as redox proteins [128], drugs [140], small biomolecules [141], hormones [136], and so on. The reversible adsorption of surfactants on the naked surface of CNT-CR conjugate also provided a simple approach to the further enhancement of the electrochemical response of hydrophobic species and the improvement of the antifouling capacity of the CNT sensing films [136].

\subsection{Self-Assembling Immobilization}

3.3.1. Polyelectrolyte Assisted Self-Assembly. The applications of CNTs in electrochemical sensors by self-assembled methods were mainly achieved through the attachment of water-soluble polyelectrolytes on the sidewall of CNTs. The molecular design of strong SWNT/polyelectrolyte multilayer composites has been reported previously [143]. The typical 


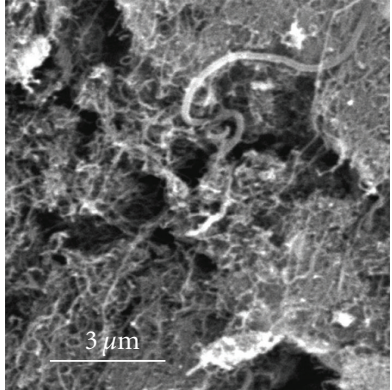

(a)

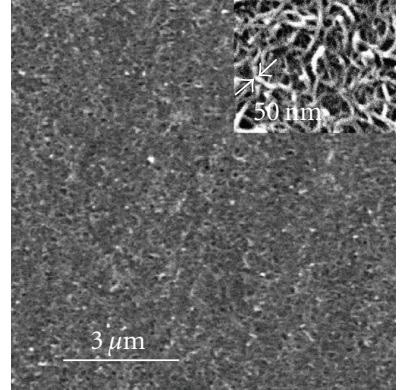

(b)

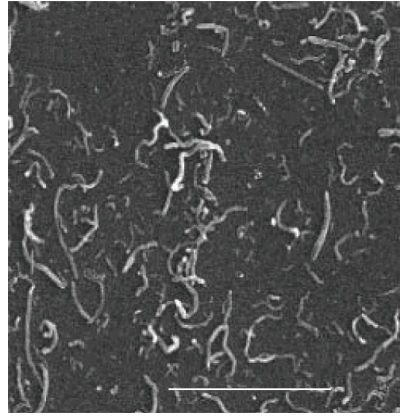

(a)

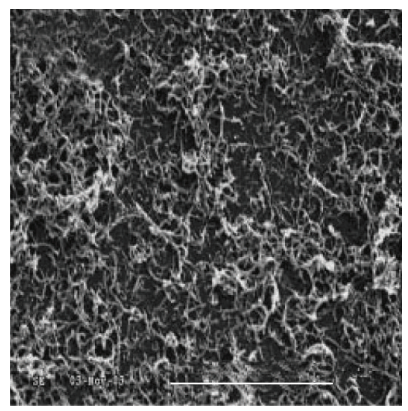

(c)

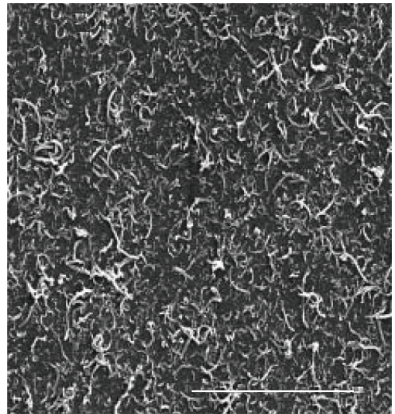

(b)

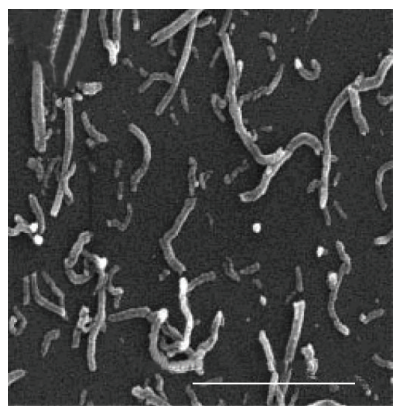

(d) XPS and photoacoustic Fourier transform infrared (PAFTIR) spectroscopies. They found that the mild sonication of MWNTs in aqueous PDDA resulted in a significant improvement of CNT dispersibility and greatly enhanced their adhesion to Au and Si substrates. The MWNT-PDDA interaction was due to the presence of an unsaturated contaminant in the PDDA chain, as confirmed by both XPS and PA-FTIR, which entered into a $\pi-\pi$ interaction with the CNTs. Electrostatic group repulsions of the coated CNTs then provided the dispersibility and adhesion. Guo et al. firstly reported the electrostatic assembly of calf thymus DNA on MWNT-modified gold electrode via PDDA and used this electrode to study the interaction between chlorpromazine chloride and DNA [44]. Soon, they also prepared a CNTbased amperometric cholesterol biosensor through layer-bylayer (LBL) deposition of PDDA and cholesterol oxidase (ChOx) on MWNT-modified gold electrode, followed by electrochemical generation of a nonconducting poly $(\mathrm{o}-$ phenylenediamine) (PPD) film as the protective coating [145]. Zhang et al. fabricated multilayer films of shortened MWNTs that were homogeneously and stably assembled on GCE with the LBL method based on the electrostatic interaction of positively charged PDDA and negatively charged and shortened MWNTs (Figure 8), which were further applied to the electrocatalytic reduction of $\mathrm{O}_{2}$ [142] as well as the selective determination of DA [146]. Recently, $\mathrm{He}$ et al. introduced a new fabrication of DNA-CNT particles using the LBL technique on SWNTs by the alternative deposition of PDDA and DNA on the water-soluble oxidized SWNTs [147]. The electrodes modified by the DNA/PDDA/SWNT particles were used as DNA sensors for the investigation of DNA damage by nitric oxide. The self-assembly of negatively charged poly(aminobenzenesulfonic acid) (PABS) on SWNTs was proposed by Liu et al. [148], which was used for the assembly of a conducting polymer, polyaniline (PANT), on the surface of SWNTs. The obtained PANI/PABS-SWNT
FIGURE 8: Representative SEM images of $\{\mathrm{PDDA} / \mathrm{MWNT}\}_{1}$ (a), $\{\mathrm{PDDA} / \mathrm{MWNT}\}_{3}(\mathrm{~b})$, and $\{\mathrm{PDDA} / \mathrm{MWNTs}\}_{5}$ (c) assembled on a silicon wafer. The scale bar in (a)-(c) was $5 \mu \mathrm{m}$. (d) represents the SEM image of $\{\text { PDDA/MWNTs }\}_{1}$ with a high amplification with a scale bar of $1 \mu \mathrm{m}$. [Reprinted with permission from Zhang et al. [142], Langmuir, 20, 8781 (2004). Copyright 2004, American Chemical Society.]

multilayer films were very stable and showed high electrocatalytic ability toward the oxidation of $\mathrm{NADH}$ at a much lower potential (about $+50 \mathrm{mV}$ versus $\mathrm{Ag} \mid \mathrm{AgCl}$ ). Lenihan et al. proposed a protocol for immobilizing alkaline phosphatase on the surface of MWNTs utilizing an LBL methodology. They firstly incubated CNTs with streptavidin to form a protein layer on the surface of the nanotubes and then attached biotinylated alkaline phosphatase to streptavidin, anchoring the sensing protein onto the surface of CNTs, which was used to the determination of 1-naphthyl phosphate. Besides macromolecules, small conjugated molecules were also used for the construction of CNT-based electrochemical sensors. Yan et al. described and characterized the adsorption of electroactive methylene blue (MB) dye onto SWNTs to form an electrochemically functional nanostructure $[138,149]$. They found that MB essentially interacted with SWNTs through charge-transfer and hydrophobic interactions, leading to the formation of an MB-SWNT adsorptive nanostructure, which exhibited distinct electrochemical properties from those of $\mathrm{MB}$ adsorbed onto GCE. The stable adsorption of water-soluble and positively charged $\mathrm{MB}$ molecules onto formed nanostructure in water quite well and to fabricate a narrostructure on a solid substrate. SWNTs was further demonstrated to be able to solubilize the functional nanocomposite by LBL assembling of the formed 


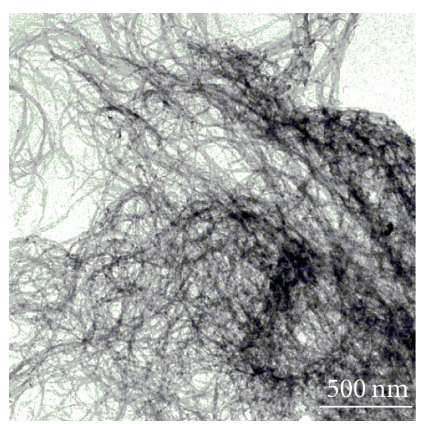

(a)

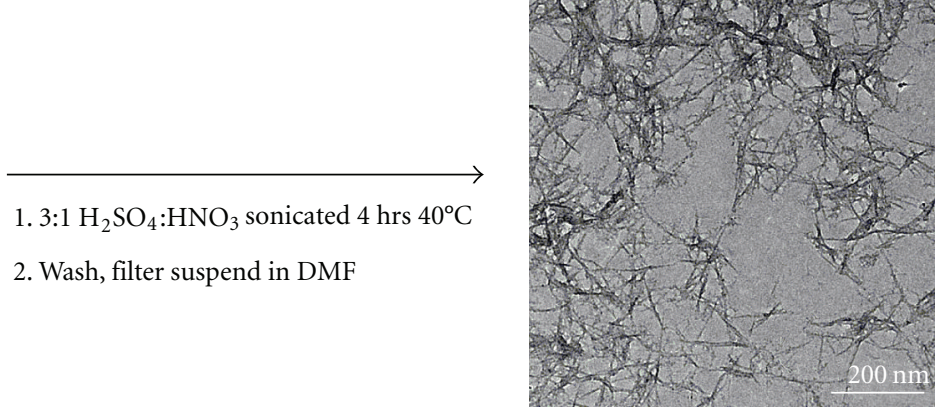

(b)

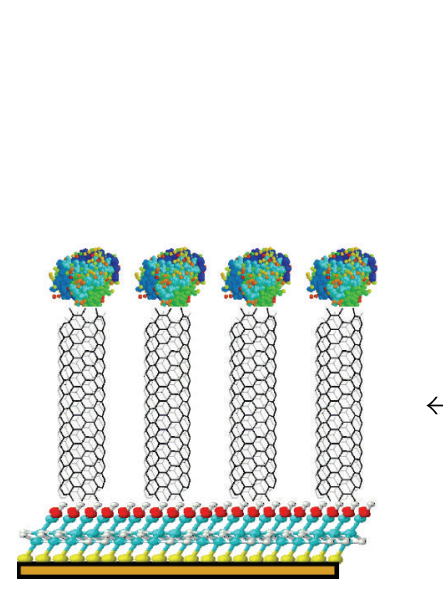

(d)

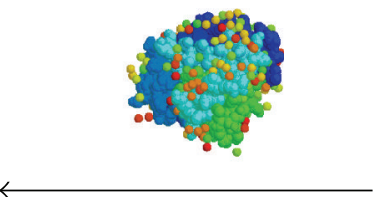

Microperoxidase MP-11
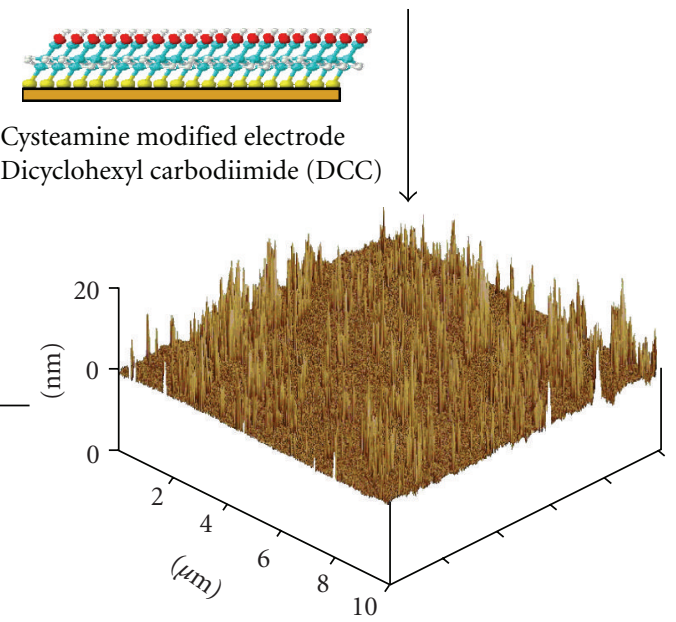

(c)

FIGURE 9: A schematic showing the steps involved in the fabrication of aligned shortened SWNTs arrays for direct electron transfer with enzymes such as microperoxidase MP-11. [Reprinted with permission from Gooding et al. [150], J. Am. Chem. Soc., 125, 9006 (2003). Copyright 2003, American Chemical Society.]

3.3.2. Direct Self-Assembly. The negatively charged carboxyl groups on CNTs produced during the acid treatments provide two approaches for the direct self-assembling immobilization of CNTs on electrode surfaces: one is the covalent bonding of CNTs to cysteamine self-assembled monolayer (SAM) modified gold electrodes via the reaction of carboxyl groups on CNTs and amino groups on cysteamine SAM in the presence of coupling reagents; the other is the attachment of CNTs to electrode surfaces via the electrostatic interactions between negatively charged carboxyl groups on CNTs and the positively charged species on the electrode surfaces. The self-assembly of CNTs on a gold electrode was reported by Liu et al. [151]. They firstly cut as-grown nanotubes into short pipes and thiol-derivatized at the open ends by chemical methods. The ordered assembly of SWNTs was then made by their spontaneous chemical adsorption to gold via $\mathrm{Au}-\mathrm{S}$ bonds. They found that the nanotubes were organized on gold, forming a self-assembled monolayer structure with a perpendicular orientation, and the adsorption kinetics of the nanotubes was very slow in comparison to conventional alkanethiols. Different from the work by Liu et al. [151], Gooding et al. fabricated an aligned CNTs array for the direct electrochemistry of microperoxidase MP-11 via a three-step procedure [150] (Figure 9). Later, they applied this method to GOx and also accomplished the direct electron transfer between the electrode and the redox active centre of GOx, flavin adenine dnucleotide (FAD) [152]. Recently, Xu et al. fabricated an MWNT monolayer modified gold electrode by a similar method and achieved the direct electrochemistry of horseradish peroxidase (HRP) physically adsorbed on the surface of MWNTs [153]. In contrast to the covalent methods for attaching CNTs to cysteamine modified gold electrodes, Qu et al. [154] attached acid-treated SWNTs to cysteamine modified gold electrodes via electrostatic adsorption. Chattopadhyay et al. also developed another method for preparing aligned CNT arrays on the surface of ordinary pyrolytic graphite (PG) electrodes from randomly dispersed CNTs by using a Nafion solution [155]. Based on the successful fabrication of the CNT arrays on the electrode surfaces, proteins like HRP were either covalently attached [156] or physically adsorbed [157] onto the end of the CNT arrays and achieved their electroanalytical applications.

3.4. Carbon Nanotube Paste Electrodes. CNT paste electrodes (CNTPEs) refer to the paste electrodes made up 
of liquid binder and CNTs. CNTPEs retain the properties of the classical carbon paste electrodes (CPEs) such as the feasibility to incorporate different substances, the low background currents, the wide potential range, the easy renewal and composite nature. CNTPEs also preserve the unique electrochemical properties of CNTs, like the ability to promote electron-transfer reactions of various species, especially for biomolecules. Compared with other methods for preparing CNT-based electrochemical sensors, CNTs in CNTPEs do not need any additional treatment (e.g., purification, modification or shortening treatment) and are suitable for all kinds of CNTs. Britto et al. [158] firstly reported a dramatic improvement in the electrochemical behavior of DA with $\Delta E_{p}$ of $30 \mathrm{mV}$ at nonactivated carbon nanotube electrodes constructed by using bromoform as binder. Davis et al. [159] further explored the possibility of using CNTs as the electrode materials. They achieved for the first time the direct electrochemistry of proteins at a CNTPE that was prepared from protein decorated CNTs by physical adsorption. The formal appellation "CNT paste" or "CNTP" electrode was firstly reported by Valentini et al. in 2003 [160]. In that work, they prepared CNTPEs by mixing SWNTs with mineral oil. Studies on the composition of the SWNT paste electrodes showed a different behavior, as compared to graphite paste electrodes (CPEs). In the case of CPEs, the treatment of graphite powder with $\mathrm{HNO}_{3}$ oxidation hardly changed the electrochemical properties of CPEs. As for CNTPEs, the $\mathrm{HNO}_{3}$ oxidation treatment significantly improved the electrochemical activity of CNTPEs toward many electroactive substances, especially for small biomolecules. Later, Valentini et al. [161] further explored the various advantages of CNTPEs over conventional carbon paste $(\mathrm{CP}), \mathrm{Pt}$, and glassy carbon electrodes, such as a very low capacitance (background current) and fast electron transfer rates toward various redox couples, especially for two-electron quinonic structure species. Since then, more and more works focus on the preparation and applications of CNTPEs in electrochemical sensors, including the determination of amitrole [162], HcySH [163] and DNA [164] at CNTPEs, the determination of carbohydrates at a copper particle incorporated CNTPE [165], the determination of lactate, phenols, catechols, alcohols or glucose at enzyme incorporated CNTPEs [166, 167], and the electrocatalytic oxidation of NADH at a 3,4dihydroxybenzaldehyde (3,4-DHB) modified CNTPE [168, 169]. Using solid binders in preparing CNTPEs was also reported. Wang et al. prepared CNT/Teflon composite electrodes by the dispersion of CNTs within a Teflon binder [170]. The resulting CNT/Teflon material brought new capabilities for electrochemical devices by combining the advantages of CNTs and "bulk" composite electrodes, including the accelerated electron transfer, the minimization of surface fouling and surface renewability. The electrocatalytic properties of CNTs were not impaired by their association with the Teflon binder. Later, Chen et al. prepared a CNT-epoxy composite microdisc electrode by mixing CNT powder with epoxy resin/hardener and packing the resulting CNT-epoxy composite into the opening end of capillary [171].

\subsection{Abrasive Immobilization}

3.5.1. Carbon Nanotube Powder Microelectrodes. Powder microelectrodes (PMEs) have been proved to be an effective technology for the purpose. PMEs, originated from Liu's laboratory, are a convenient technique for both the characterization of powder materials and the subsequent electroanalytical applications [172]. In fact, the so-called PME is a combination of porous and microelectrode. Besides, PMEs have the properties of the thin layer cell to some extent. No binder is needed for preparing PMEs; this not only makes the preparation simple but also can prevent impurities and keep the powder material in its pristine state [172]. Liu et al. [173] firstly reported the immobilization of CNTs on PMEs by filling CNTs in the microcaves of PMEs through a simple rubbing operation. The resultant CNT-based PMEs (CNTPMEs) were further modified by $\mathrm{Os}(\mathrm{bpy})_{3}{ }^{2+}$ and used for the electrocatalytic determination of nitrite. Then, CNTPMEs were used for the determination of hydrazine [174] and cysteine (CySH) [175], the direct electrochemistry of HRP [176], and the studies on the electrochemical properties and scavenge of superoxide anion in aprotic media by Hu et al. [177].

\subsubsection{Carbon Nanotube Abrasively Modified Conventional} Scale Electrodes. The grinding immobilization of CNTs on the surface of conventional scale electrodes was firstly reported by Luo et al. [178]. In that work, a CNT-intercalated graphite electrode (CNT-IE) was fabricated by grinding with a suitable amount of CNTs powder. A thin CNT layer was formed on the graphite surface by intercalating CNTs into the soft graphite layers with the aid of mechanical force and also the action of chemical and physical adsorption. CNTIE can effectively separate the oxidation potential of DA and AA, which was used for the simultaneous determination of DA and AA [178] and the selective determination of DA and serotonin (5-HT) in the presence of AA [179]. CNT-IE was further employed by Shi et al. to prepare an amperometric cholesterol biosensor by immobilizing of ChOx in sol-gel on a Pt-decorated CNT-IE [180] and a Ptdecorated CNT intercalated waxed graphite electrode [181]. Salimi et al. developed a CNT intercalated bppg electrode by gently rubbing the electrode surface of bppg on fine qualitative filter paper containing CNTs for 1 minute, which was used for the determination of EP [182] (Figure 10). Based on this electrode, they also prepared a glucose electrochemical biosensor by coating the CNT intercalated bppg electrode with a sol-gel composite film containing GOx [183]. Later, Salimi et al. produced a CNT intercalated GCE by immobilizing MWNTs on GCE that was preheated for 5 minutes at $50^{\circ} \mathrm{C}$ through gentle rubbing of the electrode surface on a filter paper supporting CNTs, which was applied to the determination of morphine [184], and thiols like thiocytosine, L-CySH, and glutathione (GSH) [185].

3.6. Electropolymerization Immobilization. The polymerization of various monomers in the presence of dispersed CNTs in solutions by electrochemical methods has been employed for the immobilization of CNTs on the electrode surface. 


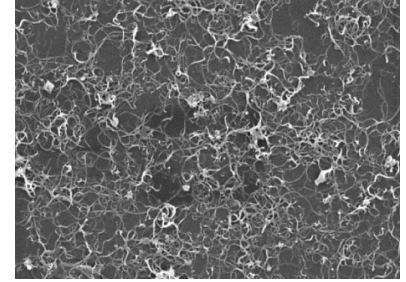

(a)

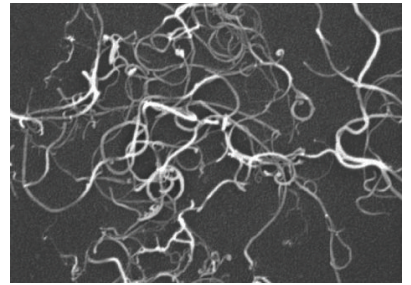

(b)
Figure 10: SEM images of CNTs used to fabricate the CNTmodified bppg electrode, magnification (a) 10000 and (b) 33000. [Reprinted with permission from Salimi et al. [182], Analyst, 129, 225 (2004). Copyright 2004, Royal Society of Chemistry.]

In this process, CNTs were enwrapped in polymers during the electropolymerization process in the form of counter ions or dopants. Wu et al. reported a marvelous method for the dispersion and immobilization of CNTs on the electrode surface by water-soluble alizarin red S (ARS, 3,4-dihydroxy9,10-dioxo-2- anthracenesulfonic acid, sodium salt) [186]. Pan et al. prepared a CNT-based glucose electrochemical biosensor by the simultaneous immobilization of CNTs and $\mathrm{GOx}$ on the gold electrode through the electropolymerization of o-aminophenol (o-AP) in $0.2 \mathrm{M}$ acetate buffer solution ( $\mathrm{pH}$ 5.0) containing GOx, o-AP monomer and fresh CNT dispersion [187]. Cheng et al. fabricated a MWNT/polypyrrole (PPy) modified electrode through cyclic sweeping from 0.0 to $0.7 \mathrm{~V}$ at GCE with the scan rate $0.1 \mathrm{~V} / \mathrm{s}$ for eight circles in solution containing $0.1 \mathrm{M}$ pyrrole, $0.2 \mathrm{mg} / \mathrm{mL}$ MWNTs and $0.2 \mathrm{M} \mathrm{KCl}$ in phosphate buffer $(\mathrm{pH}$ 2.0) [188]. It is clear that in these two works, CNTs were used as the dopants in the polymers. Wang et al. reported a onestep preparation route of amperometric enzyme electrodes by incorporating the CNT dopant and the biocatalyst (e.g., $\mathrm{GOx}$ ) in an electropolymerized polypyrrole film [189]. They found that the entrapment of CNTs had little effect upon the electropolymerization rate and redox properties of the resulting film, and the CNT dopants retained its electrocatalytic activity to impart high sensitivity and selectivity. Recently, we established a noncovalent method for the dissolution of MWNTs in water by a conjuaged organic dye, azocarmine B (ACB) [190]. The resulting ACB-MWNT mixture could be used for the immobilization of MWNTs on a glass carbon electrode by a simple electropolymerization method, which showed excellent electrochemical response toward the oxidation of nitric oxide (NO), an important radical molecule in life sciences.

3.7. Direct Growth. Despite the randomly dispersed CNTs, well-aligned CNTs were also used for constructing electrochemical sensors. These CNT-based sensors were generally constructed from CNT ensembles directly grown from CVD methods. Based on their different density, aligned CNT electrodes have the electrochemical properties resembling conventional scale electrodes at high density or microelectrode arrays at low density. This section will introduce the fabrication of aligned CNT electrochemical sensors made up of these two kinds.

\subsubsection{Dense Carbon Nanotube Forests}

(1) Unmodified Carbon Nanotubes. The unmodified aligned CNT electrodes were typically constructed by two steps: the CVD synthesis and the transfer of the aligned CNT ensembles to various substrates. Sometimes, the prepared aligned CNT electrodes were further activated by electrochemical methods. Ye et al. developed an aligned CNT electrode for the selective determination of UA [191]. They found that compared to GCE, the CNT electrode catalyzed the oxidation of UA and L-AA, reducing the overpotentials by about 0.028 and $0.416 \mathrm{~V}$, respectively, and resolved the overlapping voltammetric response of UA and L-AA into two well-defined voltammetric peaks in both cyclic voltammetry (CV) and differential pulse voltammetry (DPV). Chen et al. developed a simple method for preparing ordered CNTs (OCNTs) in the nanopores of an alumina template membrane [192]. Ye et al. also reported a nonenzymatic glucose electrochemical sensor using aligned CNTs [193]. They firstly synthesized the aligned CNTs on a tantalum (Ta) plate and then attached the CNT ensembles to the surface of GCE using conductive silver paint. The CNT-based electrode was used without any further treatment. Compared to GCE, a substantial $(+400 \mathrm{mV})$ decrease in the overpotential of the glucose oxidation reaction was observed at this electrode with oxidation starting at ca. $+0.10 \mathrm{~V}$ (versus $3 \mathrm{M} \mathrm{KCl}$ $\mathrm{Ag} \mid \mathrm{AgCl})$.

(2) Modified Carbon Nanotubes. The modified aligned CNT electrochemical sensors were usually fabricated through the immobilization of functional species (e.g., biocatalysts like enzymes) by various methods. Soundarrajan et al. developed a simple pyrolytic method for largescale production of aligned CNTs arrays perpendicular to the substrate [194]. These aligned CNT arrays can be transferred onto various substrates of particular interest (e.g., polymer films for organic optoelectronic devices) in either a patterned or nonpatterned fashion. They further prepared aligned coaxial nanowires by electrochemically depositing a concentric layer of an appropriate conducting polymer onto the individual aligned CNTs, which were used for electrochemical sensing applications. On the basis of electropolymerization of some organic monomers, GOx was immobilized on the aligned CNTs to prepared CNTbased glucose electrochemical biosensors by Gao et al. using pyrrole [195, 196], Loh et al. using 3,3'-diaminobenzidine (DAB) [197], and Ye et al. using o-aminophenol [198] as the monomers. The physical adsorption of GOx on the naked [199] or the Pt decorated [200] surfaces of aligned CNTs were also employed for constructing glucose electrochemical biosensors. Recently, Ye et al. developed a novel oxygen sensor for working at a relatively low potential by the physical adsorption of hemin on an aligned CNT electrode [201]. They found that CV of the hemin-modified MWNTs electrode in pH 7.4 PBS clearly showed the dioxygen reduction peaks close to $0.0 \mathrm{~V}$ (versus $\mathrm{Ag} \mid \mathrm{AgCl}$ ). 
(a)

Ni nanoparticles made by electrochemical deposition

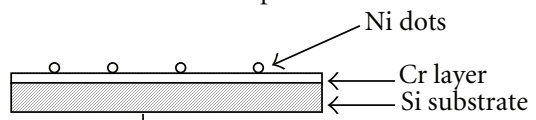

Aligned CNTs growth by PECVD

(b)

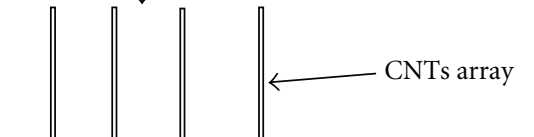

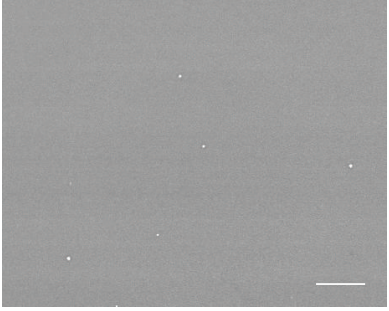

(a)

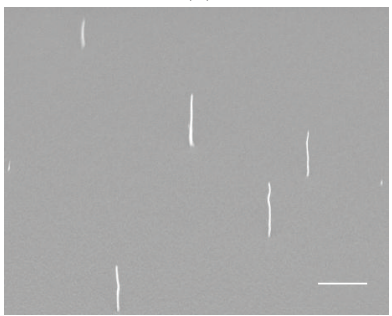

(b)

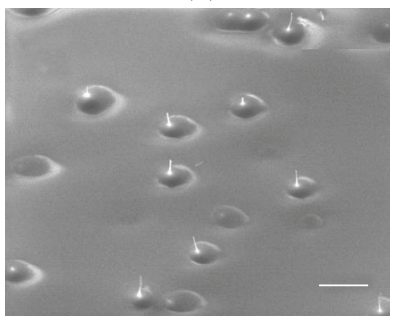

(c)

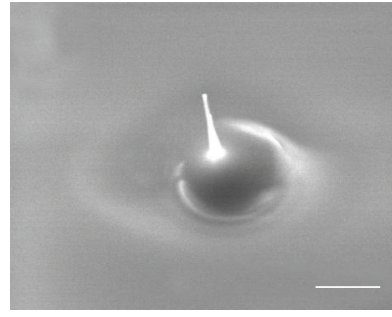

(d)

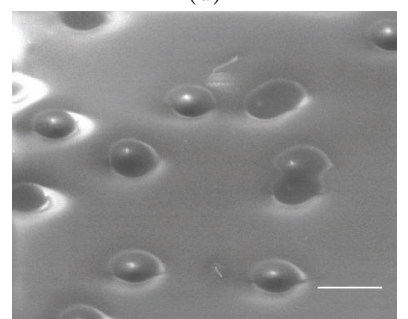

(e)

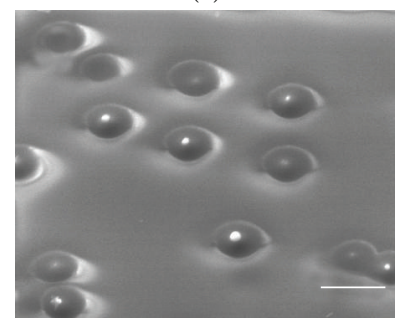

(f)

(A)

(B)

FIgURE 11: Fabrication scheme of the NEAs (A): (a) Ni nanoparticles electrodeposition; (b) aligned carbon nanotube growth; (c) coating of $\mathrm{SiO}_{2}$ and M-Bond; and (d) polishing to expose CNTs. Scanning electron microscope images of the NEAs (B): (a) Top view; (b)-(f) from a $45^{\circ}$ side view. All of the scale bars represent $5 \mu \mathrm{m}$. (a) Electrodeposited Ni nanoparticles; (b) low site density aligned CNTs array; (c) CNTs array coated with $\mathrm{SiO}_{2}$ and an epoxy layer, (d) close-up look at a single half-embedded CNTs; (e) CNTs after polishing; and (f) second electrodeposition of Ni nanoparticles on the broken CNTs only. [Adapted with permission from Tu et al. [202], Nano Lett., 3, 107 (2003). Copyright 2003, American Chemical Society.]

3.7.2. Carbon Nanotube Nanoelectrode Arrays. At low density, the CNT ensembles possessed the electrochemical properties resembled the microelectrodes, which were denoted as CNT nanoelectrode arrays (NEAs). To make each nanotube work as an individual nanoelectrode, the spacing needs to be sufficiently larger than the diameter of the nanotubes to prevent diffusion layer overlap with the neighboring electrodes. In contrast to the conventional scale aligned CNT ensembles at high density, the size reduction of each individual electrode and the increased total number of electrodes result in improvements in both the signal-tonoise ratio and detection limits (DLs). A typical procedure for preparing CNT-based NEAs included the direct CVD growth of well-aligned CNTs with low density, the coating of the CNT layer by insulating materials (e.g., epoxy) and the removing of the protruding parts of CNTs by polishing. Sometimes, the CNT-based NEAs were further electrochemically activated by applying a potential bias $1.0 \mathrm{M} \mathrm{NaOH}$ for a certain period to obtain functional groups like carboxyl groups. The major works regarding the construction of CNT-based NEAs were done by Ren [28, 202-204] and Meyyappan [205-207]. Ren et al. firstly fabricated CNT-based NEAs from low site density aligned CNTs by plasma-enhanced CVD on Ni nanoparticles made by electrochemical deposition [202] (Figure 11). They found that each nanotube was separated from the nearest neighbor by several micrometers and NEAs of $1 \mathrm{~cm}^{2}$ consisted of up to millions of individual nanoelectrodes, each with a diameter of $100 \mathrm{~nm}$. Based on this method, they further constructed a glucose electrochemical biosensor through the covalent immobilization of GOx on the ends of CNT NEAs that were activated in $1.0 \mathrm{M} \mathrm{NaOH}$ at $1.5 \mathrm{~V}$ for 90 seconds beforehand [28]. The CNT-based NEAs were also used successfully by Ren et al. for the voltammetric detection of trace concentrations of lead (II) $[203,204]$ and cadmium(II) [204] at ppb level. Meyyappan et al. mainly focused on the construction of ultrasensitive DNA sensors from CNT-based NEAs. Based on the signal change of the electrochemical indicator, $\mathrm{Ru}(\mathrm{bpy})_{3}{ }^{2+}$, before and after the hybridization of the oligonucleotide probes that were covalently attached to the open ends of CNTs with the target oligonucleotides, ultrasensitive determinations of DNA/RNA were achieved with low detection limits of nM level [205207]. 


\section{Carbon Nanotube-Based Electrochemical Sensors for Electroanalysis}

Although possessing the electrochemical properties similar to edge plane pyrolytic graphite electrodes, CNTs still have some overwhelming advantages for fabricating carbon material-based electrochemical sensors, including the good conductivity, the good biocompatibility, the large specific area, the well-defined nanotube structure, the modifiable surface, the functional groups on the surface with pretreatments and the capacity of being solubilized or dispersed in solutions. Based on these unique properties, numerous works have been dealt with CNT-based electrochemical sensors, which can be mainly divided into two kinds: the nonenzymatic and the enzymatic CNT-based electrochemical sensors.

\subsection{Carbon Nanotube-Based Nonenzymatic Electrochemical Sensors}

\subsubsection{Carbon Nanotube-Based Nonenzymatic Electrochemical Sensors for Biomedical Analysis}

(1) Thiols. Aminothiols are of physiological importance as biological agents and metabolites. The levels of these compounds in biological matrices such as plasma and urine are valuable biomarkers in a number of clinical situations. Increased levels of $\mathrm{HcySH}$ and $\mathrm{CySH}$ are associated with risk of cardiovascular diseases. The ratio of GSH to glutathione disulfide (GSSG) indicates the redox status of cells. In addition, $\mathrm{N}$-acetylcysteine is an important mucolytic agent used to reduce the viscosity of pulmonary secretions in respiratory diseases. A substantial challenge to the development of electrochemical methods for thiol detection was that the direct oxidation of thiols at solid electrodes is slow and usually large overpotentials are required [171]. Recently, Cao et al. reported the direct determination of LCySH and GSH at a MWNT modified electrode [208]. They found that the CNT-modified electrode exhibited efficiently electrocatalytic oxidation for L-CySH and GSH with a relatively high sensitivity, stability and long-life. Coupled with high performance liquid chromatography (HPLC), this electrode was utilized for the amperometric detection of these thiols. The peak currents of L-CySH and GSH were linear to their concentrations ranging from $3.0 \times 10^{-7}$ to $1.0 \times$ $10^{-3} \mathrm{M}$ with the calculated detection limits (signal-to-noise ratio $(\mathrm{S} / \mathrm{N})=3)$ of $1.2 \times 10^{-7}$ and $2.2 \times 10^{-7} \mathrm{M}$, respectively. This method was successfully applied to the content estimate of L-CySH and GSH in rat striatal microdialysates. This work paved the way to determine thiols by CNT-based electrochemical sensors. Since then, many works regarding the determination of thiols by electrochemical methods used CNTs to construct the working electrodes. In general, these CNT-based electrochemical sensors were constructed from two types of sensing materials: CNTs and Pt-CNT composites.

(a) Unmodified Carbon Nanotube-Based Electrochemical Sensors. The electrochemical behavior of $\mathrm{CySH}$ at CNT powder microelectrodes (CNTPMEs) was investigated by Zhao et al. [175]. In contrast to the absence of signals at a GCE and a graphite powder modified powder microelectrode, $\mathrm{CySH}$ exhibited a sensitive oxidation peak at around $0.58 \mathrm{~V}$ (versus $\mathrm{SCE}$ ) in $0.2 \mathrm{M} \mathrm{H}_{2} \mathrm{SO}_{4}$ at a CNTPME, indicating the strong ability of CNTs to improve the electrochemical response of $\mathrm{CySH}$. Chen et al. reported the fabrication of a CNTbased microdisc electrode by mixing MWNTs with epoxy for a specially designed miniaturized capillary electrophoresis (CE)-amperometric detection system for the separation and detection of several bioactive thiols [171]. The end-channel CNT amperometric detector offered favorable signal-tonoise characteristics at a relatively low potential $(0.8 \mathrm{~V})$ for detecting thiol compounds. Four thiols ( $\mathrm{HcySH}, \mathrm{CySH}$, $\mathrm{GSH}$, and $\mathrm{N}$-acetylcysteine) were separated within 130 seconds at a separation voltage of $2000 \mathrm{~V}$ using a $20 \mathrm{mM}$ phosphate running buffer ( $\mathrm{pH} 7.8)$. A highly linear response was obtained for $\mathrm{HcySH}, \mathrm{CySH}, \mathrm{GSH}$, and $\mathrm{N}$-acetylcysteine over the range of $5-50 \mu \mathrm{M}$ with detection limits of $0.75,0.8$, 2.9 , and $3.3 \mu \mathrm{M}$, respectively. Lawrence et al. reported an effective means for the determination of $\mathrm{HcySH}$ at a CNTP electrode [163]. HcySH showed a well-defined electrochemical signal emerging at $+0.28 \mathrm{~V}$ and a current plateau at $+0.64 \mathrm{~V}$ on the CNTP electrode. In contrast, the HcySH response obtained at the carbon paste electrode showed only a slight increase in the oxidation current at $+0.40 \mathrm{~V}$. The sensitive determination of $\mathrm{HcySH}$ was also achieved by Gong et al. at a CNT-modified GCE [70]. Cyclic voltammetric results clearly showed that CNTs, especially those pretreated with $\mathrm{HNO}_{3}$, possessed an excellent electrocatalytic activity toward the oxidation of $\mathrm{HcySH}$ at a low potential $(0.0 \mathrm{~V}$ versus $\mathrm{Ag} \mid \mathrm{AgCl}$ ). The remarkable catalytic property of acidpretreated CNTs was believed essentially associated with oxygen-containing moieties introduced on the tube surface. Zhang et al. also studied the electrochemical behaviors of GSH and GSSG at an acid-treated MWNT modified GCE [42]. They found that the functionalized CNTs exhibited efficiently electrocatalysis on the current responses of GSH and GSSG. Recently, Salimi et al. reported the electrochemical responses of three thiols, thiocytosine, GSH and L-CySH, at a CNT-modified GCE constructed by abrasive methods [185]. They found that the overpotentials of these species were apparently reduced along with a dramatic increase in the peak currents in comparison to bare GCE. Furthermore, the thiols amperometric responses of the coated electrodes were extremely stable, with more than $95 \%$ of the initial activity after 30 minutes stirring of $0.1 \mathrm{mM}$ thiols.

(b) Platinum-Carbon Nanotube Composite-Based Electrochemical Sensors. Besides the unmodified CNTs, Pt decorated CNTs were also used for the sensitive determination of thiols. Xian et al. prepared a MWNT/Pt microparticle nanocomposite by electrodepositing Pt microparticles onto the MWNT matrix [209]. The GCE modified with this nanocomposite was used for the measurement of thiols, such as $\mathrm{L}-\mathrm{CySH}$ and GSH. Compared with the MWNT or Pt microparticle modified electrode, the nanocomposite modified electrode exhibited high sensitivity and good stability 
for detection of thiols, which was successfully applied to the HPLC-electrochemical detection (ECD) system for the determination of L-CySH and GSH in rat striatum. The electrochemical behavior of $\mathrm{L}-\mathrm{CySH}$ on the $\mathrm{Pt} / \mathrm{CNT}$ electrode was investigated by Fei et al. using cyclic voltammetry [210]. In that work, CNTs were grown directly on graphite disk by CVD, and Pt was electrochemically deposited on the activated CNT/graphite electrode by electroreduction of $\mathrm{Pt}(\mathrm{IV})$ complex ion on the surface of CNTs. Among graphite, $\mathrm{CNT} /$ graphite, and Pt/CNT electrodes, the improved electrochemical behavior of $\mathrm{CySH}$ oxidation was found with the $\mathrm{Pt} / \mathrm{CNT}$ electrode.

(2) Carbohydrates. Electrocatalytic oxidation of carbohydrates is of great interest in the points of view ranging from medical applications of the blood glucose sensing to ecological approaches (e.g., waste-water treatment in food industry). Most previous studies on this subject involved the use of GOx, which catalyzes the oxidation of glucose to gluconolactone. However, due to the intrinsic nature of enzymes, such enzyme-based sensors suffer from the stability problem. Thus, great efforts are made to achieve direct determination of carbohydrates. Ye et al. recently reported the direct electrocatalytic oxidation of glucose in alkaline medium at well-aligned MWNT electrodes [193]. Compared to GCE, a substantial $(+400 \mathrm{mV})$ decrease in the overpotential of the glucose oxidation reaction was observed at MWNT electrodes with oxidation starting at ca. $+0.10 \mathrm{~V}$ (versus $3 \mathrm{M}$ $\mathrm{KCl}-\mathrm{Ag} \mid \mathrm{AgCl})$. The only problem of using this electrode for the direct determination of glucose was the serious interferences from some electroactive biomolecules like UA and AA, which might coexist in real biological samples. Deo et al. also reported on the electrocatalytic oxidation of carbohydrates at glassy carbon electrodes modified with SWNT coatings [69]. They found that the oxidation processes of four carbohydrates, including galactose, fructose, mannose and xylose, started around $+0.25 \mathrm{~V}$ in $0.1 \mathrm{M} \mathrm{NaOH}$ solution. Moreover, the amperometric responses of these species at the CNT-modified electrodes were extremely stable, with no loss in sensitivity over a continuous 2-hour operation.

Besides unmodified CNTs, the composites made up of copper particles and CNTs were also used by several works to achieve the electrooxidation of carbohydrates. Male et al. reported a copper decorated CNT-based electrochemical sensor for the deterimiation of carbohydrates [72]. In that work, copper ( $\mathrm{Cu})$ nanoparticles $(4-8 \mathrm{~nm}$ in diameter), prepared by using sodium borohydride to reduce copper dodecyl sulfate $\left(\mathrm{Cu}(\mathrm{DS})_{2}\right)$, were used with SWNTs to fabricate electrochemical sensors. Nafion was used to solubilize SWNTs and displayed interactions with $\mathrm{Cu}$ nanoparticles to form a network, connecting $\mathrm{Cu}$ nanoparticles to a glassy carbon (GC) or $\mathrm{Cu}$ electrode surface. The composite of $\mathrm{SWNT} / \mathrm{Cu}_{\text {nano }}$ gave a much enhanced current response at $+0.65 \mathrm{~V}$ with a relatively low starting oxidation potential $(+0.3 \mathrm{~V}$ versus $\mathrm{Ag} \mid \mathrm{AgCl}(3 \mathrm{M} \mathrm{NaCl}))$ in comparison to the GC electrode modified by either Cu nanoparticles or SWNTs alone. Similar results were observed from amperometric detection when $0.1 \mathrm{mM}$ glucose was detected at $+0.65 \mathrm{~V}$.
The current responses for other saccharides $(100 \mu \mathrm{M})$ were analyzed and compared to the glucose response. The monosaccharides, galactose (120\%), arabinose (94\%), xylose (109\%), fructose (99\%), and mannose (97\%) gave similar responses as glucose. However, the current signal was lower for the dissacharides (i.e., maltose (50\%), lactose $(56 \%)$, sucrose $(39 \%)$, trehalose $(28 \%)$ and the trisaccharide raffinose $(56 \%))$.

(3) Electroactive Microbiomolecules. The determination of neurotransmitters and other important microbiomolecules is of considerable significance in biochemical and clinical diagnosis. Generally, these species are electroactive, providing a simple but sensitive way for their determination by electrochemical methods. However, owning to the overlapping of the oxidation potentials of these species, it is difficult to selectively determine them at bare electrodes. To overcome this obstacle, various materials have been used to modify the bare electrodes. Among these modifiers, CNTs have become the most outstanding material and most recent works on the determination of the microbiomolecules employ CNTs as the sensing materials.

(a) Unmodified Carbon Nanotube-Based Electrochemical Sensors. The work regarding the enhanced electrochemical response of some biomolecules at CNT electrodes was firstly reported by Luo et al. [16]. In contrast to the poor response at bare GCE, DA exhibited a pair of well-defined redox peaks at SWNT modified GCE. Similar enhanced signals of AA and NE were also observed at the modified electrodes. Since then, many works focused on the selective or simultaneous determination of these species at CNT-modified electrodes (Table 1).

(b) Carbon Nanotube Composite-Based Electrochemical Sensors. The selective determination of the electroactive microbiomolecules was also performed at CNT composite modified electrodes. Compared with CNTs, the combination of CNTs with other components not only provides higher stability and better uniformity of the composite films but also endows the composite films with the unique properties of both components. A typical example is that the composite films made up of CNTs and Nafion can effectively eliminate the interference of negatively charged AA on the determination of other species due to the exclusion of AA from the electrode surface by a negatively charged Nafion film. Table 2 lists the recent works on the determination of electroactive microbiomolecules at CNT composite films modified electrodes.

(4) Amino Acids. Amino acids detected by electrochemical methods are generally electroactive and usually contain phenol moieties. Xu et al. prepared a MWNT film-modified electrode and coupled this electrode to an ion chromatography system for the simultaneous determination of oxidizable amino acids, including $\mathrm{CySH}$, tryptophane and tyrosine [217]. The results show that the peak currents responded linearly to the concentrations of these analytes when the 
TABLE 1: Sensitive determination of electroactive microbiomolecules at CNT-based sensors.

\begin{tabular}{|c|c|c|c|c|c|c|}
\hline Targets & Electrodes & Supporting electrolyte & Detection potential/V & Linear range $/ \mu \mathrm{M}$ & $\mathrm{DL} / \mu \mathrm{M}$ & Ref. \\
\hline UA & SWNT/Au & 0.1 M HAc-NaAc pH 5.0 & 0.451 & $4.0 \sim 700$ & 1.0 & {$[211]$} \\
\hline Thymine & MWNT-CD/CE & $\mathrm{NaHCO}_{3}-\mathrm{Na}_{2} \mathrm{CO}_{3} \mathrm{pH} 10.8$ & 0.87 & $25 \sim 1800$ & 5.0 & {$[131]$} \\
\hline NE & SWNT/GCE & B-R pH 5.72 & 0.261 & $10 \sim 1100$ & 6.0 & {$[212]$} \\
\hline Xanthine (Xa) & MWNT/GCE & HAc-NaAc pH 5.20 & 0.8 & $0.2 \sim 20$ & 0.004 & {$[213]$} \\
\hline DA & \multirow{2}{*}{ MWNT-IE } & \multirow{2}{*}{0.05 M PBS pH 7.4} & 0.13 & $0.5 \sim 10$ & 0.1 & \multirow{2}{*}[179]{} \\
\hline $5-\mathrm{HT}$ & & & 0.32 & $1 \sim 15$ & 0.2 & \\
\hline Hypo-xanthine & MWNT-DHP/GCE & $0.1 \mathrm{M}$ PBS pH 7.3 & 1.06 & $0.5 \sim 200$ & 0.2 & {$[94]$} \\
\hline DA & \multirow{2}{*}{ MWNT-IE } & \multirow{2}{*}{$50 \mathrm{mM} \mathrm{NaH}_{2} \mathrm{PO}_{4}$ pH 5.0} & 0.4 & $0.5 \sim 10$ & 0.1 & \multirow{2}{*}[178]{} \\
\hline $\mathrm{AA}$ & & & 0.13 & $80 \sim 1360$ & 20 & \\
\hline DA & \multirow{3}{*}{ MWNT/GCE } & \multirow{3}{*}{$0.2 \mathrm{M}$ PBS pH 5.0} & 0.24 & $0.0005 \sim 10$ & 0.00025 & \multirow{3}{*}[214]{$^{*}$} \\
\hline $\mathrm{NE}$ & & & - & $0.0005 \sim 10$ & 0.00025 & \\
\hline 5-HT & & & - & $0.0007 \sim 10$ & 0.00035 & \\
\hline DA & \multirow{3}{*}{ SWNT/CFNE } & \multirow{3}{*}{25 mM Tris-HCl pH 7.4} & \multirow{3}{*}{-} & $0.1 \sim 100$ & 0.0077 & \multirow{3}{*}[76]{} \\
\hline $\mathrm{EP}$ & & & & $0.3 \sim 100$ & 0.038 & \\
\hline NE & & & & $0.5 \sim 100$ & 0.042 & \\
\hline UA & Aligned MWNTs & PBS pH 7.4 & 0.295 & $0.2 \sim 80$ & 0.1 & [191] \\
\hline Dopa & SWNT/GCE & $0.1 \mathrm{M}$ PBS pH 5.0 & 0.27 & $0.5 \sim 20$ & 0.3 & {$[30]$} \\
\hline EP & MWNT/bppg & $0.1 \mathrm{M}$ PBS pH 4.3 & 0.18 & $0.1 \sim 100$ & 0.02 & {$[182]$} \\
\hline DA & \multirow{3}{*}{ MWNT/GCE } & \multirow{3}{*}{$0.2 \mathrm{M}$ PBS pH 5.0} & \multirow{3}{*}{ - } & $0.0005 \sim 10$ & 0.0002 & \multirow{3}{*}[215]{$^{*}$} \\
\hline NE & & & & $0.0004 \sim 10$ & 0.0002 & \\
\hline 5-HT & & & & $0.0007 \sim 10$ & 0.0003 & \\
\hline
\end{tabular}

*The results were obtained from an electrochemical detection (ED) system for liquid chromatography (LC).

TABLE 2: Sensitive determination of electroactive microbiomolecules at CNT composite film-modified electrodes.

\begin{tabular}{|c|c|c|c|c|c|c|}
\hline Targets & Electrodes & Supporting electrolyte & Detection potential/V & Linear range $/ \mu \mathrm{M}$ & $\mathrm{DL} / \mu \mathrm{M}$ & Ref. \\
\hline $\mathrm{UA}$ & CNT- $\beta-\mathrm{CD} / \mathrm{PG}$ & $0.2 \mathrm{M}$ HAc-NaAc pH 4.5 & 0.45 & $0.5 \sim 50$ & 0.2 & {$[134]$} \\
\hline DA & MWNT-Nafion/GCE & $0.1 \mathrm{M}$ PBS pH 5.5 & 0.235 & $0.05 \sim 1.0$ & 0.0025 & {$[62]$} \\
\hline $\mathrm{XA}$ & \multirow{2}{*}{ MWNT-DHP/GCE } & \multirow{2}{*}{$0.1 \mathrm{M}$ PBS pH 5.5} & 0.77 & $0.02 \sim 20$ & 0.04 & \multirow{2}{*}[79]{} \\
\hline UA & & & 0.38 & $0.1 \sim 100$ & 0.01 & \\
\hline DA & \multirow{2}{*}{ MWNT-DHP/GCE } & \multirow{2}{*}{0.1 M PBS pH 7.0} & 0.18 & $0.05 \sim 5.0$ & 0.011 & \multirow{2}{*}[96]{} \\
\hline $5-\mathrm{HT}$ & & & 0.36 & $0.02 \sim 5.0$ & 0.005 & \\
\hline NE & $\mathrm{CNT}-\beta-\mathrm{CD} / \mathrm{PG}$ & $0.1 \mathrm{M}$ PBS pH 6.0 & 0.25 & $1.0 \sim 300$ & 0.5 & {$[135]$} \\
\hline DA & \multirow{2}{*}{ MWNT-CHIT/GCE } & \multirow{2}{*}{$0.1 \mathrm{M}$ PBS pH 7.2} & 0.144 & $0.5 \sim 100$ & 0.2 & \multirow{2}{*}{ [102] } \\
\hline $\mathrm{AA}$ & & & -0.029 & $5.0 \sim 1000$ & 2.0 & \\
\hline DA & MWNT-Nafion/GCE & $0.1 \mathrm{M}$ PBS pH 6.0 & 0.235 & $0.01 \sim 10$ & 0.0025 & {$[64]$} \\
\hline UA & \multirow{2}{*}{ MWNT-CHIT/GCE } & \multirow{2}{*}{$0.1 \mathrm{M}$ PBS pH 5.5} & 0.484 & $2.0 \sim 100$ & 0.75 & \multirow{2}{*}{ [105] } \\
\hline EP & & & 0.329 & $5.0 \sim 250$ & 1.0 & \\
\hline DA & MWNT-Nafion/CFME & $0.05 \mathrm{M}$ PBS pH 7.5 & 0.145 & $2.0 \sim 20$ & 0.07 & {$[65]$} \\
\hline DA & MWNT-RTIL/GCE & $0.1 \mathrm{M}$ PBS pH 7.0 & 0.16 & $1.0 \sim 100$ & 0.1 & {$[124]$} \\
\hline EP & MWNT-PBCB/GCE & $0.1 \mathrm{M}$ PBS pH 6.0 & 0.28 & $0.05 \sim 50$ & 0.01 & [216] \\
\hline
\end{tabular}

concentrations ranged from $1.5 \times 10^{-6}$ to $2.5 \times 10^{-4} \mathrm{M}$ for $\mathrm{CySH}, 5.5 \times 10^{-7}$ to $1.5 \times 10^{-4} \mathrm{M}$ for tryptophane and $9.0 \times 10^{-7}$ to $3.5 \times 10^{-4} \mathrm{M}$ for tyrosine, respectively. The detection limits were $7.0 \times 10^{-7} \mathrm{M}$ for $\mathrm{CySH}, 2.0 \times$ $10^{-7} \mathrm{M}$ for tryptophane and $3.5 \times 10^{-7} \mathrm{M}$ for tyrosine $(\mathrm{S} / \mathrm{N}$ $=3)$. $\mathrm{Wu}$ et al. investigated the electrochemical behavior of tryptophan at MWNT/GCE [51]. Compared with a bare electrode, the oxidation peak current of tryptophan was obviously increased, and the peak potential negatively shifted. Under the chosen conditions, the DPV peak current was linear to the concentration of tryptophan in the range of $2.5 \times 10^{-7} \sim 1.0 \times 10^{-4} \mathrm{M}$, and the detection limit was $2.7 \times 10^{-8} \mathrm{M}$. The voltammetric response of tryptophan at a SWNT modified GCE was also studied by Huang et al. [97]. In pH $2.5 \mathrm{Na}_{2} \mathrm{HPO}_{4}$-citric acid buffer, tryptophan yielded a well-defined and very sensitive oxidation peak at about $1.08 \mathrm{~V}$ at the SWNT-film coated GCE. The oxidation peak current increased greatly and the peak potential shifted toward the negative direction at the SWNT-modified GCE in contrast to that at the bare GCE. Under optimized 
conditions, the oxidation peak current was proportional to the concentration of tryptophan over the range from $4 \times 10^{-8}$ to $1 \times 10^{-5} \mathrm{M}$. The detection limit was $1 \times 10^{-8} \mathrm{M}$ for 3 minutes accumulation.

The electrochemical determination of traditionally "nonelectroactive" amino acids was also performed by Deo et al. at a SWNT modified electrode that was coated by a nickel hydroxide film [74]. The determination process was achieved through the electrocatalytic oxidation of these amino acids at the $\mathrm{Ni}(\mathrm{OH})_{2}$ layer that was electrodeposited on surface of SWNTs. In the presence of amino acid, the Ni-CNT layer underwent an electrocatalytic process in which amino acids reduce the newly formed $\mathrm{NiO}(\mathrm{OH})$ species. The results showed that under flow injection analysis conditions, a linear response was observed from $10 \sim 80 \mathrm{mM}$ arginine with a detection limit of around $1 \mathrm{mM}$ (based on $\mathrm{S} / \mathrm{N} \sim 3$ ). This electrode was also applied to the detection of other amino acids like histidine, lysine, asparagine, methionine and phenylalanine.

4.1.2. Carbon Nanotube-Based Nonenzymatic Electrochemical Sensors for Drug Analysis. The development of sensitive analytical techniques of drugs has drawn much attention due to the promising applications in environment protection, pharmacology and biomedical studies. However, due to the chemical stability and the large bodies, the responses of these substances were generally weak at common bare electrodes. To improve the detection sensitivity, various nanomaterials are employed to fabricate modified electrodes with high performance. Among these materials, CNTs have also been widely to improve the sensitivity of some drugs. Compared with other nanomaterials, CNTs have some advantages, such as good conductivity and strong electrocatalytic activity. The enhanced adsorption of some water insoluble or conjugated drugs on the hydrophobic and $\pi$-conjugated sidewalls of CNTs contributes to the sensitive determination of these species at CNT electrodes. Table 3 lists the applications of CNT-based electrochemical sensors for drug analysis.

\subsection{Carbon Nanotube-Based Enzymatic Electrochemical} Sensors

4.2.1. Carbon Nanotube-Based Enzymatic Electrochemical Biosensors for Electroanalysis. The incorporation of enzymes in a transducer allows one to fabricate enzyme electrodes which exhibit high selectivity, high-sensitivity and longterm stable response to bioanalytes. Many different materials and methods have been used to immobilize enzymes on the electrode surfaces, such as sol-gels, carbon pastes, conductive polymers and recently nanostructured materials. Of particular interest is the use of CNTs as an electrochemical transducer, due to the excellent electron transfer rate, the well-defined nanostructure, the good biocompatibility, and the modifiable surface allowing biomaterial immobilization of CNTs.

(1) Glucose Oxidase. Among all the enzyme-based biosensors, glucose biosensors are most widely studied because the diagnosis of diabetes mellitus requires an accurate monitoring of blood glucose levels. Most of the amperometric glucose biosensors are based on glucose oxidase $(\mathrm{GOx})$, which catalyzes the oxidation of glucose to gluconolactone:

$$
\text { Glucose }+\mathrm{O}_{2} \stackrel{\mathrm{GOx}}{\longrightarrow} \text { Gluconolactone }+\mathrm{H}_{2} \mathrm{O}_{2} \text {. }
$$

The quantification of glucose can be achieved via the electrochemical detection of the enzymatically liberated $\mathrm{H}_{2} \mathrm{O}_{2}$. However, the overpotential necessary for the oxidation or the reduction of $\mathrm{H}_{2} \mathrm{O}_{2}$ at solid electrodes is rather high. Recently, Wang et al. demonstrated that the overpotential of $\mathrm{H}_{2} \mathrm{O}_{2}$ can be greatly reduced at CNT-based electrodes [63], indicating the promising applications of CNTs in constructing glucose electrochemical biosensors. The hybrids of CNTs and some noble metal nanoparticles, such as palladium, platinum, gold, copper and iridium, have also been demonstrated to lower the $\mathrm{H}_{2} \mathrm{O}_{2}$ oxidation/reduction overpotential efficiently. Besides the materials, the immobilization methods effectively influence the activity and the quality of enzyme electrodes. Typical GOx immobilization methods include electropolymerization embedment, composite blending, covalent bonding, electrodeposition and physical adsorption.

(a) Electropolymerization Embedment. Electropolymerization represents an attractive and well-controlled one-step avenue for preparing amperometric enzyme electrodes. The main advantages of this immobilization avenue are the simple one-step preparation, exclusion of electroactive and surface-active interferences, control of film thickness, and localization of biocatalysts onto tiny electrode surfaces [189]. The electropolymerization of some monomers on the surface of CNTs provided a simple but effective approach for the immobilization of GOx on CNTs, including pyrrole, oaminophenol, o-phenylenediamine, and so on. In a typical immobilization process, GOx and the monomers are placed together in the supporting electrolytes on a certain ratio. GOx is then immobilized on the electrode surface via the physical entrapment of GOx within the electropolymerized film during the electropolymerization process. Gao et al. reported a glucose electrochemical biosensor through the immobilization of GOx on well-aligned CNTs via pyrrole electropolymerization [195, 196]. They prepared the biosensor by immobilizing GOx in the electropolymerization film of pyrrole through electrochemically oxidizing pyrrole monomer $(0.1 \mathrm{M})$ in a $\mathrm{pH} 7.45$ buffer solution containing $2 \mathrm{mg} / \mathrm{mL}$ GOx and $0.1 \mathrm{M} \mathrm{NaClO}_{4}$ at a constant potential of $1.0 \mathrm{~V}$ for 1 minute at $10^{\circ} \mathrm{C}$. The oxidation potential of $\mathrm{H}_{2} \mathrm{O}_{2}$ at this electrode $(0.45 \mathrm{~V}$ versus $\mathrm{Ag} \mid \mathrm{AgCl})$ was found to be apparently lower than that at a gold electrode (0.65 V versus $\mathrm{Ag} \mid \mathrm{AgCl})$, providing a selective approach for glucose determination. Callegari et al. proposed a convenient and versatile strategy for the construction of glucose amperometric biosensors [230]. They prepared the sensors by the coimmobilization of GOx and a suitable redox mediator, namely ferrocenyl-derivatised SWNTs (FcSWNTs) within a thin polypyrrole film adsorbed onto the GCE surface. They found that Fc-SWNTs might provide preferential routes for the electrical wiring of the enzyme to 
TABLE 3: Sensitive determination of drugs at CNT-modified electrodes.

\begin{tabular}{|c|c|c|c|c|c|c|}
\hline Targets & Electrodes & $\begin{array}{l}\text { Supporting } \\
\text { electrolyte }\end{array}$ & Detection potential/V & Linear range $/ \mu \mathrm{M}$ & $\mathrm{DL} / \mu \mathrm{M}$ & Ref. \\
\hline 6-Mercaptopurine & MWNT/GCE & 0.1 M PBS pH 7.0 & 0.53 & $0.4 \sim 100$ & 0.2 & {$[218]$} \\
\hline Daunomycin & MWNT-DHP/GCE & 0.1 M PBS pH 5.0 & -0.564 & $0.02 \sim 10$ & 0.008 & {$[83]$} \\
\hline 6-Benzylamino-purine & CNT/GCE & $\mathrm{NH} 3-\mathrm{NH} 4 \mathrm{Cl}$ & 0.65 & $0.08 \sim 10$ & 0.005 & [219] \\
\hline Chloramphenicol & MWNT-DHP/GCE & $0.1 \mathrm{M}$ PBS pH 7.0 & -0.65 & $0.3 \sim 12$ & 0.045 & {$[84]$} \\
\hline Indole-3-acetic acid & MWNT-DHP/GCE & $0.1 \mathrm{M}$ PBS pH 2.0 & 0.68 & $0.1 \sim 50$ & 0.02 & {$[80]$} \\
\hline Vitamin B6 & MWNT-DHP/GCE & $0.1 \mathrm{M}$ PBS pH 6.0 & 0.8 & $0.5 \sim 100$ & 0.2 & [220] \\
\hline Thyroxine & MWNT-DHP/GCE & $0.1 \mathrm{M} \mathrm{HCl}$ & 0.8 & $15 \sim 400 \mu \mathrm{g} / \mathrm{L}$ & $5 \mu \mathrm{g} / \mathrm{L}$ & {$[81]$} \\
\hline 8-Azaguanine & MWNT-DHP/GCE & 0.1 M PBS pH 7.0 & 0.86 & $0.025 \sim 10$ & 0.01 & {$[87]$} \\
\hline Insulin & MWNT/GCE & $\begin{array}{l}0.1 \mathrm{M} \text { PBS pH } \\
7.4+0.02 \%(\mathrm{v} / \mathrm{v}) \\
\text { Tween- } 80\end{array}$ & 0.8 & $0.1 \sim 1.0$ & 0.014 & [221] \\
\hline Tinidazole & MWNT-DHP/GCE & $0.1 \mathrm{M} \mathrm{B}-\mathrm{R} \mathrm{pH} 10.0$ & -0.78 & $0.05 \sim 40$ & 0.01 & [222] \\
\hline Metronidazole & MWNT-DHP/GCE & 0.1 M B-R pH 9.0 & -0.71 & $0.025 \sim 10$ & 0.006 & {$[88]$} \\
\hline Fluphenazin & MWNT-MPS/Au & $\begin{array}{l}0.05 \mathrm{M} \text { HAc- } \mathrm{NaAc} \\
\mathrm{pH} 3.0\end{array}$ & 0.78 & $0.05 \sim 15$ & 0.01 & [223] \\
\hline Thyroxine & SWNT-DHP/GCE & $0.1 \mathrm{M} \mathrm{HCl}$ & 0.78 & $0.1 \sim 7.0$ & 0.02 & {$[82]$} \\
\hline Reserpine & MWNT-DHP/GCE & 0.1 M PBS pH 6.0 & 0.64 & $0.02 \sim 10$ & 0.0075 & {$[90]$} \\
\hline Mitomycin c & MWNT-DHP/GCE & - & 0.79 & $0.25 \sim 100$ & 0.08 & {$[91]$} \\
\hline Epirubicin & SWNT-DHP/GCE & 0.1 M PBS pH 7.0 & -0.74 & $0.05 \sim 10$ & 0.02 & {$[92]$} \\
\hline Brucine & MWNT/GCE & $\mathrm{H}_{2} \mathrm{SO}_{4} \mathrm{pH} 1.0$ & 0.405 & $1.0 \sim 100$ & 0.2 & [224] \\
\hline Amitrole & CNTPE & 0.05 M PBS pH 7.4 & 0.9 & $0.8 \sim 7.0$ & 0.57 & {$[162]$} \\
\hline Simvastatin & MWNT-DHP/GCE & $0.1 \mathrm{M} \mathrm{H}_{2} \mathrm{SO}_{4}$ & 1.06 & $0.1 \sim 7.5$ & 0.05 & {$[93]$} \\
\hline Morphine & MWNT/GCE & $0.1 \mathrm{M}$ PBS pH 7.0 & 0.5 & $0.5 \sim 150$ & 0.2 & [184] \\
\hline Prochlorperazine & MWNT/DDT/Au & 0.05 M PBS pH 5.8 & 0.69 & $0.5 \sim 15$ & 0.1 & [225] \\
\hline Melatonin & MWNT-DHP/GCE & $0.1 \mathrm{M}$ PBS pH 7.5 & 0.61 & $0.08 \sim 10$ & 0.02 & [226] \\
\hline Diclofenac sodium & MWNT-DHP/GCE & $\begin{array}{l}0.1 \mathrm{M} \text { HAc-NaAc } \\
\text { pH } 5.0\end{array}$ & 0.69 & $0.17 \sim 75$ & 0.08 & [227] \\
\hline Ofloxacin & MWNT-CR/GCE & $0.1 \mathrm{M}$ PBS pH 6.0 & 0.9 & $0.05 \sim 30$ & 0.009 & [140] \\
\hline Acetylspiramycin & SWNT-DHP/GCE & $0.1 \mathrm{M}$ PBS pH 5.5 & 0.89 & $6.7 \sim 133$ & 1.3 & [228] \\
\hline Lincomycin & MWNT-DHP/GCE & $0.1 \mathrm{M}$ PBS pH 7.0 & 0.85 & $0.45 \sim 150$ & 0.2 & [229] \\
\hline
\end{tabular}

the electrode, likely via the aligned ferrocenyl groups, and illustrate the potentialities of such redox-active CNTs for the elaboration of mediated biosensors. The coimmobilization of GOx on iron-phthalocyanine ( $\mathrm{FePc}$ ) functionalized wellaligned MWNTs by the electropolymerization of nonconducting polymers was performed by Ye et al. to prepare a glucose biosensor [198]. FePc on CNTs was used to electrocatalyze the oxidation of $\mathrm{H}_{2} \mathrm{O}_{2}$ that was liberated by the enzymatic reaction of glucose. Wang et al. recently proposed a one-step method for the construction of glucose biosensors by applying a fixed potential (usually $0.7 \mathrm{~V}$ ) onto a GCE that was placed beforehand in an aqueous solution containing CNTs, GOx and pyrrole monomer [189]. They found that the CNT dopant retained their electrocatalytic activity toward hydrogen peroxide to impart high sensitivity upon entrapment within the PPy network. The simultaneous incorporation of CNTs and GOx thus endowed amperometric transducers with biocatalytic and electrocatalytic properties and represented a simple and effective route for preparing enzyme electrodes. A similar method was used by Pan et al. to fabricate glucose biosensors except that additional supporting electrolytes were added to the electropolymerization solution [187].

\section{(b) Blending}

(i) Composite Films. Blending of enzymes and some polymeric materials that are capable of forming uniform and stable films on electrode surfaces provides a convenient noncovalent approach for the immobilization of enzymes while maintaining the native properties and reactivities of enzymes. This makes the composite blending technique a potential tool for the development of new electrochemical biosensors. Leaching of the entrapped enzymes does not occur or occurs very slowly because these species usually have large bodies and possible interactions (e.g., electrostatic and hydrophobic interactions) between enzymes and the film matrices might exist. Several types of film matrices have been employed for constructing glucose electrochemical biosensors, including sol-gels, Nafion, and CHIT. However, 
due to their poor conductivity and film compactness, the performance of the biosensors fabricated from these species and enzymes were usually poor. This deficiency can be completely overcome by the incorporation of CNTs, which leads to the improvement of the conductivity and the diffusion process of the composite films.

On the basis of the stable dispersion of CNTs in Nafion solutions, Wang et al. firstly studied the electrochemical behavior of $\mathrm{H}_{2} \mathrm{O}_{2}$ at CNT-based electrodes [63]. In contrast to the absence of redox activity at a bare GCE over a wide potential range $(-0.4 \sim 1.0 \mathrm{~V})$, the CNT-coated electrode was found to exhibit significant oxidation and reduction currents of $\mathrm{H}_{2} \mathrm{O}_{2}$ with a rather low starting potential (around $+0.20 \mathrm{~V}$ ), providing a highly selective low-potential biosensing of glucose when GOx was immobilized in the CNTNafion composite. The excellent analytical performance of the CNT/Nafion/GOx electrode was further demonstrated by Tsai et al. [71]. They found that under optimal conditions, the glucose biosensor displayed a sensitivity of $330 \mathrm{nA} / \mathrm{mM}$, a linear range of up to $2 \mathrm{mM}$, a detection limit of $4 \mu \mathrm{M}$, and a response time of $<3$ seconds. Zhu et al. fabricated an amperometric glucose biosensor based on an enzyme electrode modified by CNT/Pt nanoparticles [231]. GOx in gelatin was cross-linked by the use of glutaraldehyde (GDI). Compared with normal $\mathrm{GOx} / \mathrm{Pt}$ electrode, the analytical property of GOx/CNT-Pt/GCE electrode was apparently improved, reflected by the lowered detection limit, overpotential and response time. Salimi et al. developed a glucose biosensor by introducing GOx into a sol-gel composite at the surface of a bppg electrode modified with MWNTs [183]. The CNTmodified electrode was found to offer excellent electrocatalytic activity toward reduction and oxidation of hydrogen peroxide liberated in the enzymatic reaction between GOx and glucose, enabling sensitive determination of glucose. The amperometric detection of glucose carried out at $0.3 \mathrm{~V}$ (versus SCE) in 0.05 M PBS (pH 7.4) showed a good linear response range of $0.2 \sim 20 \mathrm{mM}$ glucose with a low detection limit of $50 \mu \mathrm{M}(\mathrm{S} / \mathrm{N}=3)$. In addition, the response time of the electrode was less than 5 seconds when it was stored dried at $4^{\circ} \mathrm{C}$. The sensor showed almost no change in the analytical performance after operation for 3 weeks. Recently, Joshi et al. described the construction of amperometric biosensors based on the incorporation of SWNT modified with GOx into a redox polymer hydrogel [121]. The composite films were constructed by firstly incubating GOx in a SWNT solution and then cross-linking within a poly[(vinylpridine) $\mathrm{Os}$ (bipyridyl) ${ }_{2} \mathrm{Cl}^{2+/ 3+}$ ] polymer film. Incorporation of $\mathrm{GOx}$ modified SWNTs into the redox polymer films resulted in a 2-10-fold increase in the oxidation and reduction peak currents during cyclic voltammetry.

(ii) Carbon Pastes. As a typical method, carbon pastes have been extensively used to prepare enzyme-based electrochemical biosensor because this method has some unique advantages, such as easy fabrication, low cost, wide potential window, high signal-to-noise ratio and retaining of enzyme activity. Recently, Rubianes et al. studied the electrochemical response of $\mathrm{H}_{2} \mathrm{O}_{2}$ at a CNTPE by the hydrodynamic voltammetric method. Similar to that at the MWNTNafion/GCE [63], the signals of $\mathrm{H}_{2} \mathrm{O}_{2}$ were significantly improved at CNTPE in comparison with common carbon paste electrodes. And, decreases of $300 \mathrm{mV}$ in the oxidation overpotential and $400 \mathrm{mV}$ in the reduction overpotential were obtained for hydrogen peroxide, allowing the development of a highly selective and sensitive glucose biosensor without using any metal, redox mediator, or anti-interference membrane. Ricci et al. also prepared a Prussian blue (PB) modified CNTPE, which showed a high sensitivity toward hydrogen peroxide with a detection limit of $7.4 \times 10^{-6} \mathrm{M}$. Further, they fabricated a glucose biosensor by incorporating GOx into the paste, creating a sensitive tool for the detection of glucose in the range between 0.1 and $50 \mathrm{mM}$.

(c) Covalent Bonding. Although the noncovalent methods for fabricating CNT-based electrochemical biosensors have some advantages like easy fabrication and low cost, the poor stability and leaching of enzymes sometimes significantly influence the analytical performance of these biosensors. To overcome this limitation, great efforts have been made to covalently attach enzymes to the electrode surfaces via various methods and reagents. Xue et al. described a simple method for fabricating glucose biosensors by covalently attaching GOx onto a SWNT modified Pt electrode [232, 233]. The Pt/SWNT electrode was firstly activated with EDC in PBS with $\mathrm{pH} 5.5$ for 1 hour, and then immersed in the PBS containing $5 \mathrm{mg} / \mathrm{mL}$ GOx at $4^{\circ} \mathrm{C}$ for 12 hours. The resulting enzyme electrode was washed thoroughly with PBS and stored at $-10^{\circ} \mathrm{C}$. This biosensor showed a stable amperometric response at a low applied potential $(0.4 \mathrm{~V}$ versus SCE), a wide response range of $\mathrm{pH}$ (5.5-8.0) and good stability (kept 90\% activity after 4 months) [233]. As mentioned above, Gooding et al. also covalently immobilized MP-11 on the open end of a SWNT array that was fabricated by self-assembling methods with the aid of EDC [150]. Hrapovic et al. [73] recently developed a highly sensitive hydrogen peroxide sensor by the incorporation of CNTs and Pt nanoparticles into the Nafion films on a GCE, which exhibited a linear range from $25 \mathrm{nM}$ to $10 \mu \mathrm{M}\left(R^{2}=0.997\right.$, sensitivity of $3.57 \mathrm{~A} \mathrm{M}^{-1} \mathrm{~cm}^{-2}$ ), and also from $100 \mu \mathrm{M}$ to $2 \mathrm{mM}\left(R^{2}=0.996\right.$, sensitivity of $\left.1.85 \mathrm{~A} \mathrm{M}^{-1} \mathrm{~cm}^{-2}\right)$, with a rather low detection limit of $25 \mathrm{nM}(\mathrm{S} / \mathrm{N}=3)$ (Figure 12). They further prepared a glucose biosensor by cross-linking the GOx films that were dropped and dried on the CNT/Ptmodified GC electrode with $2.5 \%$ glutaraldehyde (GDI). This nanocomposite biosensor exhibited a rapid response ( 3 seconds), a low detection limit $(0.5 \mu \mathrm{M}, \mathrm{S} / \mathrm{N}=3)$ and a wide linear range from $0.5 \mu \mathrm{M}$ up to $5 \mathrm{mM}$ with a sensitivity of $2.11 \mu \mathrm{A} / \mathrm{mM}$. There was also an interesting work performed by Zhang et al. for the covalent immobilization of GOx on CNT composites using RTILs as the CNT dispersing reagent and N-succinimidyl acrylate (NSA) as both the surface modifier of CNTs and the functional sites for GOx covalent immobilization [123].

(d) Other Methods. Some other methods have also been proposed by several workers for immobilizing of GOx on 


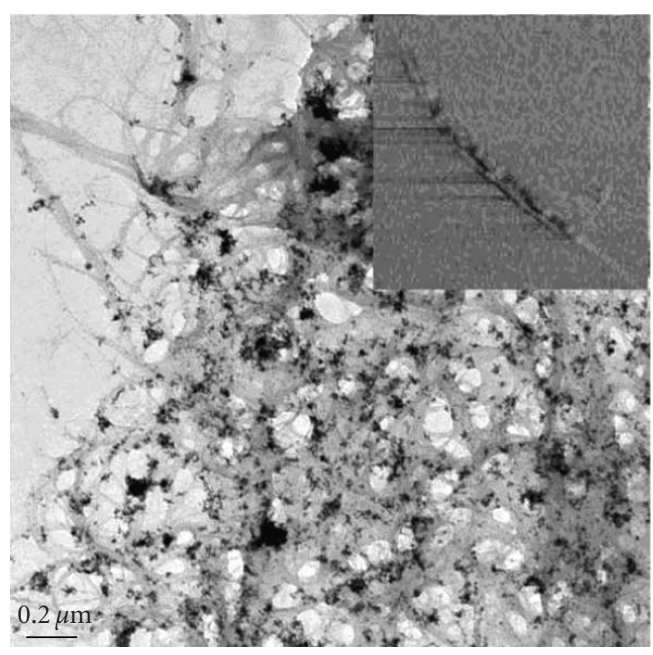

(a)

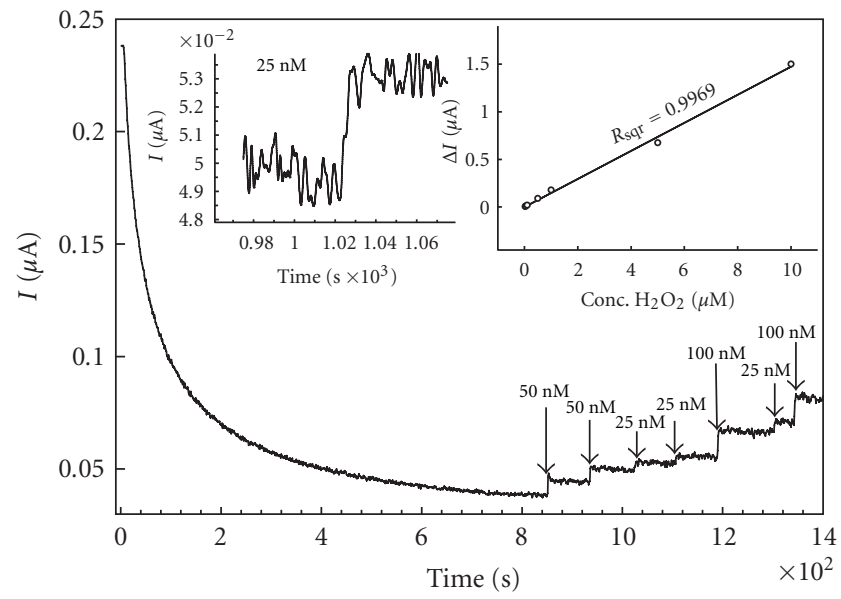

(b)

FIGURE 12: (a) TEM micrograph of SWNTs in the presence of Pt nanoparticles. Inset: AFM tapping-mode phase image (size, $1 \mu \mathrm{m} \times 1 \mu \mathrm{m}$; data scale, $20 \mathrm{~nm}$ ) of one SWNTs in the presence of Pt nanoparticles. (b) Performance of GC/CNT $+\mathrm{Pt}_{\text {nano }}$ electrode in amperometric detection of low concentrations of hydrogen peroxide at $+0.55 \mathrm{~V}$ versus $\mathrm{Ag} \mid \mathrm{AgCl}(3 \mathrm{M} \mathrm{NaCl})$. The inset (left) shows detection limit of 25 $\mathrm{nM}$ with $\mathrm{S} / \mathrm{N}=3$. Inset (right) shows calibration curve for $\mathrm{H}_{2} \mathrm{O}_{2}$ concentrations between $25 \mathrm{nM}$ and $10 \mu \mathrm{M}$. [Adapted with permission from Hrapovic et al. [73], Anal. Chem., 76, 1083 (2004). Copyright 2004, American Chemical Society.]

CNT-based electrodes to prepare glucose electrochemical biosensors, such as physical adsorption and coelectrodeposition. Wang et al. developed a novel biosensor, comprising of electrode of gold/MWNT-GOx (Au/MWNT-GOx) [199]. MWNTs were grown on n-type silicon substrates using an ASTeX microwave plasma system. After growth of MWNTs on silicon substrate, a thin gold film was E-beam evaporated on the top surface of MWNTs. Then, the silicon substrate was etched away using a mixture acid solution of $\mathrm{HCl}$ and $\mathrm{HNO}_{3}$. Finally, the electrode modified with MWNTs $(\mathrm{Au} / \mathrm{MWNTs})$ was put into the $0.1 \mathrm{M}$ PBS containing GOx, and the GOx was immobilized by MWNTs. The biosensor showed a linear response to glucose concentration within the range from 0.05 to $13 \mathrm{mM}$ with a low detection limit of less than $0.01 \mathrm{mM}$ for glucose, suggesting MWNTs enhanced efficiency of electron transfer between GOx and electrode greatly, resulting in high sensitivity in detecting glucose. Loh et al. prepared a glucose biosensor by the physical adsorption of GOx on the poly $\left(3,3^{\prime}\right.$-diaminobenzidine) (PDAB) filmmodified electrode [197]. They firstly grew MWNTs (10-mm thick, erected) in a quartz furnace using ethylenediamine on 1-mm diameter tantalum substrates seeded with cobalt nanoparticles, which was further functionalized with DAB by the electropolymerization of $\mathrm{DAB}$ using a $\mathrm{CV}$ method and a self-limiting, very thin layer of polymer with $\mathrm{NH}_{2}$ functional groups can be introduced onto the CNTs surface in one easy step. For immobilizing the GOx on the DAB-modified electrode surface, a second round of $\mathrm{CV}$ was then performed with GOx in the buffer solution to attach the GOx on the DAB-modified CNTs. They believed that the immobilization of GOx probably proceeded via entrapment within the highly porous wiring matrix of CNTs. This glucose biosensor had some overwhelming advantages, such as the low detection potential due to the lowered overpotential of $\mathrm{H}_{2} \mathrm{O}_{2}$ at the CNT electrode and the absence of the concomitant oxidation of interferent molecules like AA and UA. Tang et al. fabricated a new amperometric biosensor, based on adsorption of GOx at the Pt nanoparticle-modified CNT electrode [200]. The CNT/graphite electrode $(0.4 \times 0.4 \mathrm{~cm}$, geometry area $0.16 \mathrm{~cm}^{2}$ ) was prepared by the CVD method and used as the working electrode. Using a standard threeelectrode cell, Pt nanoparticles were electrodeposited on the CNT electrode by the potential step deposition method from $\mathrm{N}_{2}$-saturated $7.7 \mathrm{mM} \mathrm{H}_{2} \mathrm{PtCl}_{6}$ plus $0.5 \mathrm{M} \mathrm{HCl}$ aqueous solution. GOx immobilization was achieved by incubation for 12 hours in a GOx solution $(500 \mathrm{U} / \mathrm{mL})$ at less than $4^{\circ} \mathrm{C}$. The obtained GOx/Pt/CNT electrode was washed carefully with double-distilled water and dried at less than $4^{\circ} \mathrm{C}$, and then $0.5 \mathrm{wt} \%$ Nafion solution was cast on the surface of the resulting GOx/Pt/CNT electrode to avoid the loss of GOx in determination and to improve the anti-interferent ability. The excellent electrocatalytic activity and special three-dimensional structure of the enzyme electrode resulted in good characteristics such as a large determination range $(0.1 \sim 13.5 \mathrm{mM})$, a short response time (within 5 seconds), a large current density $\left(1.176 \mathrm{~mA} / \mathrm{cm}^{2}\right)$, and high sensitivity $\left(91 \mathrm{~mA} \mathrm{M}^{-1} \mathrm{~cm}^{-2}\right.$ ) and stability (73.5\% remains after 22 days). Lim et al. employed an electrodeposition method for the codeposition of GOx and palladium nanoparticles onto a Nafion-solubilized CNTs film [58]. The codeposited Pd-GOx-Nafion CNTs bioelectrode retained its biocatalytic activity and offered an efficient oxidation and reduction of the enzymatically liberated $\mathrm{H}_{2} \mathrm{O}_{2}$, allowing for fast and sensitive glucose quantification. The combination of Pd-GOx electrodeposition with Nafion-solubilized CNTs enhanced the storage time and performance of the sensor. An extra Nafion coating was used to eliminate common interferents such as UA and AA. The fabricated Pd-GOx-Nafion CNTs 
glucose biosensor exhibited a linear response up to $12 \mathrm{mM}$ glucose and a detection limit of $0.15 \mathrm{mM}(\mathrm{S} / \mathrm{N}=3)$.

\section{(2) Other Enzymes}

(a) Cholesterol Oxidase. The determination of cholesterol is of great significance in clinical diagnosis of coronary heart disease, arteriosclerosis, myocardial infarction and brain thrombosis. Among the various biosensors of cholesterol, cholesterol oxidase (ChOx)-based electrochemical biosensors are especially attractive because they offer a simple, rapid and inexpensive means of quantifying cholesterol. Similar to glucose electrochemical biosensors, most of the amperometric cholesterol biosensors are based on the $\mathrm{ChOx}$ enzyme, which catalyzes the oxidation of cholesterol to 4cholesten-3-one:

$$
\text { Cholesterol }+\mathrm{O}_{2} \stackrel{\text { ChOx }}{\longrightarrow} \text { 4-Cholesten-3-one }+\mathrm{H}_{2} \mathrm{O}_{2} \text {. }
$$

The quantification of cholesterol can be achieved via electrochemical detection of the enzymatically liberated $\mathrm{H}_{2} \mathrm{O}_{2}$. Guo el al. proposed a CNT-based amperometric cholesterol biosensor through the LBL deposition of PDDA and ChOx on an MWNT-modified gold electrode, followed by electrochemical generation of a nonconducting PPD film as the protective coating [145]. Due to the strong electrocatalytic properties of MWNTs toward $\mathrm{H}_{2} \mathrm{O}_{2}$ and the low permeability of PPD film for electroactive species, such as AA, UA and acetaminophen, this biosensor exhibited high sensitivity and good anti-interferent ability in the detection of cholesterol with a linear range up to $6.0 \mathrm{mM}$ and a detection limit of $0.2 \mathrm{mM}$. Tan et al. developed an amperometric cholesterol biosensor based on sol-gel CHIT/silica and MWNT organic-inorganic hybrid composite material [119]. They firstly prepared a Prussian blue-modified GCE (PB/GCE) by electrodeposition, followed by the casting of the aqueous mixture of MWNTs, sol-gel silica, CHIT and ChOx on the surface of $\mathrm{PB} / \mathrm{GCE}$. The analytical characteristics and dynamic parameters of the biosensors with and without MWNTs in the hybrid film were compared. The results showed that the analytical performance of the biosensor can be improved greatly after introduction of MWNTs. Shi et al. recently fabricated a novel $\mathrm{H}_{2} \mathrm{O}_{2}$ sensor by intercalating Pt nanoparticle decorated CNTs (CNT-Pt) prepared using a chemical reduction method on the surface of a waxed graphite electrode [181]. The Pt nanoparticles at the waxed graphite electrode exhibited high catalytic activity for the reduction of hydrogen peroxide. Based on this, ChOx was immobilized with sol-gel on the CNT-Pt based electrode to construct a cholesterol biosensor, which was found to have excellent analytical performance for cholesterol detection with a rapid response ( $<20$ seconds), a wide linear range of $4.0 \times 10^{-6}-1.0 \times 10^{-4} \mathrm{M}$, and a low detection limit of $1.4 \times$ $10^{-6} \mathrm{M}$.

(b) Dehydrogenases. Similar to the oxidases, some dehydrogenases are also employed to construct various electrochemical biosensors, including alcohol-dehydrogenase (ADH),
D-fructose dehydrogenase (FDH) and glucose dehydrogenase $(\mathrm{GDH})$. Generally, the response of dehydrogenasebased electrochemical biosenors is a current due to the electrooxidation of NADH that is produced in the enzymatic reaction

$$
\text { Substrate }+\mathrm{NAD}^{+} \stackrel{\text { Dehydrogenase }}{\longrightarrow} \text { Product }+\mathrm{NADH} \text {. }
$$

In this process, $\mathrm{NAD}^{+}$behaves as an enzymatic mediator. This section will firstly focus on the development of CNT-based NADH electrochemical sensors and then on the construction of dehydrogenases-based electrochemical biosensors.

(i) Carbon Nanotube-Based NADH Electrochemical Sensors. The direct electrochemical oxidation of $\mathrm{NADH}$ is becoming more and more interesting since many dehydrogenases need it as cofactors to catalyze redox reaction. However, the direct electrochemical oxidation of NADH at a bare electrode takes place at high overpotentials, for example, the reported overpotential at $\mathrm{pH} 7.0$ is about $1.1 \mathrm{~V}$ at carbon electrodes and $1.3 \mathrm{~V}$ at Pt electrodes. Many efforts have been made to reduce the overpotential of NADH electrooxidation. Musameh et al. [234] firstly reported the electrocatalytic oxidation of NADH at a GC electrode modified with disordered CNT coatings with a decrease of $490 \mathrm{mV}$ in overpotential. Since then, many works dealt with the electrocatalytic oxidation of NADH at various CNT-based electrodes. Chen et al. studied the electrochemical behavior of NADH at an OCNT/GC electrode [192, 235]. They found that the direct electrocatalytic oxidation of $\mathrm{NADH}$ occurred at a much lower potential (at about $0.0 \mathrm{~V}$ ) with high stability at an OCNT/GC electrode than at disordered CNT-modified electrode. A reduction of the overpotential of more than $600 \mathrm{mV}$ was achieved, and the anodic peak currents increased linearly with NADH concentration from $2 \times 10^{-5}$ to $1 \times$ $10^{-3} \mathrm{M}$ with a low detection limit of about $5 \times 10^{-7} \mathrm{M}$. Recently, Zhang et al. [236] developed a CHIT-CNT system by integrating the redox mediator Toluidine Blue $\mathrm{O}$ (TBO) and CNTs in CHIT for the determination of NADH. In that work, they firstly covalently attached TBO to CHIT via a twostep procedure and then solubilized CNTs in the aqueous solution of CHIT-TBO. The resulting mixture was cast on the surface of a GCE to form thin CHIT-TBO/CNT surface films. As compared to CHIT-TBO, the CHIT-TBO/CNT films displayed large amplification of a current due to the TBOmediated oxidation of NADH at $-0.10 \mathrm{~V}$. This was discussed in terms of the TBO/CNT synergy that resulted in the improved charge propagation through the CHIT-TBO/CNT matrix. The electrocatalytic oxidation of NADH was also achieved by Liu et al. at PANI/PABS-SWNT multilayer films [148].

(ii) Dehydrogenase-Based Electrochemical Biosensors. Based on the electrocatalytic oxidation of NADH at CNT electrodes, several dehydrogenase-based electrochemical biosensors have been constructed. Wang et al. reported a MWNTbased alcohol biosensor, based on the incorporation of alcohol-dehydrogenase $/ \mathrm{NAD}^{+}$within a three-dimensional 


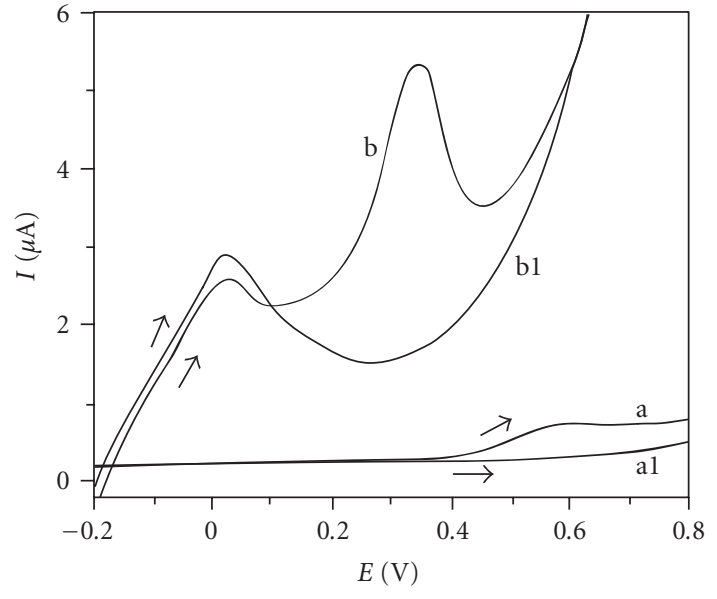

(A)

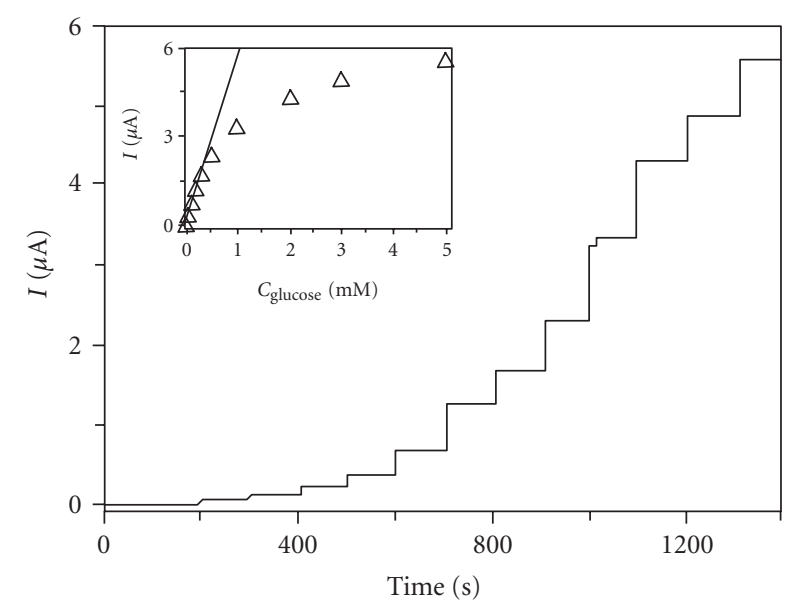

(B)

FIgURE 13: (A) Linear scan voltammograms recorded at (a) GC/CHIT and (b) GC/CNT-CHIT film electrodes in 0.10 mM NADH solution. Traces a 1 and b1 were recorded in a background electrolyte solution. For the clarity of presentation, traces b and b1 were shifted downward by $6 \mu \mathrm{A}$ along the $y$-axis. Scan rate, $50 \mathrm{mV} / \mathrm{s}$. (B) Amperometric response of the GC/CNT-CHIT-GDI-GDH film electrode to additions of glucose aliquots $(10 \mu \mathrm{M}-5.0 \mathrm{mM})$ into a stirred solution of $\mathrm{pH} 7.40$ phosphate buffer that contained $0.10 \mathrm{mM} \mathrm{NAD}^{+}$. Insets: corresponding calibration plots. Potential, 0.400 V. [Adapted with permission from Zhang et al. [103], Anal. Chem., 76, 5045 (2004). Copyright 2004, American Chemical Society.]

MWNT/Teflon matrix [237]. The MWNT component offered a marked decrease in the overpotential for the oxidation of liberated NADH along with minimal surface fouling effects, hence allowing convenient low-potential stable detection of ethanol. Antiochia et al. developed a new mediated CNTP amperometric biosensor of fructose [238]. The biosensor was formed by a CNTP electrode modified with an electropolymerized film of 3,4-dihydroxy benzaldehyde $(3,4-\mathrm{DHB})$, based on the activity of a commercial available D-fructose dehydrogenase $(\mathrm{FDH})$ immobilized on an immobilon membrane placed on the top of the electrode surface. The biosensor response current was directly proportional to $\mathrm{D}$-fructose concentration from $5 \times 10^{-6}$ to $2 \times 10^{-3} \mathrm{M}$ with a detection limit of $1 \times 10^{-6} \mathrm{M}$. On the basis of the electrocatalytic oxidation of NADH at a CNT-CHIT composite film-modified GCE, Zhang et al. recently proposed a simple but useful approach for the fabrication of glucose biosensors by the incorporation of glucose dehydrogenase (GDH) into the CNT-CHIT films through the tethering of GDH to CHIT with GDI [103] (Figure 13). The stability and sensitivity of the GC/CNTCHIT-GDI-GDH biosensor allowed for the interferencefree determination of glucose in the physiological matrix (urine). In $\mathrm{pH} 7.4 \mathrm{PBS}$, linear least-square calibration plots over the range $5 \sim 300 \mu \mathrm{M}$ glucose (10 points) had slopes $80 \mathrm{~mA} \mathrm{M}^{-1} \mathrm{~cm}^{-2}$ and a correlation coefficient 0.996 . The detection limit was $3 \mu \mathrm{M}$ glucose $(\mathrm{S} / \mathrm{N}=3)$. Another advantage of such electrode system was that oxygen did not influence its analytical performance. This was in contrast to oxidase-based electrodes that were prone to interferences from changing levels of oxygen in the samples. Rubianes et al. also studied the performance of enzymatic biosensors based on the immobilization of different dehydrogenase within a CNTPE prepared from MWNTs and mineral oil
[167]. The strong electrocatalytic activity of CNTs toward the oxidation of $\mathrm{NADH}$ allowed an effective low-potential amperometric determination of ethanol, in connection with the incorporation of alcohol dehydrogenase $/ \mathrm{NAD}^{+}$within the composite matrix. Compared to the analogous enzymatic CPEs, a great enhancement in the response was observed at the enzymatic CNTPEs.

(c) Other Enzymes. There were also some other enzymes used by several workers to prepare electrochemical biosensors, such as acetylcholinesterase, alkaline phosphatase, organophosphorus hydrolase, urease and tyrosinase. Based on the reversible Nernstian response of a SWNT modified electrode to analytes associated with solution $\mathrm{pH}$ change, $\mathrm{Xu}$ et al. constructed voltammetric urease and acetylcholinesterase biosensors by immobilizing the enzymes with a sol-gel hybrid material that was cast on the surface of the SWNT modified electrode [31]. These biosensors were used for the determination of urea and acetylthiocholine according the potential shift of the anodic peak of SWNTs. Moreover, the methods for preparing sensors and biosensors were simple and reproducible, and the range of analytes could be extended to substrates of other hydrolyases and esterases. Lenihan et al. proposed a new approach to the modification of CNTs with biomolecules for the development of nanoscale biosensors [239]. Alkaline phosphatase was immobilized on the surface of MWNTs utilizing an LBL methodology. CNTs were incubated with streptavidin, resulting in the formation of a protein layer on the surface of the nanotubes. Biotinylated alkaline phosphatase was then allowed to bind to streptavidin, anchoring the sensing protein onto the surface. Electrochemical biosensors were constructed by using carbon nanotubes compacted into 
pellets. Electrodes constructed in this manner were observed to generate an electrochemical signal that was a function of substrate concentration. Trojanowicz et al. prepared pesticide paraoxon biosenors by the physical adsorption of organophosphorus hydrolase on the surface of MWNT modified working graphite ink electrode of the threeelectrode screen-printed sensing stripe [240]. Joshi et al. reported the fabrication of a disposable biosensor based on acetylcholinesterase-CNT-modified thick film strip electrode for organophosphorus (OP) insecticides [41]. The degree of inhibition of the enzyme acteylcholinesterase (AChE) by OP compounds was determined by measuring the electrooxidation current of the thiocholine generated by the AChE catalyzed hydrolysis of acteylthiocholine (ATCh). The large surface area and electro-catalytic activity of CNTs lowered the overpotential for thiocholine oxidation to $200 \mathrm{mV}$ (versus $\mathrm{Ag} \mid \mathrm{AgCl}$ ) without the use of mediating redox species and enzyme immobilization by physical adsorption. The biosensor detected as low as $0.5 \mathrm{nM}(0.145 \mathrm{ppb})$ of the model organophosphate nerve agent paraoxon with good precision, reproducibility and stability. HRP was also employed by several workers to prepare hydrogen peroxide biosensors. $\mathrm{Xu}$ et al. used MWNTs as a coimmobilization matrix for the incorporation of HRP and electron transfer mediator MB onto a GCE surface [241]. Cyclic voltammetry and amperometric measurements demonstrated the feasibility of $\mathrm{MB}$ as an electron carrier between the immobilized peroxidase and the surface of GCE. The amperometric response of this resulting biosensor to $\mathrm{H}_{2} \mathrm{O}_{2}$ showed a linear relation in the range from $4 \mu \mathrm{M}$ to $2 \mathrm{mM}$ with a detection limit of $1 \mu \mathrm{M}(\mathrm{S} / \mathrm{N}=3)$. Yamamoto et al. reported a hydrogen peroxide biosensor based on the immobilization of HRP on the surface of a MWNT modified electrode via the crosslinking of HRP and BSA composite film by GDI [29]. The MWNT-HRP modified electrode showed excellent response of reduction current for the determination of $\mathrm{H}_{2} \mathrm{O}_{2}$ at the potential of $-300 \mathrm{mV}$ (versus $\mathrm{Ag} \mid \mathrm{AgCl}$ ) with a linear concentration range of $3.0 \times 10^{-7} \sim 2.0 \times 10^{-4} \mathrm{M}$ and a low detection limit of $1.0 \times 10^{-7} \mathrm{M}(\mathrm{S} / \mathrm{N}=3)$.

\subsubsection{Carbon Nanotube-Promoted Direct Electron Transfer of} Redox Proteins and Enzymes. The direct electron transfer of redox proteins and enzymes at electrode surface has attracted more and more attention recently. These works are of great importance for studying the biological redox process, which can help us to understand the energy transform and the material metaboly in life action. But unfortunately, it is difficult for these macrobiomolecules to achieve direct exchange electron at electrode surfaces because they usually have big and complex structures with the redox centers deeply immersing in the bodies. Furthermore, the adsorption of these species at the electrode surface often results in the change of their native configuration and the consequent denature. Earlier, mediators were employed by some groups to improve the electron contact between enzymes and electrodes. However, using mediators generally makes the biosensors complicated and leads to a slow response. The development of mediatorless biosensors, thus, becomes the goal of extensive researches. The first work regarding the direct electron transfer of proteins at CNT electrodes was reported by Davis et al. in 1997 by the physical adsorption of horse heart cytochrome c (Cyt c) on CNTs [159]. Since then, many works focused on the achievement of the direct electron transfer of various redox proteins and enzymes at CNT electrodes, including hemoglobin $(\mathrm{Hb})[46,56,77$, 242], myoglobin (Mb) [50, 52, 243, 244], Cyt c [43, 53, 154, 245-247], peroxidases (e.g., HRP [122, 176, 248, 249], catalase (Ct) $[34,250]$ and MP-11 $[122,150,251])$, oxidases (e.g., GOx [78, 152, 252-255], putrescine oxidase (POx) $[256,257]$, xanthine oxidase (XOs) $[258,259])$, and so on.

\section{(1) Direct Electron Transfer of Redox Proteins and Enzymes at Carbon Nanotube Electrodes}

\section{(a) Heme proteins}

(i) Myoglobin. Myoglobin (Mb) is a small size heme protein with a molar mass of approximately 17500 , and it functions in both transport and short-term storage of oxygen. Due to its commercial availability and a well-known structure, $\mathrm{Mb}$ is considered to be an ideal model protein for the study of heme proteins or enzymes. Thus, the achievement of the direct electron transfer (DET) of $\mathrm{Mb}$ not only provides a convenient approach for fabricating Mb-based biosensors but also creates nice model systems for studying the biological functions of these proteins. Similar to other nanoscale materials, the good conductivity, the nanosized tubular structural and the functional groups make CNTs act as molecular wires to allow the electrical communication between the underlying electrodes and Mb. Recently Zhao's group developed a simple but effective method for the immobilization and the direct electron transfer of $\mathrm{Mb}$ at CNT-based electrodes $[50,52,253,254]$. In a typical procedure, $\mathrm{Mb}$ was immobilized on the surface of a MWNT modified electrode by immersing the CNT electrode in an acetate buffer solution of $\mathrm{Mb}$ for a long period (e.g., 72 hours), followed by thoroughly washing with doubledistilled water to remove loosely bonded enzyme molecules. The resultant electrode exhibited a pair of well-defined redox peaks with cathodic and anodic peak potentials at 0.298 and $0.198 \mathrm{~V}$ (versus SCE), respectively. The shapes of the cathodic and anodic peak were nearly symmetric, and the reduction and oxidation peaks have the same heights, indicating a reversible process of $\mathrm{Mb}$ at this electrode. This biosensor was further used for the sensitive detection of nitric oxide (NO) [50, 254], $\mathrm{O}_{2}$ [253], and $\mathrm{H}_{2} \mathrm{O}_{2}$ [52] (Figure 14).

(ii) Hemoglobin. Hemoglobin (Hb), functioning physiologically in the storage and transport of molecular oxygen in the blood of vertebrates, has a molecular weight of 64.000 to 67.000 , and comprises four polypeptide subunits (two $\alpha$ and two $\beta$ subunits), each of which has an iron-bearing heme within molecularly accessible crevices and has a similar structure. Although $\mathrm{Hb}$ does not play a role as an electron carrier in biological systems, it has been shown to possess enzyme-like catalytic activity. Similar to Mb, it is also an ideal 


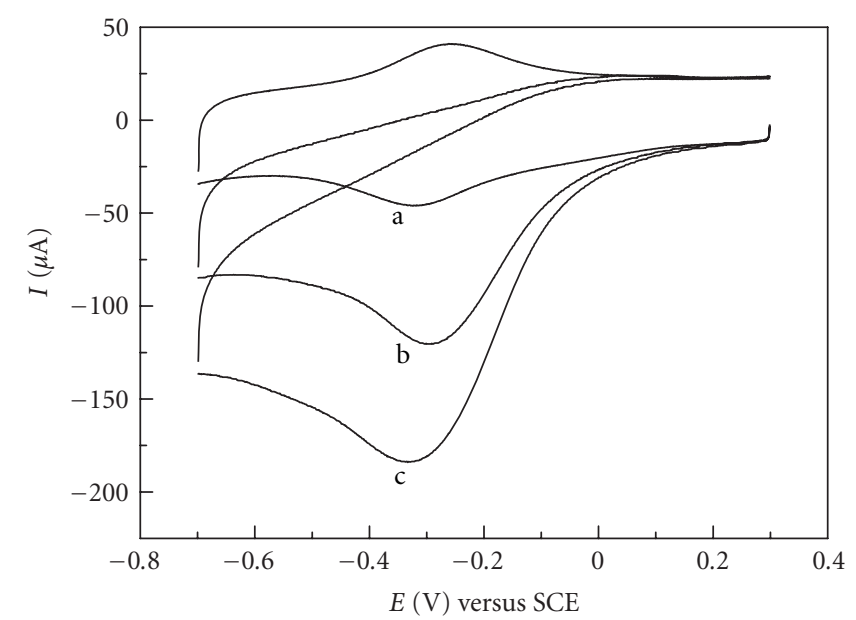

(A)

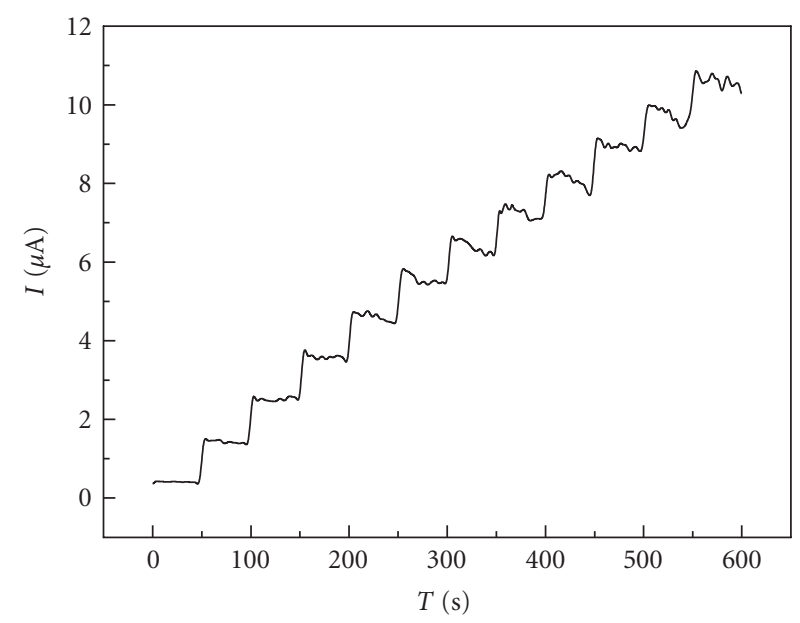

(B)

Figure 14: (A) CV of Mb/MWNT/GCE in the presence of $\mathrm{H}_{2} \mathrm{O}_{2}$ : (a) $0 \mathrm{mM}$, (b) $0.4 \mathrm{mM}$, and (c) $0.8 \mathrm{mM}$; scan rate: $200 \mathrm{mV} / \mathrm{s}$. (B) Amperometric response of $\mathrm{H}_{2} \mathrm{O}_{2}$ at Mb/MWNT/GCE in $0.1 \mathrm{M} \mathrm{PBS}$ ( $\mathrm{pH} 4.0$ ); each addition was $30 \mu$ mol/L $\mathrm{H}_{2} \mathrm{O}_{2}$; operation potential -0.14 V. [Adapted with permission from Zhao et al. [52], Anal. Biochem., 329, 160 (2004). Copyright 2004, Elsevier Science.]

model molecule for the study of direct electron transfer reactions of heme enzymes because of its commercial availability and a known and documented structure. The direct electron transfer of $\mathrm{Hb}$ at $\mathrm{CNT}$ electrodes has been achieved by Cai et al. through different immobilization methods $[46,77]$. Based on the facilitated dispersing of CNTs in water by CTAB, Cai et al. fabricated a CNT-based Hb electrochemical biosensor by firstly casting the mixture of CNT aqueous suspension and $\mathrm{Hb}$ phosphate buffer solution and fixing the resultant composite film with a Nafion coating [77]. Cyclic voltammetric results showed a pair of well-defined redox peaks, correspondeding to the direct electron transfer of $\mathrm{Hb}$, with a formal potential $\left(E^{\circ \prime}\right)$ at about $0.343 \mathrm{~V}$ (versus SCE) in the PBS ( $\mathrm{pH}$ 6.8). Further experiments demonstrated that the immobilized $\mathrm{Hb}$ retained its bioelectrocatalytic activity for the reduction of $\mathrm{H}_{2} \mathrm{O}_{2}$. The electrocatalytic current was proportional to the concentration of $\mathrm{H}_{2} \mathrm{O}_{2}$ at least up to $20 \mathrm{mM}$. Cai et al. reported an adsorption method for the immobilization of $\mathrm{Hb}$ on a CNT electrode by incubating the electrode into the protein solution $(5 \mathrm{mg} / \mathrm{mL}$ in $0.1 \mathrm{M} \mathrm{PBS}$, $\mathrm{pH}$ 5.5) for 1 hour at $4^{\circ} \mathrm{C}$ [46]. Jia et al. also reported the using of novel bamboo-like nitrogen-doping $\mathrm{CNx}$ nanotubes for the immobilization of $\mathrm{Hb}$ by dipping the CNT electrode into a $0.2 \mathrm{M}$ acetate buffer solution ( $\mathrm{pH}$ 6.0) containing $10 \mathrm{mg} / \mathrm{mL} \mathrm{Hb}$ over 72 hour at $4^{\circ} \mathrm{C}$ [54]. The transmission electron microscopy (TEM) clearly showed that $\mathrm{Hb}$ could be strongly adsorbed on the surface of $\mathrm{CNx}$ nanotubes. The CV results of $\mathrm{Hb} / \mathrm{CNx}$ nanotube modified electrode showed a pair of well-defined and quasireversible redox peaks centered at approximate $0.33 \mathrm{~V}$ (versus SCE) in pH 7.0 PBS.

(iii) Cytochrome c. Cytochrome c (Cyt c) is a basic redox heme protein with $12,384 \mathrm{~g} / \mathrm{mol}$ molecular weight and approximately spherical shaper with $34 \AA$ diameter. It plays an important role in the biological respiratory chain, whose function is to receive electrons from Cyt $\mathrm{c}$ reductase and deliver them to Cyt $\mathrm{c}$ oxidase. As mentioned above, the direct electron transfer of Cyt at CNT electrodes was firstly reported by Davis et al. in 1997 [159]. The electrochemistry of Cyt $c$ was later studied by Wang et al. using cyclic voltammetry at a GCE modified with SWNTs [245]. A pair of well-defined redox waves was obtained in Cyt $\mathrm{c}$ aqueous solution at an activated SWNT film-modified electrode. The electrode reaction of Cyt $\mathrm{c}$ was found to be a diffusioncontrolled process. The peak current increased linearly with the concentration of Cyt $\mathrm{c}$ in the range from $3.0 \times 10^{-5} \sim$ $7.0 \times 10^{-4} \mathrm{M}$ with a detection limit of $1.0 \times 10^{-5} \mathrm{M}$. Chen et al. successfully immobilized MWNTs on the surface of a Pt electrode by mixing with DNA [43]. The experimental data indicated that Cyt c can strongly adsorb on the surface of the modified electrode, and forms an approximate monolayer. The immobilized MWNTs can promote the redox of Cyt c, which gave reversible redox peaks with a formal potential of $81 \mathrm{mV}$ versus SCE. Recently, Qu et al. [154] characterized the SWNTs submonolayer film that was prepared by electrostatically adsorbing nanotubes onto a 2 -aminoethanethiol self-assembled monolayer (SAM) on a gold bead electrode using tapping-mode atomic force microscopy (TM-AFM). The results showed that the orientation of SWNTs on the SAM was horizontal and the surface coverage was quite low. However, this electrode was demonstrated to be capable of facilitating the direct electron transfer of Cyt $\mathrm{c}$ in solution. Zhao et al. also studied the direct electron transfer of Cyt c on a MWNT modified electrode [53]. In contrast to the time-consuming methods by immersing the CNT electrodes in the protein or enzyme solutions for a long period [50, $52,243,244]$, they fabricated the Cyt c modified CNT electrodes by placing a MWNT modified electrode in a Cyt c solution $(0.09 \mathrm{mmol} / \mathrm{L}, \mathrm{pH} 7.0 \mathrm{PBS})$ and then performing a consecutive cyclic potential scans in the potential range from 0.3 to $-0.8 \mathrm{~V}$ with a scan rate $50 \mathrm{mV} / \mathrm{s}$ up to obtain a stable 
CV curve. The results from electrochemical impedance spectroscopy (EIS) and CV suggested that Cyt c could be tightly adsorbed on the surface of MWNTs and MWNTs showed an obvious promotion for the direct electron transfer between Cyt $\mathrm{c}$ and electrode. A couple of well-defined and quasi-reversible $\mathrm{CV}$ peaks of Cyt $\mathrm{c}$ can be observed in a PBS ( $\mathrm{pH} 7.0)$. Cyt $\mathrm{c}$ adsorbed on MWNTs exhibited a remarkable electrocatalytic activity for the reduction of hydrogen peroxide $\left(\mathrm{H}_{2} \mathrm{O}_{2}\right)$.

\section{(b) Peroxidases}

(i) Horseradish Peroxidase. Horseradish peroxidase (HRP), functioning physiologically as the biocatalysis of $\mathrm{H}_{2} \mathrm{O}_{2}$, has been extensively investigated, due to its commercial availability and the well-known structure. HRP has been used as a typical model for studying the structural, kinetic and thermodynamic properties of peroxidases. The first work on the direct electron transfer of HRP was reported by Zhao et al. using CNT-based powder microelectrodes (CNTPME) [176]. The immobilization of HRP was achieved by mixing $1 \mathrm{mg}$ CNT powder with $200 \mathrm{~mL} 0.1 \mathrm{M}$ PBS solution containing $1 \mathrm{mg} / \mathrm{mL}$ HRP and packing the dry mixture into the microcaves of CNTPME. The resultant electrode exhibited a pair of reversible redox peaks -0.7 and $-0.6 \mathrm{~V}$ in $0.1 \mathrm{M}$ PBS ( $\mathrm{pH} 7.0$ ). It was found that the adsorbing HRP kept its catalytic activity to $\mathrm{H}_{2} \mathrm{O}_{2}$ upon the immobilization on the CNT electrode. Cai et al. [248] also developed a HRP biosensor based on the method used for constructing $\mathrm{Mb}$ biosensors [77]. It was found that HRP underwent effective and stable direct electron transfer reaction and retained its catalytic activity toward $\mathrm{H}_{2} \mathrm{O}_{2}$. Based on the stable dispersion of CNTs in RTILs, Zhao et al. prepared a HRP biosensor by firstly dispersing HRP and MWNTs in an RTIL, then grinding the mixture to form a black gel and casting the gel on the electrode surface with spinning [122]. HRP coated by RTIL-modified gold and glassy carbon electrodes allowed efficient electron transfer between the electrode and the protein and also catalyzed the reduction of $\mathrm{O}_{2}$ and $\mathrm{H}_{2} \mathrm{O}_{2}$.

(ii) Catalase. Catalase $(\mathrm{Ct})$ is a redox enzyme, present in almost all aerobic organisms. It catalyses the disproportionation of hydrogen peroxide into oxygen and water without the formation of free radicals, so it serves in part to protect cells from the toxic effects of hydrogen peroxide. Catalase contains four equal subunits, and each of them has a molecular weight of 57.000 daltons and is equipped with a Fe (III)-protoporphyrin-IX. The direct electron transfer of Ct was mainly accomplished through physical adsorption approaches. Wang et al. recently studied the direct electron transfer of $\mathrm{Ct}$ at a gold electrode modified with SWNTs [34]. They found that a pair of well-defined redox peaks was obtained for $\mathrm{Ct}$ with the reduction peak potential at $-0.414 \mathrm{~V}$ and a peak potential separation of $32 \mathrm{mV}$ in $0.05 \mathrm{M}$ PBS ( $\mathrm{pH}$ 5.9). Both reflectance FT-IR spectra and the dependence of the reduction peak current on the scan rate revealed that $\mathrm{Ct}$ adsorbed onto the SWNT surfaces. Compared to other types of carbonaceous electrode materials (e.g., graphite and carbon soot), the electron transfer rate of Ct redox reaction was greatly enhanced at the SWNT-modified electrode. The peak current was found to increase linearly with the Ct concentration in the range of 8 $\times 10^{-6} \sim 8 \times 10^{-5} \mathrm{M}$ used for the electrode preparation. The catalytic activity of $\mathrm{Ct}$ adsorbates at the SWNT appears to be retained, as the addition of $\mathrm{H}_{2} \mathrm{O}_{2}$ produced a characteristic catalytic redox wave. Similar direct electron transfer of $\mathrm{Ct}$ at a SWNT modified GCE was studied by Zhao et al. [250].

(iii) Microperoxidase. Microperoxidase (MP-11) is an oligopeptide consisting of eleven amino acids and a covalently linked FeIII-protoporphyrin IX heme site. The direct electron transfer between MP-11 and electrodes can be used in biosensors and biofuel cells. In biofuel cells, the MP-11 modified electrodes are used as cathode materials to catalyze the reduction of oxygen. The direct electron transfer of MP-11 has recently been studied by Dong et al. in different CNT-based electrode systems $[122,251]$. Based on the immobilization of enzymes in the RTIL-MWNT composite films, Dong et al. also studied the direct electron transfer of MP-11 at this film-modified electrode [122]. In $0.1 \mathrm{M}$ PBS, a pair of well-defined redox waves was obtained, corresponding to the active FeIII/II center of MP-11 at $E_{1 / 2}\left[\left(E_{p a}+E_{p c}\right) / 2\right.$ (versus $\mathrm{Ag} \mid \mathrm{AgCl}$ ) $]=-0.25 \mathrm{~V}$ with a peak separation of $61 \mathrm{mV}$ at a scan rate of $100 \mathrm{mV} / \mathrm{s}$. This result was different from the report by Willner et al. at $E_{1 / 2}=-0.4 \mathrm{~V}$ (versus $\mathrm{SCE}$ ), which was attributed to the fact that the redox active center in MP-11, an iron protoporphyrin IX, was not shielded by a polypeptide and was easily affected by the environments of the ionic liquids compared with other systems. They also studied the direct electron transfer of MP-11 by cyclic voltammetry at a GCE modified with MWNTs. In that work, MP-11 was immobilized by immersing the CNT electrode in $0.1 \mathrm{M}$ PBS containing $1 \mathrm{mg} / \mathrm{mL}$ MP- 11 at $4^{\circ} \mathrm{C}$ for about 10 hours. The resulting electrode showed a pair of well-defined redox peaks with a formal potential at about $-0.26 \mathrm{~V}$ (versus $\mathrm{Ag} \mid \mathrm{AgCl}$ ) in PBS ( $\mathrm{pH} 7.0$ ). The experimental results also demonstrated that the immobilized MP-11 retained its bioelectrocatalytic activity to the reduction of $\mathrm{H}_{2} \mathrm{O}_{2}$ and $\mathrm{O}_{2}$.

\section{(c) Oxidases}

(i) Glucose Oxidase. Glucose oxidase (GOx), from Aspergillus or Penicillium, is a homodimer with a molecular weight of about $150 \sim 180 \mathrm{kDa}$ containing two tightly bound flavine adenine dinucleotide (FAD) cofactors and catalyzes the electron transfer from glucose to oxygen accompanying the production of gluconic acid and hydrogen peroxide. Industrially, it has been used in the production of gluconic acid. The most important application is in biosensors for the quantitative determination of glucose in body fluids, foodstuffs, beverages, and fermentation liquor. As mentioned above, although CNTs have been widely used to 
fabricate the GOx-based glucose electrochemical biosensors due to the excellent electrocatalytic activity of CNTs toward $\mathrm{H}_{2} \mathrm{O}_{2}$, few works accomplished the direct electron transfer between GOx and the underlying electrodes. Xu et al. recently studied the electrochemical behavior of GOx at a MWNT modified electrode by cyclic voltammetry [252]. They found that the MWNT electrode exhibited two pairs of redox peaks with formal potentials of -0.45 and $-0.55 \mathrm{~V}$ (versus SCE) when immersed into $0.1 \mathrm{M}$ PBS containing $2 \mathrm{mg} / \mathrm{mL}$ GOx for 2 hours, which were attributed to the responses from GOx in the solution and adsorbed on the MWNT surface, respectively. In addition, with the increase of scan time, the currents of both redox peaks decreased except that the redox peaks at $-0.45 \mathrm{~V}$ disappeared after about 1 hour, and the redox peaks at $-0.55 \mathrm{~V}$ tended to be a stable value. The reservation of adsorbed GOx at MWNTs foretells the possibility of immobilization of GOx on CNTs by physical adsorption. Wang et al. proposed a simple approach for the immobilization and the direct electron transfer of GOx at CNT electrodes [254]. The GOx modified SWNT (GOx/SWNT) electrode was prepared by just dropping $5 \mu \mathrm{L} 1.0 \times 10^{-4} \mathrm{M}$ GOx solution onto the surface of the electrode surface and allowing to dry under ambient conditions. The resultant GOx/SWNT electrode was rinsed firstly with water and then the working buffer solution prior to any measurements. A pair of well-defined redox peaks was obtained for GOx with the reduction peak potential at $-0.465 \mathrm{~V}$ and a peak potential separation of $23 \mathrm{mV}$ in $0.05 \mathrm{M}$ PBS. The specific enzyme activity of GOx adsorbates at SWNTs was proved to be retained by spectral methods. Based on the facilitated dispersing of CNTs in water by CTAB [77], Cai et al. fabricated a CNT-based GOx biosensor by firstly casting the mixture of CNT aqueous suspension and GOx phosphate buffer solution and fixing the resultant composite film with a Nafion coating [78]. Cyclic voltammetric results showed a pair of well-defined redox peaks, which corresponded to the direct electron transfer of GOx, with a midpoint potential of about $-0.466 \mathrm{~V}$ (versus SCE) in the PBS (pH 6.9). The experimental results also demonstrated that the immobilized GOx retained its bioelectrocatalytic activity for the oxidation of glucose, suggesting that the electrode may find use in biosensors (e.g., it may be used as a bioanode in biofuel cells).

(ii) Putrescine Oxidase and Xanthine Oxidase. Besides GOx, the direct electron transfer of some other oxidases like putrescine oxidase $(\mathrm{POx})$ and xanthine oxidase $(\mathrm{XOx})$ was also investigated. Similar to other oxidases, $\mathrm{POx}$ is a rather big molecule $(>200 \mathrm{kDa})$ with the redox center deeply inlaid in its structure, which reacts with biogenic amines (e.g., putrescine, cadaverine and histamine) with a certain degree of substrate specifically as follows:

$$
\begin{aligned}
& \mathrm{H}_{2} \mathrm{~N}-\left(\mathrm{CH}_{2}\right)_{n}-\mathrm{NH}_{2}+\mathrm{O}_{2}+\mathrm{H}_{2} \mathrm{O} \\
& \quad \stackrel{\text { POx }}{\longrightarrow} \mathrm{H}_{2} \mathrm{~N}-\left(\mathrm{CH}_{2}\right)_{n-1}-\mathrm{CHO}+\mathrm{NH}_{3}+\mathrm{H}_{2} \mathrm{O}_{2} .
\end{aligned}
$$

Although feasible, the electrochemical measurement of $\mathrm{H}_{2} \mathrm{O}_{2}$ at positive potentials usually suffers from the serious interfer- ences from some electroactive micromolecules like UA and AA, even for CNT electrodes. The direct electron transfer of POx at CNT electrodes was mainly accomplished by Luong et al. [256, 257]. In their earlier work, POx was immobilized on the electrode surface by the deposition of a mixture of MWNTs, PDDA, APTES, and POx on the electrode surface and the coating of the resulting electrode by a Nafion film [256]. The use of APTES permits the adsorption of GOx on CNTs. They believed that nanoscale "dendrites" of MWNTs were reasoned to form a network, projecting outward from the electrode surface acting like bundled ultramicroelectrodes, thereby permitting access to the active site and facilitating direct electron transfer to the immobilized enzyme. This was demonstrated by the appearance of a pair of redox peaks for POx with an oxidation peak near $-0.45 \mathrm{~V}$ and a reduction peak near $-0.49 \mathrm{~V}$ (versus $\mathrm{Ag} \mid \mathrm{AgCl}, 3 \mathrm{M} \mathrm{NaCl}$ ) in $0.05 \mathrm{M}$ PBS (pH 7.0). The direct electron transfer permitted the detection of putrescine at negative potentials, circumventing the interference of endogenous ascorbic and uric acids. Compared with the most common interfering species, such as spermine, spermidine, cadaverine, and histamine, a detection limit of $5 \mu \mathrm{M}$ and a response of 20 times greater were found for putrescine. Later, Luong et al. further fabricated a POxbased biosensor through a covalent method [85]. In that work, MWNTs were dissolved in a mixture of APTES, Nafion and ethanol with sonication to get uniformly dispersed CNTs. The resulting mixture was dropped on the electrode surface and allowed to dry. Upon the enzyme preparation, a drop of the enzyme solution was dried on the CNT/APTES modified electrode and a certain volume of GDI was dropped on the resulting electrode to cross-link the enzyme with APTES. Similar to the noncovalent immobilization method [256], POx exhibited a pair of well-defined peaks at $-0.52 \mathrm{~V}$ (versus $\mathrm{Ag} \mid \mathrm{AgCl}$ ) in $0.05 \mathrm{M}$ borate buffer ( $\mathrm{pH} 8.35$ ), providing a selective and sensitive method for putrescine determination. Similar to the immobilization of GOx on CNT electrodes [254], Wang et al. reported the noncovalent immobilization of XOx on CNT electrodes by just dropping the XOx solution onto the surface of the electrode surface and allowing to dry under ambient conditions [251]. The resulting electrodes were completely rinsed with water prior to any measurements, which exhibited a pair of well-defined redox peaks at around $-0.46 \mathrm{~V}$ with a small peak separation of $28 \mathrm{mV}$ in $0.05 \mathrm{M}$ phosphate buffer (pH 7.0).

(2) Fundamentals of Direct Electron Transfer of Redox Proteins and Enzymes at Carbon Nanotube Electrodes. Based on the above discussions, it is clear that CNT electrodes can effectively facilitate the direct electron transfer of various redox proteins and enzymes. However, few works gain insights into the fundamental information of this important process. Guiseppi-Elie et al. studied the direct electron transfer between SWNTs and the redox center of adsorbed GOx [260]. It was found that both FAD and GOx spontaneously adsorbed to annealed CNTs and displayed quasi-reversible one-electron transfer. They believed that the nanotubes become positioned within a tunneling distance of the 
cofactors with little consequence to denaturation. Willner's group proposed an approach for the covalent attachment of reconstituted GOx on the end of aligned SWNTs [261]. The electrons were transported along distances higher than $150 \mathrm{~nm}$ and the transport rate was controlled by the nanotube length, interfacial electron transfer rate constants for 50 and $100 \mathrm{~nm}$ SWNTs were 42 and $19 \mathrm{~s}^{-1}$, respectively. Such plugging of CNTs into enzymes was also reported by Gooding et al. by two different ways [152]. In the first method, native GOx was covalently attached to the ends of the aligned tubes, which allowed close approach to FAD and direct electron transfer to be observed with a rate constant of $0.3 \mathrm{~s}^{-1}$. The second strategy was similar to the method proposed by Willner et al. [261], that is, FAD was attached to the ends of the tubes and the enzyme reconstituted around the surface immobilized FAD. This latter approach allowed more efficient electron transfer to the FAD with a rate constant of $9^{-1}$. The direct electron transfer of both native and reconstituted GOx at aligned CNTs demonstrated the molecular wire role of CNTs in promoting the electron transfer of redox proteins and enzymes. Rusling et al. [156] investigated the electrochemical behaviors of HRP and Mb covalently bound to the ends of SWNT forest electrodes. Their data indicated that the "trees" in the nanotube forest behaved electrically similar to a metal, conducting electrons from the external circuit to the redox sites of the enzymes. The peroxidase activity of these enzymes was demonstrated, with detection limits for hydrogen peroxide in buffer solutions of $\sim 100 \mathrm{nM}$. The direct electron transfer of MP-11 covalently attached to aligned SWNT arrays was also examined by Gooding et al. [150]. It was found that although the enzyme also adsorbed along the hydrophobic walls of the nanotubes, the majority of the electron transfer was dominated by proteins immobilized on the electroactive ends of the nanotubes, which further supported the excellent electrochemical properties of the ends of the nanotubes. In addition, despite different distributions of tube lengths, the rate constants for heterogeneous electron transfer to the enzyme were essentially the same, demonstrating the efficiency of the shortened nanotubes as molecular wires. Jiang et al. recently studied the electrochemical redox processes of Cyt $c$ at a SWNT modified electrode by in situ UV-vis and circular dichroism (CD) spectroelectrochemistry [39]. It was found that SWNTs can effectively decrease the effect of electric field on the configurational changes of Cyt $\mathrm{c}$ and stabilize the Met80-Fe bond of adsorbed Cyt c, and that electron transfer induced a more opening configurational change at SWNT/GCE than that at the bare electrode, which might be responsible for the direct electron transfer of enzymes on CNT electrodes and the retaining of their biocatalytic activity. The CNT-induced configurational change of enzymes has been verified by Gooding et al. [262]. Rate constants for direct electron transfer to GOx at CNT-modified electrodes and graphite electrodes suggest that the enzyme was partially denatured from its native configuration, thus bringing the redox-active center of the enzyme closer to the electrode and allowing appreciable electron transfer.
4.3. Carbon Nanotube-Based DNA Electrochemical Sensors. Sequence-specific DNA detection has been a topic of significant interest due to its promising application in the diagnosis of pathogenic and genetic diseases. Electrochemical DNA biosensors are currently receiving considerable attention because of their high sensitivity, portability, low-cost and rapid response. Such devices rely on the conversion of the nucleic acid recognition processes into a useful electrical signal. Similar to other electrochemical sensors, the DNA electrochemical sensors benefit much from the use of CNTs based on the enhanced oxidation of the oxidable bases, the improved responses of the indicaters or the excellent properties of CNTs as the carrier platforms.

Fang's group has reported several CNT-based DNA electrochemical sensors for the determination of sequencespecific DNA over the last few years [188, 263-265]. In an earlier work, they developed a novel and sensitive electrochemical DNA biosensor based on MWNTs functionalized with carboxylic acid groups for the covalent DNA immobilization and the enhanced hybridization detection [263]. The MWNT modified GCE was fabricated from a simple casting method and oligonucleotides with the $5^{\prime}$-amino group were covalently bonded to the carboxyl groups of CNTs with the aid of EDC. The hybridization process on the electrode was monitored by DPV analysis using an electroactive intercalator daunomycin (DNR) as an indicator. The sensitive response of DNR at CNT electrode led to a significant increase of the hybridization signal of DNA compared to DNA sensors with oligonucleotides directly incorporated on carbon electrodes. Similar improved hybridization responses of DNA covalent immobilized on CNT electrodes were also observed by Wang et al. [266] and Kerman et al. [267] using $\mathrm{MB}$ and Escherichia coli single-strand binding protein (SSB) as the indicators, respectively. Wang et al. proposed an effective method for amplifying electrical detection of DNA hybridization based on CNTs carrying a large number of CdS particle tracers [268]. Such use of CNT amplification platforms was combined with an ultrasensitive stripping voltammetric detection of the dissolved CdS tags following dual hybridization events of a sandwich assay on a streptavidin modified 96-well microplate. Fang et al. also reported a new indicator free biosensing strategy for direct electrochemical detection of DNA hybridization by AC impedance measurement [264]. They firstly immobilized the oligonucleotide probes on a MWNT modified GCE through the entrapping of DNA as the sole counter anion during the electropolymerization growth of the PPy films. Before and after hybridization reaction with the complementary DNA sequences, a decrease of impedance values was observed as a result of the reduction of the electrode resistance. Hybridization amounts of the one-base, two-base and threebase mismatched sequences were obtained only in a $51 \%$, $18 \%$ and $8.2 \%$ response when compared to that for the complementary matched sequence. Such unique response was attributed to the concomitant conductivity changes of the PPy-polymerized CNTs, and offered great promise for reagentless DNA hybridization analysis. Later, they further improved this method by adding zinc ions $\left(\mathrm{Zn}^{2+}\right)$ to the hybridization solution, resulting in the formation of 


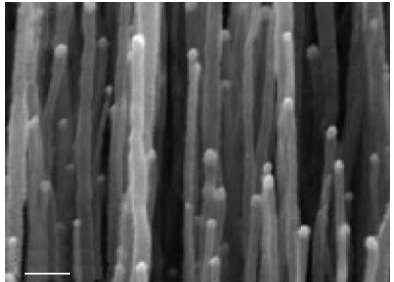

(a)

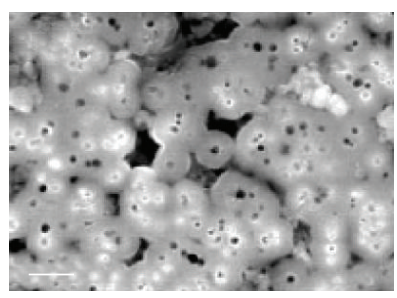

(c)

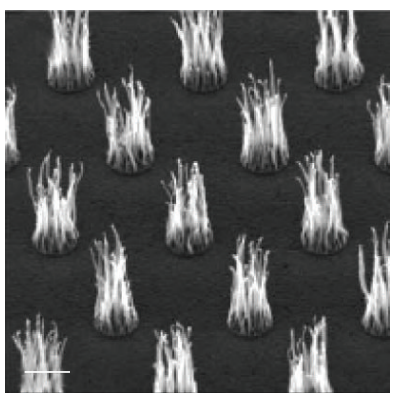

(f)

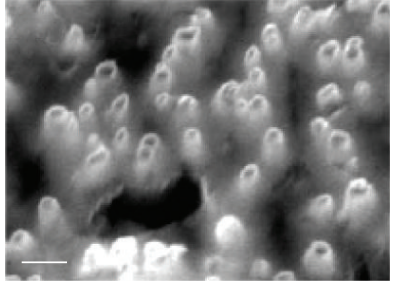

(b)

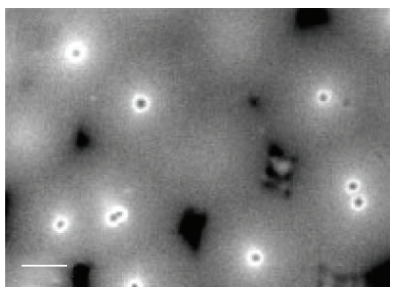

(d)

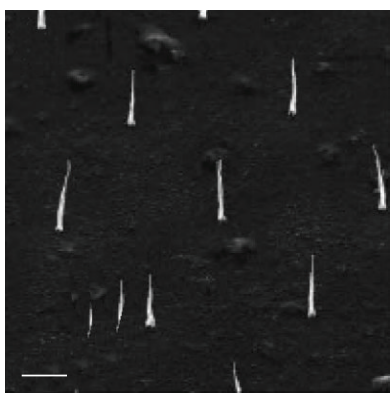

(g)

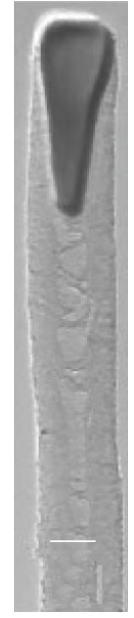

(e)

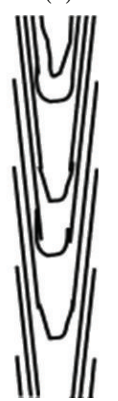

(h)

Figure 15: SEM images of (a) an as-grown MWCNT array, (b) the surface of a polished MWCNT array embedded in an $\mathrm{SiO}_{2}$ matrix, (c) a high-density MWCNT nanoelectrode array (hd, $2 \times 10^{9}$ electrodes $\mathrm{cm}^{-2}$ ), (d) a low-density one (ld-1, $7 \times 10^{7}$ electrodes $\mathrm{cm}^{-2}$ ), (f) an as-grown MWCNT array on $2 \mathrm{~mm} \mathrm{Ni} \mathrm{spots} \mathrm{patterned} \mathrm{with} \mathrm{UV} \mathrm{lithography,} \mathrm{(g)} \mathrm{an} \mathrm{as-grown} \mathrm{MWCNT} \mathrm{array} \mathrm{on} \sim 100 \mathrm{~nm}$ diameter Ni spots patterned with e-beam lithography, and (h) a schematic of the defective bamboo-like structure. (a), (b), (f), and (g) are $45^{\circ}$ uperspective views while (c) and (d) are top views. (e) is the TEM view of a single MWCNT. The scale bars in (a) $-(\mathrm{g})$ are $500 \mathrm{~nm}, 200 \mathrm{~nm}, 500 \mathrm{~nm}, 500 \mathrm{~nm}$, $50 \mathrm{~nm}, 2 \mu \mathrm{m}$, and $5 \mu \mathrm{m}$, respectively. [Reprinted with permission from Koehne et al. [206], J. Mater. Chem., 14, 676 (2004). Copyright 2003, Royal Society of Chemistry.]

metallized double-stranded DNA (M-DNA) that can significantly change the electrochemical impedance response [265]. Recently, Fang et al. reported a new sensitive electrochemical biosensor based on magnetite nanoparticles for monitoring DNA hybridization by using MWNT/PPy-modified glassy carbon electrode [188]. In such detection system, mercapatoacetic acid (RSH)-coated magnetite nanoparticles, capped with $5^{\prime}-\left(\mathrm{NH}_{2}\right)$ oligonucleotide, were used as DNA probe to complex a 29-base polynucleotide target (a piece of human porphobilinogen deaminase PBGD promoter from 170 to 142). Target sequence hybridized with the probe resulted in the decrease of the reduction peak current of DNR connected with probe. As mentioned above, Meyyappan et al. reported a novel approach for the fabrication of nanoelectrode arrays using vertically aligned MWNTs embedded within a $\mathrm{SiO}_{2}$ matrix $[205,206]$ (Figure 15). Based on the a low background and a small cell time constant of these nanoelectrodes, they prepared a highly sensitive DNA sensors by covalently attaching the DNA probes on the ends of the CNTs and monitoring the electrochemical response of $\mathrm{Ru}(\mathrm{bpy})_{3}{ }^{2+}$ mediator amplified guanine oxidation.
Wu et al. studied the electrochemical behaviors of DNA, guanine and adenine at a MWNT-DHP composite filmmodified electrode (MWNT-DHP/GCE) [95]. Compared with the undiscerned responses at the bare electrode, adenine and guanine exhibited a sensitive oxidation peak at 0.73 and $1.02 \mathrm{~V}$ on MWNT-DHP/GCE in $0.1 \mathrm{M}$ PBS ( $\mathrm{pH} 7.0)$, respectively. The responses were also observed for the hydrolyzed product of calf thymus DNA, providing a simple but sensitive method for DNA measurement. The enhanced oxidation of guanine and adenine residues in DNA was also observed by Wang et al. at a SWNT modified GCE [269]. On the basis of the enhanced oxidation of guanine on pretreated CNTPEs, Pedano et al. recently proposed an adsorptive stripping potentiometric method for the measurement of nucleic acids [164]. Trace $(\mu \mathrm{g} / \mathrm{L})$ levels of the oligonucleotides and polynucleotides can be readily detected following short accumulation periods with detection limits of $2.0 \mu \mathrm{g} / \mathrm{L}$ for a 21-base oligonucleotide and $170 \mu \mathrm{g} / \mathrm{L}$ for calf thymus dsDNA. The interaction between nucleic acids and CNTPE was demonstrated to be mainly hydrophobic. 
Besides the application in DNA detection, CNTs were also used as the carrier platforms of DNA by several workers. Guo et al. examined the electrochemical characteristics of the covalent immobilization of calf thymus DNA molecules on MWNTs by EDC [45]. By studying the $\mathrm{CV}$ and the electrochemical impedance spectroscopy (EIS) of $\mathrm{Fe}(\mathrm{CN})_{6}{ }^{3-} / \mathrm{Fe}(\mathrm{CN})_{6}{ }^{4-}$, they found that most of calf thymus DNA are covalently immobilized on MWNTs via diimide-activated amidation between the carboxylic acid groups on CNTs and the amino groups on DNA bases, though the direct adsorption of the DNA molecules on MWNTs can be also observed. The studies on the interaction between DNA molecules and small biomolecules ethidium bromide (EB) implied that DNA molecules immobilized at the surface of MWNTs still had the ability to interact with small biomolecules. Based on the strong adsorption of PDDA on CNTs, Guo et al. also proposed an LBL method for the immobilization of DNA on the electrode surface and monitored the electrostatic assembly of DNA on PDDA modified CNTs by the piezoelectric quartz crystal impedance (PQCI) technique [44]. It was found that PDDA played a key role in the attachment of DNA to MWNTs and acted as a bridge to connect DNA with MWNTs, though the direct adsorption of DNA on MWNTs has been observed. Recently, He et al. introduced a new fabrication of DNACNT particles using the LBL technique on SWNTs [147]. PDDA, a positively charged polyelectrolyte, and DNA as a negatively charged counterpart macromolecule were alternatively deposited on the water-soluble oxidized SWNTs. Pure DNA/PDDA/SWNT particles can be prepared and separated by simple unltracentrifugation. An electrode modified by the DNA/PDDA/SWNT particles shows a dramatic change of the electrochemical signal in solutions of $\mathrm{Ru}(\mathrm{bpy})_{3}{ }_{3}{ }^{2+}$ as a reporting redox probe. A preliminary application of the DNA-modified carbon nanotubes in the development of DNA sensors used in the investigation of DNA damage by nitric oxide was presented.

\section{Conclusions and Perspectives}

As a new type of carbonaceous materials, carbon nanotubes (CNTs) possess some unique properties that are much different from either the conventional scaled materials or other types of nanoparticles, such as the special and well-defined tubular structure of nanosizes, the excellent chemical stability, the modifiable surface and the strong electrocatalytic activity. These special properties foresee their promising applications in electroanalytical chemistry for constructing CNT-based sensors. The fact is that the modification of electrodes with CNTs has been observed to apparently improve the responses of substrates from small $\mathrm{H}_{2} \mathrm{O}_{2}$ molecules to huge redox proteins. Most of current works mainly focused on the fabrication of randomly dispersed CNTbased electrochemical sensors and few reports deal with the fabrications of well organized nanostructures of CNTs. As a tubular nanomaterials, the key advantages of CNTs are their small diameter and huge length to diameter ratio that allows them to be used as molecular wires for facilitating electron transfer between proteins and electrodes or to be organized in a low density manner for using as a single nanoelectrode or nanoelectrode arrays with ultrasensitivity. Since the direct growth by CVD methods inevitably surfers from the need of rigorous conditions, development of simple physical or chemical immobilization methods that can control the orientation of CNTs on electrode surfaces has become a matter of great urgency.

\section{Abbreviations}

\begin{tabular}{|c|c|}
\hline AA: & Ascorbic acid \\
\hline AChE: & Acteylcholinesterase \\
\hline $\mathrm{ADH}:$ & Alcohol-dehydrogenase \\
\hline o-AP: & o-aminophenol \\
\hline APTES: & 3-aminopropyltriethoxy-silane \\
\hline ARS: & $\begin{array}{l}\text { 3,4-dihydroxy-9,10-dioxo-2- } \\
\text { anthracenesulfonic acid, sodium } \\
\text { salt }\end{array}$ \\
\hline ASV: & Anodic stripping voltammetry \\
\hline ATCh: & Acteylthiocholine \\
\hline$[\mathrm{bmim}] \mathrm{PF}_{6}$ : & $\begin{array}{l}\text { 1-butyl-3-methylimidazolium } \\
\text { hexafluorophosphate }\end{array}$ \\
\hline Bppg: & Basal-plane pyrolytic graphite \\
\hline CCNNEs: & $\begin{array}{l}\text { Ceramic-carbon nanotubes nanocomposite } \\
\text { electrodes }\end{array}$ \\
\hline CDs: & Cyclodextrins \\
\hline CE: & Capillary electrophoresis \\
\hline CFNE: & Carbon fiber nanoelectrode \\
\hline CHIT: & Chitosan \\
\hline ChOx: & Cholesterol oxidase \\
\hline CNTPEs: & Carbon nanotube paste electrodes \\
\hline CNTPMEs: & Carbon nanotube powder microelectrodes \\
\hline CNTs: & Carbon nanotubes \\
\hline CNT-IE: & $\begin{array}{l}\text { Carbon nanotubes-intercalated graphite } \\
\text { electrode }\end{array}$ \\
\hline CoTMPyP: & $\begin{array}{l}\text { [tetrakis(N-methylpyridyl)porphyrinato] } \\
\text { cobalt }\end{array}$ \\
\hline CP: & Carbon paste \\
\hline CPEs: & Carbon paste electrodes \\
\hline Ct: & Catalase \\
\hline CTAB: & Cetyltrimethylammonium bromide \\
\hline CV: & Cyclic voltammetry \\
\hline CVD: & Chemical vapour deposition \\
\hline CySH: & Cysteine \\
\hline Cyt c: & Cytochrome c \\
\hline Da: & Dalton \\
\hline DA: & Dopamine \\
\hline DAB: & Diaminobenzidine \\
\hline DCC: & Dicyclohexyl carbodiimide \\
\hline DET: & Direct electron transfer \\
\hline DHB: & Dihydroxybenzaldehyde \\
\hline DHP: & Dihexadecyl hydrogen phosphate \\
\hline DL: & Detection limit \\
\hline DMF: & N,N-dimethylformamide \\
\hline dsDNA: & Double-strand DNA \\
\hline ssDNA: & Single-strand DNA \\
\hline DNR: & Daunomycin \\
\hline DPV: & Differential pulse voltammetry \\
\hline
\end{tabular}




\begin{tabular}{|c|c|}
\hline$E^{\circ \prime}:$ & Formal potential \\
\hline EB: & Ethidium bromide \\
\hline ECD: & Electrochemical detection \\
\hline EDC: & $\begin{array}{l}\text { 1-ethyl-3-(3- } \\
\text { dimethylaminopropyl)carbodiimide }\end{array}$ \\
\hline EIS: & Electrochemical impedance spectroscopy \\
\hline$\Delta E_{p}:$ & Redox peak separation \\
\hline EP: & Epinephrine \\
\hline ESEM: & Environmental scanning electron microscopy \\
\hline ET: & Electron transfer \\
\hline FAD: & Flavin adenine dnucleotide \\
\hline Fc-SWNTs: & Ferrocenyl-derivatised SWNTs \\
\hline FDH: & D-fructose dehydrogenase \\
\hline FePc: & Iron-phthalocyanine \\
\hline FIA: & Flow injection analysis \\
\hline GCE: & Glassy carbon electrode \\
\hline GDH: & Glucose dehydrogenase \\
\hline GDI: & Glutaraldehyde \\
\hline GOx: & Glucose oxidase \\
\hline GSH: & Glutathione \\
\hline GSSG: & Glutathione disulfide \\
\hline $\mathrm{Hb}:$ & Hemoglobin \\
\hline HcySH: & Homocysteine \\
\hline HOPG: & Highly oriented pyrolytic graphite \\
\hline HPLC: & High performance liquid chromatography \\
\hline HRP: & Horseradish peroxidase \\
\hline 5-HT: & Serotonin \\
\hline IR: & Infrared spectra \\
\hline LBL: & Layer-by-layer \\
\hline Mb: & Myoglobin \\
\hline MB: & Methylene blue \\
\hline MCMB: & Mesocarbon microbeads \\
\hline M-DNA: & Metallized double-stranded DNA \\
\hline MWNTs: & Multiwalled carbon nanotubes \\
\hline MP-11: & Microperoxidase \\
\hline $\mathrm{NAD}^{+}:$ & $\beta$-nicotinamide adenine dinucleotide \\
\hline NADH: & $\begin{array}{l}\text { Reduced } \beta \text {-nicotinamide adenine } \\
\text { dinucleotide }\end{array}$ \\
\hline NE: & Norepinephrine \\
\hline NEAs: & Nanoelectrode arrays \\
\hline NMP: & N-methyl-2-pyrrolidone \\
\hline NSA: & $\mathrm{N}$-succinimidyl acrylate \\
\hline OCNTs: & Ordered carbon nanotubes \\
\hline $\mathrm{OMIMPF}_{6}$ : & $\begin{array}{l}\text { 1-octyl-3-methyl imidazolium } \\
\text { hexafluorophosphate }\end{array}$ \\
\hline OP: & Organophosphorus \\
\hline PABS: & Poly(aminobenzenesulfonic acid) \\
\hline PA-FTIR: & Photoacoustic Fourier transform infrared \\
\hline PANT: & Polyaniline \\
\hline PB: & Prussian blue \\
\hline PBS: & Phosphate buffer solution \\
\hline PDAB: & $\operatorname{Poly}\left(3,3^{\prime}\right.$-diaminobenzidine $)$ \\
\hline PDDA: & Poly(diallyl dimethyl ammonium) chloride \\
\hline PG: & Pyrolytic graphite \\
\hline PMEs: & Powder microelectrodes \\
\hline Pox: & Putrescine oxidase \\
\hline PPD: & Poly(o-phenylenediamine) \\
\hline PPy: & Polypyrrole \\
\hline PQCI: & Piezoelectric quartz crystal impedance \\
\hline
\end{tabular}

$\begin{array}{ll}\text { RTILs: } & \text { Room-temperature ionic liquids } \\ \text { RSH: } & \text { Mercapatoacetic acid } \\ \text { SAMs: } & \text { Self-assembled monolayers } \\ \text { SCE: } & \text { Saturated calomel electrode } \\ \text { SDS: } & \text { Sodium dodecyl sulphate } \\ \text { SEM: } & \text { Scanning electron microscopy } \\ \text { S/N: } & \text { Signal-to-noise ratio } \\ \text { SSB: } & \text { Escherichia coli single-strand binding protein } \\ \text { sulfo-NHS: } & \text { N-hydroxysulfo-succinimide } \\ \text { SWNTs: } & \text { Single-walled carbon nanotubes } \\ \text { TBO: } & \text { Toluidine Blue O } \\ \text { TEM: } & \text { Transmission electron microscopy } \\ \text { TGA: } & \text { Thermogravimetric analysis } \\ \text { TM-AFM: } & \text { Tapping-mode atomic force microscopy } \\ \text { TPP: } & \text { Tetra-phenyl-porphyrin } \\ \text { UA: } & \text { Uric acid } \\ \text { Xa: } & \text { Xanthine } \\ \text { XOx: } & \text { Xanthine oxidase } \\ \text { XPS: } & \text { X-ray photoelectron spectroscopy }\end{array}$

\section{Acknowledgment}

The research is supported by the National Natural Science Foundation of China (Nos. 30770549, 20805035, and 90817103).

\section{References}

[1] P. J. Britto, K. S. V. Santhanam, and P. M. Ajayan, "Carbon nanotube electrode for oxidation of dopamine," Bioelectrochemistry and Bioenergetics, vol. 41, no. 1, pp. 121-125, 1996.

[2] Q. Zhao, Z. Gan, and Q. Zhuang, "Electrochemical sensors based on carbon nanotubes," Electroanalysis, vol. 14, no. 23, pp. 1609-1613, 2002.

[3] N. Li, J. Wang, and M. Li, "Electrochemistry at carbon nanotube electrodes," Reviews in Analytical Chemistry, vol. 22, no. 1, pp. 19-33, 2003.

[4] J. Li, J. E. Koehne, A. M. Cassell, et al., "Inlaid multi-walled carbon nanotube nanoelectrode arrays for electroanalysis," Electroanalysis, vol. 17, no. 1, pp. 15-27, 2005.

[5] J. Wang, "Carbon-nanotube based electrochemical biosensors: a review," Electroanalysis, vol. 17, no. 1, pp. 7-14, 2005.

[6] J. J. Gooding, "Nanostructuring electrodes with carbon nanotubes: a review on electrochemistry and applications for sensing," Electrochimica Acta, vol. 50, no. 15, pp. 3049-3060, 2005.

[7] R. L. McCreery, "Carbon electrodes: structural effects on electron transfer kinetics," in Electroanalytical Chemistry, vol. 17, pp. 221-374, Marcel Dekker, New York, NY, USA, 1991.

[8] J. Li, A. Cassell, L. Delzeit, J. Han, and M. Meyyappan, "Novel three-dimensional electrodes: electrochemical properties of carbon nanotube ensembles," The Journal of Physical Chemistry B, vol. 106, no. 36, pp. 9299-9305, 2002.

[9] J. M. Nugent, K. S. V. Santhanam, A. Rubio, and P. M. Ajayan, "Fast electron transfer kinetics on multiwalled carbon nanotube microbundle electrodes," Nano Letters, vol. 1, no. 2, pp. 87-91, 2001.

[10] P. Papakonstantinou, R. Kern, J. Irvine, E. McAdams, J. McLaughlin, and T. McNally, "Fundamental electrochemical properties of carbon nanotube electrodes," Fullerenes Nanotubes and Carbon Nanostructures, vol. 13, supplement 1, pp. 275-285, 2005. 
[11] C. E. Banks, R. R. Moore, T. J. Davies, and R. G. Compton, "Investigation of modified basal plane pyrolytic graphite electrodes: definitive evidence for the electrocatalytic properties of the ends of carbon nanotubes," Chemical Communications, no. 6, pp. 1804-1805, 2004.

[12] R. R. Moore, C. E. Banks, and R. G. Compton, "Basal plane pyrolytic graphite modified electrodes: comparison of carbon nanotubes and graphite powder as electrocatalysts," Analytical Chemistry, vol. 76, no. 10, pp. 2677-2682, 2004.

[13] C. E. Banks, T. J. Davies, G. G. Wildgoose, and R. G. Compton, "Electrocatalysis at graphite and carbon nanotube modified electrodes: edge-plane sites and tube ends are the reactive sites," Chemical Communications, no. 7, pp. 829-841, 2005.

[14] A. Chou, T. Bocking, N. K. Singh, and J. J. Gooding, "Demonstration of the importance of oxygenated species at the ends of carbon nanotubes for their favourable electrochemical properties," Chemical Communications, vol. 7, pp. 842-844, 2005.

[15] B. Šljukić, C. E. Banks, and R. G. Compton, "Iron oxide particles are the active sites for hydrogen peroxide sensing at multiwalled carbon nanotube modified electrodes," Nano Letters, vol. 6, no. 7, pp. 1556-1558, 2006.

[16] H. Luo, Z. Shi, N. Li, Z. Gu, and Q. Zhuang, "Investigation of the electrochemical and electrocatalytic behavior of singlewall carbon nanotube film on a glassy carbon electrode," Analytical Chemistry, vol. 73, no. 5, pp. 915-920, 2001.

[17] C. Hu and S. Hu, "Surface design of carbon nanotubes for optimizing the adsorption and electrochemical response of analytes," Langmuir, vol. 24, no. 16, pp. 8890-8897, 2008.

[18] A. Kuznetsova, D. B. Mawhinney, V. Naumenko, J. T. Yates Jr., J. Liu, and R. E. Smalley, "Enhancement of adsorption inside of single-walled nanotubes: opening the entry ports," Chemical Physics Letters, vol. 321, no. 3-4, pp. 292-296, 2000.

[19] J. Liu, A. G. Rinzler, H. Dai, et al., "Fullerene pipes," Science, vol. 280, no. 5367, pp. 1253-1256, 1998.

[20] H. Hu, P. Bhowmik, B. Zhao, M. A. Hamon, M. E. Itkis, and R. C. Haddon, "Determination of the acidic sites of purified single-walled carbon nanotubes by acid-base titration," Chemical Physics Letters, vol. 345, no. 1-2, pp. 2528,2001 .

[21] D. B. Mawhinney, V. Naumenko, A. Kuznetsova, J. T. Yates Jr., J. Liu, and R. E. Smalley, "Surface defect site density on single walled carbon nanotubes by titration," Chemical Physics Letters, vol. 324, no. 1-3, pp. 213-216, 2000.

[22] C. Bower, A. Kleinhammes, Y. Wu, and O. Zhou, "Intercalation and partial exfoliation of single-walled carbon nanotubes by nitric acid," Chemical Physics Letters, vol. 288, no. 2-4, pp. 481-486, 1998.

[23] A. Kukovecz, Ch. Kramberger, M. Holzinger, et al., "On the stacking behavior of functionalized single-wall carbon nanotubes," The Journal of Physical Chemistry B, vol. 106, no. 25, pp. 6374-6380, 2002.

[24] M. T. Martínez, M. A. Callejas, A. M. Benito, et al., "Modifications of single-wall carbon nanotubes upon oxidative purification treatments," Nanotechnology, vol. 14, no. 7, pp. 691-695, 2003.

[25] J. N. Barisci, G. G. Wallace, D. Chattopadhyay, F. Papadimitrakopoulos, and R. H. Baughman, "Electrochemical properties of single-wall carbon nanotube electrodes," Journal of the Electrochemical Society, vol. 150, no. 9, pp. E409-E415, 2003.
[26] J. N. Barisci, G. G. Wallace, and R. H. Baughman, "Electrochemical studies of single-wall carbon nanotubes in aqueous solutions," Journal of Electroanalytical Chemistry, vol. 488, no. 2, pp. 92-98, 2000.

[27] M. Musameh, N. S. Lawrence, and J. Wang, "Electrochemical activation of carbon nanotubes," Electrochemistry Communications, vol. 7, no. 1, pp. 14-18, 2005.

[28] Y. Lin, F. Lu, Y. Tu, and Z. Ren, "Glucose biosensors based on carbon nanotube nanoelectrode ensembles," Nano Letters, vol. 4, no. 2, pp. 191-195, 2004.

[29] K. Yamamoto, G. Shi, T. Zhou, et al., "Study of carbon nanotubes-HRP modified electrode and its application for novel on-line biosensors," Analyst, vol. 128, no. 3, pp. 249254, 2003.

[30] X.-X. Yan, D.-W. Pang, Z.-X. Lu, J.-Q. Lü, and H. Tong, "Electrochemical behavior of L-dopa at single-wall carbon nanotube-modified glassy carbon electrodes," Journal of Electroanalytical Chemistry, vol. 569, no. 1, pp. 47-52, 2004.

[31] Z. Xu, X. Chen, X. Qu, J. Jia, and S. Dong, "Single-wall carbon nanotube-based voltammetric sensor and biosensor," Biosensors and Bioelectronics, vol. 20, no. 3, pp. 579-584, 2004.

[32] Q. Zhao, Z.-N. Gu, and Q.-K. Zhuang, "Electrochemical study of tetra-phenyl-porphyrin on the SWNTs film modified glassy carbon electrode," Electrochemistry Communications, vol. 6, no. 1, pp. 83-86, 2004.

[33] J. Wang, S. B. Hocevar, and B. Ogorevc, "Carbon nanotubemodified glassy carbon electrode for adsorptive stripping voltammetric detection of ultratrace levels of 2,4,6trinitrotoluene," Electrochemistry Communications, vol. 6, no. 2, pp. 176-179, 2004.

[34] L. Wang, J. Wang, and F. Zhou, "Direct electrochemistry of catalase at a gold electrode modified with single-wall carbon nanotubes," Electroanalysis, vol. 16, no. 8, pp. 627-632, 2004.

[35] Z.-H. Gan, Q. Zhao, Z.-N. Gu, and Q.-K. Zhuang, "Electrochemical studies of single-wall carbon nanotubes as nanometer-sized activators in enzyme-catalyzed reaction," Analytica Chimica Acta, vol. 511, no. 2, pp. 239-247, 2004.

[36] N. S. Lawrence, R. P. Deo, and J. Wang, "Electrochemical determination of hydrogen sulfide at carbon nanotube modified electrodes," Analytica Chimica Acta, vol. 517, no. 12, pp. 131-137, 2004.

[37] Y.-P. Ding, W.-L. Liu, Q.-S. Wu, and X.-G. Wang, "Direct simultaneous determination of dihydroxybenzene isomers at C-nanotube-modified electrodes by derivative voltammetry," Journal of Electroanalytical Chemistry, vol. 575, no. 2, pp. 275-280, 2005.

[38] L. Jiang, R. Wang, X. Li, L. Jiang, and G. Lu, "Electrochemical oxidation behavior of nitrite on a chitosan-carboxylated multiwall carbon nanotube modified electrode," Electrochemistry Communications, vol. 7, no. 6, pp. 597-601, 2005.

[39] X. Jiang, Z. Zhang, H. Bai, et al., "Effect of electrode surface microstructure on electron transfer induced conformation changes in cytochrome $\mathrm{c}$ monitored by in situ UV and CD spectroelectrochemistry," Spectrochimica Acta Part A, vol. 61, no. 5, pp. 943-951, 2005.

[40] Q. Zhao, L. Guan, Z. Gu, and Q. Zhuang, "Determination of phenolic compounds based on the tyrosinase-single walled carbon nanotubes sensor," Electroanalysis, vol. 17, no. 1, pp. 85-88, 2005.

[41] K. A. Joshi, J. Tang, R. Haddon, J. Wang, W. Chen, and A. Mulchandani, "A disposable biosensor for organophosphorus nerve agents based on carbon nanotubes modified thick 
film strip electrode," Electroanalysis, vol. 17, no. 1, pp. 54-58, 2005.

[42] W. Zhang, F. Wan, W. Zhu, et al., "Determination of glutathione and glutathione disulfide in hepatocytes by liquid chromatography with an electrode modified with functionalized carbon nanotubes," Journal of Chromatography B, vol. 818, no. 2, pp. 227-232, 2005.

[43] G. Wang, J.-J. Xu, and H.-Y. Chen, "Interfacing cytochrome $c$ to electrodes with a DNA-carbon nanotube composite film," Electrochemistry Communications, vol. 4, no. 6, pp. 506-509, 2002.

[44] M. Guo, J. Chen, L. Nie, and S. Yao, "Electrostatic assembly of calf thymus DNA on multi-walled carbon nanotube modified gold electrode and its interaction with chlorpromazine hydrochloride," Electrochimica Acta, vol. 49, no. 16, pp. 2637 2643, 2004.

[45] M. Guo, J. Chen, D. Liu, L. Nie, and S. Yao, "Electrochemical characteristics of the immobilization of calf thymus DNA molecules on multi-walled carbon nanotubes," Bioelectrochemistry, vol. 62, no. 1, pp. 29-35, 2004.

[46] J. Chen and C. X. Cai, "Promotion of the direct electron transfer of hemoglobin by the carbon nanotube," Chinese Chemical Letters, vol. 15, no. 7, pp. 813-816, 2004.

[47] Y. Zhang, Y. Wen, Y. Liu, D. Li, and J. Li, "Functionalization of single-walled carbon nanotubes with Prussian blue," Electrochemistry Communications, vol. 6, no. 11, pp. 11801184, 2004.

[48] M. Guo, J. Chen, J. Li, B. Tao, and S. Yao, "Fabrication of polyaniline/carbon nanotube composite modified electrode and its electrocatalytic property to the reduction of nitrite," Analytica Chimica Acta, vol. 532, no. 1, pp. 71-77, 2005.

[49] F.-H. Wu, G.-C. Zhao, and X.-W. Wei, "Electrocatalytic oxidation of nitric oxide at multi-walled carbon nanotubes modified electrode," Electrochemistry Communications, vol. 4, no. 9, pp. 690-694, 2002.

[50] G.-C. Zhao, L. Zhang, X.-W. Wei, and Z.-S. Yang, "Myoglobin on multi-walled carbon nanotubes modified electrode: direct electrochemistry and electrocatalysis," Electrochemistry Communications, vol. 5, no. 9, pp. 825-829, 2003.

[51] F.-H. Wu, G.-C. Zhao, X.-W. Wei, and Z.-S. Yang, "Electrocatalysis of tryptophan at multi-walled carbon nanotube modified electrode," Microchimica Acta, vol. 144, no. 4, pp. 243-247, 2004.

[52] G.-C. Zhao, L. Zhang, and X.-W. Wei, "An unmediated $\mathrm{H}_{2} \mathrm{O}_{2}$ biosensor based on the enzyme-like activity of myoglobin on multi-walled carbon nanotubes," Analytical Biochemistry, vol. 329, no. 1, pp. 160-161, 2004.

[53] G.-C. Zhao, Z.-Z. Yin, L. Zhang, and X.-W. Wei, "Direct electrochemistry of cytochrome $c$ on a multi-walled carbon nanotubes modified electrode and its electrocatalytic activity for the reduction of $\mathrm{H}_{2} \mathrm{O}_{2}$, "Electrochemistry Communications, vol. 7, no. 3, pp. 256-260, 2005.

[54] C. Hu, W. L. Wang, S. X. Wang, W. Zhu, and Y. Li, "Investigation on electrochemical properties of carbon nanotubes," Diamond and Related Materials, vol. 12, no. 8, pp. 1295-1299, 2003.

[55] J. Qu, Y. Shen, X. Qu, and S. Dong, "Preparation of hybrid thin film modified carbon nanotubes on glassy carbon electrode and its electrocatalysis for oxygen reduction," Chemical Communications, no. 1, pp. 34-35, 2004.

[56] N. Jia, L. Wang, L. Liu, Q. Zhou, and Z. Jiang, "Bamboo-like $\mathrm{CNx}$ nanotubes for the immobilization of hemoglobin and its bioelectrochemistry," Electrochemistry Communications, vol. 7, no. 4, pp. 349-354, 2005.
[57] S. Lefrant, M. Baibarac, I. Baltog, J. Y. Mevellec, L. Mihut, and O. Chauvet, "SERS spectroscopy studies on the electrochemical oxidation of single-walled carbon nanotubes in sulfuric acid solutions," Synthetic Metals, vol. 144, no. 2, pp. 133-142, 2004.

[58] S. H. Lim, J. Wei, J. Lin, Q. Li, and J. KuaYou, "A glucose biosensor based on electrodeposition of palladium nanoparticles and glucose oxidase onto Nafion-solubilized carbon nanotube electrode," Biosensors and Bioelectronics, vol. 20, no. 11, pp. 2341-2346, 2005.

[59] C. A. Furtado, U. J. Kim, H. R. Gutierrez, L. Pan, E. C. Dickey, and P. C. Eklund, "Debundling and dissolution of singlewalled carbon nanotubes in amide solvents," Journal of the American Chemical Society, vol. 126, no. 19, pp. 6095-6105, 2004.

[60] G. Fortier, M. Vaillancourt, and D. Bélanger, "Evaluation of nafion as media for glucose oxidase immobilization for the development of an amperometric glucose biosensor," Electroanalysis, vol. 4, no. 3, pp. 275-283, 1992.

[61] Z. Fan and D. J. Harrison, "Permeability of glucose and other neutral species through recast perfluorosulfonated ionomer films," Analytical Chemistry, vol. 64, no. 11, pp. 1304-1310, 1992.

[62] Y. Y. Sun, K. B. Wu, and S. Hu, "Selective determination of dopamine in the presence of high concentration ascorbic acid and uric acid using carbon nanotube modified glassy carbon electrode," Chemical Journal of Chinese Universities, vol. 23, no. 11, pp. 2067-2069, 2002.

[63] J. Wang, M. Musameh, and Y. Lin, "Solubilization of carbon nanotubes by Nafion toward the preparation of amperometric biosensors," Journal of the American Chemical Society, vol. 125, no. 9, pp. 2408-2409, 2003.

[64] K. Wu and S. Hu, "Electrochemical study and selective determination of dopamine at a multi-wall carbon nanotubenafion film coated glassy carbon electrode," Microchimica Acta, vol. 144, no. 1-3, pp. 131-137, 2004.

[65] S. B. Hočevar, J. Wang, R. P. Deo, M. Musameh, and B. Ogorevc, "Carbon nanotube modified microelectrode for enhanced voltammetric detection of dopamine in the presence of ascorbate," Electroanalysis, vol. 17, no. 5-6, pp. 417-422, 2005.

[66] W. Huang, C. Yang, and S. Zhang, "Simultaneous determination of 2-nitrophenol and 4-nitrophenol based on the multi-wall carbon nanotubes Nafion-modified electrode," Analytical and Bioanalytical Chemistry, vol. 375, no. 5, pp. 703-707, 2003.

[67] W. Huang, W. Hu, and J. Song, "Adsorptive stripping voltammetric determination of 4-aminophenol at a singlewall carbon nanotubes film coated electrode," Talanta, vol. 61, no. 3, pp. 411-416, 2003.

[68] Y.-C. Tsai, J.-M. Chen, S.-C. Li, and F. Marken, "Electroanalytical thin film electrodes based on a Nafion ${ }^{\mathrm{TM}}$ multi-walled carbon nanotube composite," Electrochemistry Communications, vol. 6, no. 9, pp. 917-922, 2004.

[69] R. P. Deo and J. Wang, "Electrochemical detection of carbohydrates at carbon-nanotube modified glassy-carbon electrodes," Electrochemistry Communications, vol. 6, no. 3, pp. 284-287, 2004.

[70] K. Gong, Y. Dong, S. Xiong, Y. Chen, and L. Mao, "Novel electrochemical method for sensitive determination of homocysteine with carbon nanotube-based electrodes," Biosensors and Bioelectronics, vol. 20, no. 2, pp. 253-259, 2004. 
[71] Y.-C. Tsai, S.-C. Li, and J.-M. Chen, "Cast thin film biosensor design based on a nafion backbone, a multiwalled carbon nanotube conduit, and a glucose oxidase function," Langmuir, vol. 21, no. 8, pp. 3653-3658, 2005.

[72] K. B. Male, S. Hrapovic, Y. Liu, D. Wang, and J. H. T. Luong, "Electrochemical detection of carbohydrates using copper nanoparticles and carbon nanotubes," Analytica Chimica Acta, vol. 516, no. 1-2, pp. 35-41, 2004.

[73] S. Hrapovic, Y. Liu, K. B. Male, and J. H. T. Luong, "Electrochemical biosensing platforms using platinum nanoparticles and carbon nanotubes," Analytical Chemistry, vol. 76, no. 4, pp. 1083-1088, 2004.

[74] R. P. Deo, N. S. Lawrence, and J. Wang, "Electrochemical detection of amino acids at carbon nanotube and nickelcarbon nanotube modified electrodes," Analyst, vol. 129, no. 11, pp. 1076-1081, 2004

[75] T. Abatemarco, J. Stickel, J. Belfort, B. P. Frank, P. M. Ajayan, and G. Belfort, "Fractionation of multiwalled carbon nanotubes by cascade membrane microfiltration," Journal of Physical Chemistry B, vol. 103, no. 18, pp. 3534-3538, 1999.

[76] R.-S. Chen, W.-H. Huang, H. Tong, Z.-L. Wang, and J.-K. Cheng, "Carbon fiber nanoelectrodes modified by singlewalled carbon nanotubes," Analytical Chemistry, vol. 75, no. 22, pp. 6341-6345, 2003.

[77] C. Cai and J. Chen, "Direct electron transfer and bioelectrocatalysis of hemoglobin at a carbon nanotube electrode," Analytical Biochemistry, vol. 325, no. 2, pp. 285-292, 2004.

[78] C. Cai and J. Chen, "Direct electron transfer of glucose oxidase promoted by carbon nanotubes," Analytical Biochemistry, vol. 332, no. 1, pp. 75-83, 2004.

[79] Y. Sun, J. Fei, K. Wu, and S. Hu, "Simultaneous electrochemical determination of xanthine and uric acid at a nanoparticle film electrode," Analytical and Bioanalytical Chemistry, vol. 375, no. 4, pp. 544-549, 2003.

[80] K. Wu, Y. Sun, and S. Hu, "Development of an amperometric indole-3-acetic acid sensor based on carbon nanotubes film coated glassy carbon electrode," Sensors and Actuators B, vol. 96, no. 3, pp. 658-662, 2003.

[81] K. Wu, X. Ji, J. Fei, and S. Hu, "The fabrication of a carbon nanotube film on a glassy carbon electrode and its application to determining thyroxine," Nanotechnology, vol. 15, no. 3, pp. 287-291, 2004.

[82] F. Wang, J. Fei, and S. Hu, "The influence of cetyltrimethyl ammonium bromide on electrochemical properties of thyroxine reduction at carbon nanotubes modified electrode," Colloids and Surfaces B, vol. 39, no. 1-2, pp. 95-101, 2004.

[83] S. Lü, "Electrochemical behavior and detection of daunomycin at multi-walled carbon nanotubes modified electrode," Analytical Letters, vol. 36, no. 12, pp. 2597-2608, 2003.

[84] S. Lü, X. Dang, K. Wu, and S. Hu, "Electrocatalytic reduction of chloramphenicol at multiwall carbon nanotube-modified electrodes," Journal of Nanoscience and Nanotechnology, vol. 3, no. 5, pp. 401-405, 2003.

[85] Y. Wu, X. Ji, and S. Hu, "Studies on electrochemical oxidation of azithromycin and its interaction with bovine serum albumin," Bioelectrochemistry, vol. 64, no. 1, pp. 91-97, 2004.

[86] S. Lü, "Voltammetric determination of Tinidazole using multi-walled carbon nanotubes modified glassy carbon electrode," Chinese Journal of Analytical Chemistry, vol. 32, no. 3, p. 412, 2004.

[87] S. Lü, "Electrochemical determination of 8-azaguanine in human urine at a multi-carbon nanotubes modified electrode," Microchemical Journal, vol. 77, no. 1, pp. 37-42, 2004.
[88] S. Lü, K. Wu, X. Dang, and S. Hu, "Electrochemical reduction and voltammetric determination of metronidazole at a nanomaterial thin film coated glassy carbon electrode," Talanta, vol. 63, no. 3, pp. 653-657, 2004.

[89] S. Lü, "Electrochemical determination of tannins using multiwall carbon nanotubes modified glassy carbon electrode," Russian Journal of Electrochemistry, vol. 40, no. 7, pp. 750754, 2004.

[90] H. Zhang and K. Wu, "Sensitive adsorption stripping voltammetric determination of reserpine by a glassy carbon electrode modified with multi-wall carbon nanotubes," Microchimica Acta, vol. 149, no. 1-2, pp. 73-78, 2005.

[91] W. Qu, H. Wang, and K. Wu, "Voltammetric determination of mitomycin c using a chemically-modified glassy carbon electrode," Collection of Czechoslovak Chemical Communications, vol. 70, no. 2, pp. 178-187, 2005.

[92] H. Zhang, "Fabrication of a single-walled carbon nanotubemodified glassy carbon electrode and its application in the electrochemical determination of epirubicin," Journal of Nanoparticle Research, vol. 6, no. 6, pp. 665-669, 2004.

[93] H. Zhang, C. Hu, S. Wu, and S. Hu, "Enhanced oxidation of simvastatin at a multi-walled carbon nanotubes-dihexadecyl hydrogen phosphate composite modified glassy carbon electrode and the application in determining simvastatin in pharmaceutical dosage forms," Electroanalysis, vol. 17, no. 9, pp. 749-754, 2005.

[94] S. Lü, "A multi-wall carbon nanotubes-dicetyl phosphate electrode for the determination of hypoxanthine in fish," Analytical Sciences, vol. 19, no. 9, pp. 1309-1312, 2003.

[95] K. Wu, J. Fei, W. Bai, and S. Hu, "Direct electrochemistry of DNA, guanine and adenine at a nanostructured filmmodified electrode," Analytical and Bioanalytical Chemistry, vol. 376, no. 2, pp. 205-209, 2003.

[96] K. Wu, J. Fei, and S. Hu, "Simultaneous determination of dopamine and serotonin on a glassy carbon electrode coated with a film of carbon nanotubes," Analytical Biochemistry, vol. 318, no. 1, pp. 100-106, 2003.

[97] W. S. Huang, G. Mai, Y. X. Liu, C. Yang, and W. Y. Qu, "Voltammetric determination of tryptophan at a singlewall carbon nanotubes modified electrode," Journal of Nanoscience and Nanotechnology, vol. 4, no. 4, pp. 423-427, 2004.

[98] S. Zhang, W. Qu, W. Huang, and Y. Wu, "Fabrication of multi-wall carbon nanotube film on glassy carbon electrode surface and the determination of tyrosine," Journal of Nanoscience and Nanotechnology, vol. 4, no. 5, pp. 553-557, 2004.

[99] Y. Wang, Q. Li, and S. Hu, "A multiwall carbon nanotubes film-modified carbon fiber ultramicroelectrode for the determination of nitric oxide radical in liver mitochondria," Bioelectrochemistry, vol. 65, no. 2, pp. 135-142, 2005.

[100] K. Wu, S. Hu, J. Fei, and W. Bai, "Mercury-free simultaneous determination of cadmium and lead at a glassy carbon electrode modified with multi-wall carbon nanotubes," Analytica Chimica Acta, vol. 489, no. 2, pp. 215-221, 2003.

[101] H. Yi, "Anodic stripping voltammetric determination of mercury using multi-walled carbon nanotubes film coated glassy carbon electrode," Analytical and Bioanalytical Chemistry, vol. 377, no. 4, pp. 770-774, 2003.

[102] L. Jiang, C. Liu, L. Jiang, Z. Peng, and G. Lu, "A chitosanmultiwall carbon nanotube modified electrode for simultaneous detection of dopamine and ascorbic acid," Analytical Sciences, vol. 20, no. 7, pp. 1055-1059, 2004. 
[103] M. Zhang, A. Smith, and W. Gorski, "Carbon nanotubechitosan system for electrochemical sensing based on dehydrogenase enzymes," Analytical Chemistry, vol. 76, no. 17, pp. 5045-5050, 2004.

[104] A. Star, D. W. Steuerman, J. R. Heath, and J. F. Stoddart, "Starched carbon nanotubes," Angewandte Chemie International Edition, vol. 41, no. 14, pp. 2508-2512, 2002.

[105] G. Lu, L. Jiang, F. Song, C. Liu, and L. Jiang, "Determination of uric acid and norepinephrine by chitosan-multiwall carbon nanotube modified electrode," Electroanalysis, vol. 17, no. 10, pp. 901-905, 2005.

[106] L. Y. Jiang, C. Y. Liu, L. P. Jiang, and G. H. Lu, "A multiwall carbon nanotube-chitosan modified electrode for selective detection of dopamine in the presence of ascorbic acid," Chinese Chemical Letters, vol. 16, no. 2, pp. 229-232, 2005.

[107] X. L. Luo, J. J. Xu, J. L. Wang, and H. Y. Chen, "Electrochemically deposited nanocomposite of chitosan and carbon nanotubes for biosensor application," Chemical Communications, no. 16, pp. 2169-2171, 2005.

[108] Y. Liu, D.-C. Wu, W.-D. Zhang, et al., "Polyethyleniminegrafted multiwalled carbon nanotubes for secure noncovalent immobilization and efficient delivery of DNA," Angewandte Chemie International Edition, vol. 44, no. 30, pp. 4782-4785, 2005.

[109] Y. Shan and L. Gao, "In situ coating carbon nanotubes with wurtzite ZnS nanocrystals," Journal of the American Ceramic Society, vol. 89, no. 2, pp. 759-762, 2006.

[110] X. Hu, T. Wang, X. Qu, and S. Dong, "In situ synthesis and characterization of multiwalled carbon nanotube/Au nanoparticle composite materials," The Journal of Physical Chemistry B, vol. 110, no. 2, pp. 853-857, 2006.

[111] X. Hu, T. Wang, L. Wang, S. Guo, and S. Dong, "A general route to prepare one- and three-dimensional carbon nanotube/metal nanoparticle composite nanostructures," Langmuir, vol. 23, no. 11, pp. 6352-6357, 2007.

[112] D. Ivnitski, B. Branch, P. Atanassov, and C. Apblett, "Glucose oxidase anode for biofuel cell based on direct electron transfer," Electrochemistry Communications, vol. 8, no. 8, pp. 1204-1210, 2006.

[113] M. D. Rubianes and G. A. Rivas, "Dispersion of multi-wall carbon nanotubes in polyethylenimine: a new alternative for preparing electrochemical sensors," Electrochemistry Communications, vol. 9, no. 3, pp. 480-484, 2007.

[114] A. S. Arribas, E. Bermejo, M. Chicharro, et al., "Analytical applications of glassy carbon electrodes modified with multiwall carbon nanotubes dispersed in polyethylenimine as detectors in flow systems," Analytica Chimica Acta, vol. 596, no. 2, pp. 183-194, 2007.

[115] M. Chicharro, A. S. Arribas, M. Moreno, E. Bermejo, and A. Zapardiel, "Comparative study of multi walled carbon nanotubes-based electrodes in micellar media and their application to micellar electrokinetic capillary chromatography," Talanta, vol. 74, no. 3, pp. 376-386, 2007.

[116] M. C. Rodríguez, M. D. Rubianes, and G. A. Rivas, "Highly selective determination of dopamine in the presence of ascorbic acid and serotonin at glassy carbon electrodes modified with carbon nanotubes dispersed in polyethylenimine," Journal of Nanoscience and Nanotechnology, vol. 8, no. 11, pp. 6003-6009, 2008.

[117] J.-D. Qiu, R. Wang, R.-P. Liang, and M. Xiong, "Synthesis and characterization of MWNTs/AuNPs/HS $\left(\mathrm{CH}_{2}\right)_{6} \mathrm{Fc}$ nanocomposite: application to electrochemical determination of ascorbic acid," Electroanalysis, vol. 20, no. 16, pp. 1819-1824, 2008.
[118] V. G. Gavalas, S. A. Law, J. C. Ball, R. Andrews, and L. G. Bachas, "Carbon nanotube aqueous sol-gel composites: enzyme-friendly platforms for the development of stable biosensors," Analytical Biochemistry, vol. 329, no. 2, pp. 247252, 2004.

[119] X. Tan, M. Li, P. Cai, L. Luo, and X. Zou, "An amperometric cholesterol biosensor based on multiwalled carbon nanotubes and organically modified sol-gel/chitosan hybrid composite film," Analytical Biochemistry, vol. 337, no. 1, pp. 111-120, 2005.

[120] K. Gong, M. Zhang, Y. Yan, et al., "Sol-gel-derived ceramiccarbon nanotube nanocomposite electrodes: tunable electrode dimension and potential electrochemical applications," Analytical Chemistry, vol. 76, no. 21, pp. 6500-6505, 2004.

[121] P. P. Joshi, S. A. Merchant, Y. Wang, and D. W. Schmidtke, "Amperometric biosensors based on redox polymer-carbon nanotube-enzyme composites," Analytical Chemistry, vol. 77, no. 10, pp. 3183-3188, 2005.

[122] F. Zhao, X. Wu, M. Wang, Y. Liu, L. Gao, and S. Dong, "Electrochemical and bioelectrochemistry properties of roomtemperature ionic liquids and carbon composite materials," Analytical Chemistry, vol. 76, no. 17, pp. 4960-4967, 2004.

[123] Y. Zhang, Y. Shen, J. Li, L. Niu, S. Dong, and A. Ivaska, "Electrochemical functionalization of single-walled carbon nanotubes in large quantities at a room-temperature ionic liquid supported three-dimensional network electrode," Langmuir, vol. 21, no. 11, pp. 4797-4800, 2005.

[124] Y. Zhao, Y. Gao, D. Zhan, et al., "Selective detection of dopamine in the presence of ascorbic acid and uric acid by a carbon nanotubes-ionic liquid gel modified electrode," Talanta, vol. 66, no. 1, pp. 51-57, 2005.

[125] J. Zhao, "Glucose electrochemical sensors based on nanostructructures: fabrication and analytical application," Ph.D. thesis, Wuhan University, Wuhan, China, 2006.

[126] Y. Lin, L. F. Allard, and Y.-P. Sun, "Protein-affinity of singlewalled carbon nanotubes in water," The Journal of Physical Chemistry B, vol. 108, no. 12, pp. 3760-3764, 2004.

[127] S. S. Karajanagi, H. Yang, P. Asuri, E. Sellitto, J. S. Dordick, and R. S. Kane, "Protein-assisted solubilization of singlewalled carbon nanotubes," Langmuir, vol. 22, no. 4, pp. 13921395, 2006.

[128] C. H. Yang, C. Hu, and S. Hu, "Predominating stable adsorption and direct electrochemistry of glucose oxidase on carbon nanotubes by oxygen-containing groups," Chinese Chemical Letters, vol. 18, no. 3, pp. 313-315, 2007.

[129] J. Chen, M. J. Dyer, and M.-F. Yu, "Cyclodextrin-mediated soft cutting of single-walled carbon nanotubes," Journal of the American Chemical Society, vol. 123, no. 25, pp. 6201-6202, 2001.

[130] G. Chambers, C. Carroll, G. F. Farrell, et al., "Characterization of the interaction of gamma cyclodextrin with singlewalled carbon nanotubes," Nano Letters, vol. 3, no. 6, pp. 843-846, 2003.

[131] Z. Wang, Y. Wang, and G. Luo, "The electrocatalytic oxidation of thymine at $\alpha$-cyclodextrin incorporated carbon nanotube-coated electrode," Electroanalysis, vol. 15, no. 13, pp. 1129-1133, 2003.

[132] Z.-H. Wang, G.-A. Luo, S.-F. Xiao, and G.-Y. Wang, "Electrocatalitic behavior of nitrophenol isomers at $\alpha$-cyclodextrin incorporated carbon nanotubes-coated electrode," Chemical Journal of Chinese Universities, vol. 24, part 5, pp. 811-813, 2003. 
[133] G.-Y. Wang, X.-J. Liu, G.-A. Luo, and Z.-H. Wang, " $\alpha$ cyclodextrin incorporated carbon nanotube-coated electrode for the simultaneous determination of dopamine and epinephrine," Chinese Journal of Chemistry, vol. 23, no. 3, pp. 297-302, 2005.

[134] Z. Wang, Y. Wang, and G. Luo, "A selective voltammetric method for uric acid detection at $\beta$-cyclodextrin modified electrode incorporating carbon nanotubes," Analyst, vol. 127, no. 10, pp. 1353-1358, 2002.

[135] G. Wang, X. Liu, B. Yu, and G. Luo, "Electrocatalytic response of norepinephrine at a $\beta$-cyclodextrin incorporated carbon nanotube modified electrode," Journal of Electroanalytical Chemistry, vol. 567, no. 2, pp. 227-231, 2004.

[136] C. Hu, C. Yang, and S. Hu, "Hydrophobic adsorption of surfactants on water-soluble carbon nanotubes: a simple approach to improve sensitivity and antifouling capacity of carbon nanotubes-based electrochemical sensors," Electrochemistry Communications, vol. 9, no. 1, pp. 128-134, 2007.

[137] R. J. Chen, Y. Zhang, D. Wang, and H. Dai, "Noncovalent sidewall functionalization of single-walled carbon nanotubes for protein immobilization," Journal of the American Chemical Society, vol. 123, no. 16, pp. 3838-3839, 2001.

[138] Y. Yan, M. Zhang, K. Gong, L. Su, Z. Guo, and L. Mao, "Adsorption of methylene blue dye onto carbon nanotubes: a route to an electrochemically functional nanostructure and its layer-by-layer assembled nanocomposite," Chemistry of Materials, vol. 17, no. 13, pp. 3457-3463, 2005.

[139] C. Hu, Z. Chen, A. Shen, X. Shen, J. Li, and S. Hu, "Watersoluble single-walled carbon nanotubes via noncovalent functionalization by a rigid, planar and conjugated diazo dye," Carbon, vol. 44, no. 3, pp. 428-434, 2006.

[140] C. Yang, Y. Xu, C. Hu, and S. Hu, "Voltammetric detection of ofloxacin in human urine at a Congo red functionalized water-soluble carbon nanotube film electrode," Electroanalysis, vol. 20, no. 2, pp. 144-149, 2008.

[141] C. Hu, X. Chen, and S. Hu, "Water-soluble single-walled carbon nanotubes films: preparation, characterization and applications as electrochemical sensing films," Journal of Electroanalytical Chemistry, vol. 586, no. 1, pp. 77-85, 2006.

[142] M. Zhang, Y. Yan, K. Gong, L. Mao, Z. Guo, and Y. Chen, "Electrostatic layer-by-layer assembled carbon nanotube multilayer film and its electrocatalytic activity for $\mathrm{O}_{2}$ reduction," Langmuir, vol. 20, no. 20, pp. 8781-8785, 2004.

[143] A. A. Mamedov, N. A. Kotov, M. Prato, D. M. Guldi, J. P. Wicksted, and A. Hirsch, "Molecular design of strong single-wall carbon nanotube/polyelectrolyte multilayer composites," Nature Materials, vol. 1, no. 3, pp. 190-194, 2002.

[144] D.-Q. Yang, J.-F. Rochelte, and E. Sacher, "Spectroscopic evidence for $\pi-\pi$ interaction between poly(diallyl dimethylammonium) chloride and multiwalled carbon nanotubes," The Journal of Physical Chemistry B, vol. 109, no. 10, pp. 4481-4484, 2005.

[145] M. Guo, J. Chen, J. Li, L. Nie, and S. Yao, "Carbon nanotubes-based amperometric cholesterol biosensor fabricated through layer-by-layer technique," Electroanalysis, vol. 16, no. 23, pp. 1992-1998, 2004.

[146] M. Zhang, K. Gong, H. Zhang, and L. Mao, "Layer-by-layer assembled carbon nanotubes for selective determination of dopamine in the presence of ascorbic acid," Biosensors and Bioelectronics, vol. 20, no. 7, pp. 1270-1276, 2005.

[147] P. He and M. Bayachou, "Layer-by-layer fabrication and characterization of DNA-wrapped single-walled carbon nanotube particles," Langmuir, vol. 21, no. 13, pp. 6086-6092, 2005.
[148] J. Liu, S. Tian, and W. Knoll, "Properties of polyaniline/carbon nanotube multilayer films in neutral solution and their application for stable low-potential detection of reduced $\beta$-nicotinamide adenine dinucleotide," Langmuir, vol. 21, no. 12, pp. 5596-5599, 2005.

[149] X. Li, L. Zhang, L. Su, T. Ohsaka, and L. Mao, "A miniature glucose $/ \mathrm{O}_{2}$ biofuel cell with a high tolerance against ascorbic acid," Fuel Cells, vol. 9, no. 1, pp. 85-91, 2009.

[150] J. J. Gooding, R. Wibowo, J. Liu, et al., "Protein electrochemistry using aligned carbon nanotube arrays," Journal of the American Chemical Society, vol. 125, no. 30, pp. 9006-9007, 2003.

[151] Z. Liu, Z. Shen, T. Zhu, et al., "Organizing single-walled carbon nanotubes on gold using a wet chemical selfassembling technique," Langmuir, vol. 16, no. 8, pp. 35693573,2000 .

[152] J. Liu, A. Chou, W. Rahmat, M. N. Paddon-Row, and J. J. Gooding, "Achieving direct electrical connection to glucose oxidase using aligned single walled carbon nanotube arrays," Electroanalysis, vol. 17, no. 1, pp. 38-46, 2005.

[153] J. J. Xu, G. Wang, Q. Zhang, X. H. Xia, and H. Y. Chen, "Third generation horseradish peroxidase biosensor based on selfassembling carbon nanotubes to gold electrode surface," Chinese Chemical Letters, vol. 16, no. 4, pp. 523-526, 2005.

[154] X. Qu, Z. Peng, Y. Wang, and S. Dong, "Atomic force microscopic and electrochemical investigations of an electrostatically fabricated single-wall carbon nanotubes modified electrode," Electroanalysis, vol. 17, no. 1, pp. 59-64, 2005.

[155] D. Chattopadhyay, I. Galeska, and F. Papadimitrakopoulos, "Metal-assisted organization of shortened carbon nanotubes in monolayer and multilayer forest assemblies," Journal of the American Chemical Society, vol. 123, no. 38, pp. 9451-9452, 2001.

[156] X. Yu, D. Chattopadhyay, I. Galeska, F. Papadimitrakopoulos, and J. F. Rusling, "Peroxidase activity of enzymes bound to the ends of single-wall carbon nanotube forest electrodes," Electrochemistry Communications, vol. 5, no. 5, pp. 408-411, 2003.

[157] M. O’Connor, S. N. Kim, A. J. Killard, et al., "Mediated amperometric immunosensing using single walled carbon nanotube forests," Analyst, vol. 129, no. 12, pp. 1176-1180, 2004.

[158] P. J. Britto, K. S. V. Santhanam, and P. M. Ajayan, "Carbon nanotube electrode for oxidation of dopamine," Bioelectrochemistry and Bioenergetics, vol. 41, no. 1, pp. 121-125, 1996.

[159] J. J. Davis, R. J. Coles, and H. A. O. Hill, "Protein electrochemistry at carbon nanotube electrodes," Journal of Electroanalytical Chemistry, vol. 440, no. 1-2, pp. 279-282, 1997.

[160] F. Valentini, A. Amine, S. Orlanducci, M. L. Terranova, and G. Palleschi, "Carbon nanotube purification: preparation and characterization of carbon nanotube paste electrodes," Analytical Chemistry, vol. 75, no. 20, pp. 5413-5421, 2003.

[161] R. Antiochia, I. Lavagnini, F. Magno, F. Valentini, and G. Palleschi, "Single-wall carbon nanotube paste electrodes: a comparison with carbon paste, platinum and glassy carbon electrodes via cyclic voltammetric data," Electroanalysis, vol. 16, no. 17, pp. 1451-1458, 2004.

[162] M. Chicharro, E. Bermejo, M. Moreno, A. Sánchez, A. Zapardiel, and G. Rivas, "Adsorptive stripping voltammetric determination of amitrole at a multi-wall carbon nanotubes paste electdrode," Electroanalysis, vol. 17, no. 5-6, pp. 476482, 2005. 
[163] N. S. Lawrence, R. P. Deo, and J. Wang, "Detection of homocysteine at carbon nanotube paste electrodes," Talanta, vol. 63, no. 2, pp. 443-449, 2004.

[164] M. L. Pedano and G. A. Rivas, "Adsorption and electrooxidation of nucleic acids at carbon nanotubes paste electrodes," Electrochemistry Communications, vol. 6, no. 1, pp. 10-16, 2004.

[165] J. Wang, G. Chen, M. Wang, and M. P. Chatrathi, "Carbonnanotube/copper composite electrodes for capillary electrophoresis microchip detection of carbohydrates," Analyst, vol. 129, no. 6, pp. 512-515, 2004.

[166] M. D. Rubianes and G. A. Rivas, "Carbon nanotubes paste electrode," Electrochemistry Communications, vol. 5, no. 8, pp. 689-694, 2003.

[167] M. D. Rubianes and G. A. Rivas, "Enzymatic biosensors based on carbon nanotubes paste electrodes," Electroanalysis, vol. 17, no. 1, pp. 73-78, 2005.

[168] R. Antiochia, I. Lavagnini, P. Pastore, and F. Magno, "A comparison between the use of a redox mediator in solution and of surface modified electrodes in the electrocatalytic oxidation of nicotinamide adenine dinucleotide," Bioelectrochemistry, vol. 64, no. 2, pp. 157-163, 2004.

[169] R. Antiochia, I. Lavagnini, and F. Magno, "Electrocatalytic oxidation of $\mathrm{NADH}$ at single-wall carbon-nanotube-paste electrodes: kinetic considerations for use of a redox mediator in solution and dissolved in the paste," Analytical and Bioanalytical Chemistry, vol. 381, no. 7, pp. 1355-1361, 2005.

[170] J. Wang and M. Musameh, "Carbon nanotube/teflon composite electrochemical sensors and biosensors," Analytical Chemistry, vol. 75, no. 9, pp. 2075-2079, 2003.

[171] G. Chen, L. Y. Zhang, and J. Wang, "Miniaturized capillary electrophoresis system with a carbon nanotube microelectrode for rapid separation and detection of thiols," Talanta, vol. 64, no. 4, pp. 1018-1023, 2004.

[172] C. S. Cha, C. M. Li, H. X. Yang, and P. F. Liu, "Powder microelectrodes," Journal of Electroanalytical Chemistry, vol. 368, no. 1-2, pp. 47-54, 1994.

[173] P. Liu and J. H. Hu, "Carbon nanotube powder microelectrodes for nitrite detection," Sensors and Actuators B, vol. 84, no. 2-3, pp. 194-199, 2002.

[174] Y.-D. Zhao, W.-D. Zhang, H. Chen, and Q.-M. Luo, "Anodic oxidation of hydrazine at carbon nanotube powder microelectrode and its detection," Talanta, vol. 58, no. 3, pp. 529534, 2002.

[175] Y.-D. Zhao, W.-D. Zhang, H. Chen, and Q.-M. Luo, "Electrocatalytic oxidation of cysteine at carbon nanotube powder microelectrode and its detection," Sensors and Actuators B, vol. 92, no. 3, pp. 279-285, 2003.

[176] Y.-D. Zhao, W.-D. Zhang, H. Chen, Q.-M. Luo, and S. F. Y. Li, "Direct electrochemistry of horseradish peroxidase at carbon nanotube powder microelectrode," Sensors and Actuators B, vol. 87, no. 1, pp. 168-172, 2002.

[177] Y. L. Wei, X. Ji, X. Dang, and S. Hu, "Studies on electrochemical properties and scavenge of superoxide anion in aprotic media by using carbon nanotubes powder microelectrode," Bioelectrochemistry, vol. 61, no. 1-2, pp. 51-56, 2003.

[178] Z. Wang, J. Liu, Q. Liang, Y. Wang, and G. Luo, "Carbon nanotube-modified electrodes for the simultaneous determination of dopamine and ascorbic acid," Analyst, vol. 127, no. 5, pp. 653-658, 2002.

[179] Z.-H. Wang, Q.-L. Liang, Y.-M. Wang, and G.-A. Luo, "Carbon nanotube-intercalated graphite electrodes for simultane- ous determination of dopamine and serotonin in the presence of ascorbic acid," Journal of Electroanalytical Chemistry, vol. 540, pp. 129-134, 2003.

[180] Q. Shi, T. Peng, and J. Cheng, "A cholesterol biosensor based on cholesterol oxidase immobilized in a sol-gel on a platinum-decorated carbon nanotubes modified electrode," Chinese Journal of Analytical Chemistry, vol. 33, no. 3, pp. 329-332, 2005.

[181] Q. Shi, T. Peng, Y. Zhu, and C. F. Yang, "An electrochemical biosensor with cholesterol oxidase/sol-gel film on a nanoplatinum/carbon nanotube electrode," Electroanalysis, vol. 17, no. 10, pp. 857-861, 2005.

[182] A. Salimi, C. E. Banks, and R. G. Compton, "Abrasive immobilization of carbon nanotubes on a basal plane pyrolytic graphite electrode: application to the detection of epinephrine," Analyst, vol. 129, no. 3, pp. 225-228, 2004.

[183] A. Salimi, R. G. Compton, and R. Hallaj, "Glucose biosensor prepared by glucose oxidase encapsulated sol-gel and carbonnanotube-modified basal plane pyrolytic graphite electrode," Analytical Biochemistry, vol. 333, no. 1, pp. 49-56, 2004.

[184] A. Salimi, R. Hallaj, and G.-R. Khayatian, "Amperometric detection of morphine at preheated glassy carbon electrode modified with multiwall carbon nanotubes," Electroanalysis, vol. 17, no. 10, pp. 873-879, 2005.

[185] A. Salimi and R. Hallaj, "Catalytic oxidation of thiols at preheated glassy carbon electrode modified with abrasive immobilization of multiwall carbon nanotubes: applications to amperometric detection of thiocytosine, L-cysteine and glutathione," Talanta, vol. 66, no. 4, pp. 967-975, 2005.

[186] K. Wu and S. Hu, "Deposition of a thin film of carbon nanotubes onto a glassy carbon electrode by electropolymerization," Carbon, vol. 42, no. 15, pp. 3237-3242, 2004.

[187] D. Pan, J. Chen, S. Yao, W. Tao, and L. Nie, "An amperometric glucose biosensor based on glucose oxidase immobilized in electropolymerized poly (o-aminophenol) and carbon nanotubes composite film on a gold electrode," Analytical Sciences, vol. 21, no. 4, pp. 367-371, 2005.

[188] G. Cheng, J. Zhao, Y. Tu, P. He, and Y. Fang, "A sensitive DNA electrochemical biosensor based on magnetite with a glassy carbon electrode modified by muti-walled carbon nanotubes in polypyrrole," Analytica Chimica Acta, vol. 533, no. 1, pp. 11-16, 2005.

[189] J. Wang and M. Musameh, "Carbon-nanotubes doped polypyrrole glucose biosensor," Analytica Chimica Acta, vol. 539, no. 1-2, pp. 209-213, 2005.

[190] D. Zheng, C. Hu, Y. Peng, W. Yue, and S. Hu, "Noncovalently functionalized water-soluble multiwall-nanotubes through azocarmine B and their application in nitric oxide sensor," Electrochemistry Communications, vol. 10, no. 1, pp. 90-94, 2008.

[191] J.-S. Ye, Y. Wen, W. De Zhang, L. M. Gan, G. Q. Xu, and F.-S. Sheu, "Selective voltammetric detection of uric acid in the presence of ascorbic acid at well-aligned carbon nanotube electrode," Electroanalysis, vol. 15, no. 21, pp. 1693-1698, 2003.

[192] J. Chen, J. Bao, C. Cai, and T. Lu, "Electrocatalytic oxidation of NADH at an ordered carbon nanotubes modified glassy carbon electrode," Analytica Chimica Acta, vol. 516, no. 1-2, pp. 29-34, 2004.

[193] J.-S. Ye, Y. Wen, W. De Zhang, L. M. Gan, G. Q. Xu, and F.-S. Sheu, "Nonenzymatic glucose detection using multi-walled carbon nanotube electrodes," Electrochemistry Communications, vol. 6, no. 1, pp. 66-70, 2004. 
[194] P. Soundarrajan, A. Patil, and L. Dai, "Surface modification of aligned carbon nanotube arrays for electrochemical sensing applications," Journal of Vacuum Science and Technology A, vol. 21, no. 4, pp. 1198-1201, 2003.

[195] M. Gao, L. Dai, and G. G. Wallace, "Biosensors based on aligned carbon nanotubes coated with inherently conducting polymers," Electroanalysis, vol. 15, no. 13, pp. 1089-1094, 2003.

[196] M. Gao, L. Dai, and G. G. Wallace, "Glucose sensors based on glucose-oxidase-containing polypyrrole/aligned carbon nanotube coaxial nanowire electrodes," Synthetic Metals, vol. 137, no. 1-3, pp. 1393-1394, 2003.

[197] K. P. Loh, S. L. Zhao, and W. De Zhang, "Diamond and carbon nanotube glucose sensors based on electropolymerization," Diamond and Related Materials, vol. 13, no. 4-8, pp. 1075-1079, 2004.

[198] J.-S. Ye, Y. Wen, W. De Zhang, H. F. Cui, G. Q. Xu, and F.-S. Sheu, "Electrochemical biosensing platforms using phthalocyanine-functionalized carbon nanotube electrode," Electroanalysis, vol. 17, no. 1, pp. 89-96, 2005.

[199] S. G. Wang, Q. Zhang, R. Wang, et al., "Multi-walled carbon nanotubes for the immobilization of enzyme in glucose biosensors," Electrochemistry Communications, vol. 5, no. 9, pp. 800-803, 2003.

[200] H. Tang, J. Chen, S. Yao, L. Nie, G. Deng, and Y. Kuang, "Amperometric glucose biosensor based on adsorption of glucose oxidase at platinum nanoparticle-modified carbon nanotube electrode," Analytical Biochemistry, vol. 331, no. 1, pp. 89-97, 2004.

[201] J.-S. Ye, Y. Wen, W. De Zhang, et al., "Application of multiwalled carbon nanotubes functionalized with hemin for oxygen detection in neutral solution," Journal of Electroanalytical Chemistry, vol. 562, no. 2, pp. 241-246, 2004.

[202] Y. Tu, Y. Lin, and Z. F. Ren, "Nanoelectrode arrays based on low site density aligned carbon nanotubes," Nano Letters, vol. 3, no. 1, pp. 107-109, 2003.

[203] Y. Tu, Y. Lin, W. Yantasee, and Z. Ren, "Carbon nanotubes based nanoelectrode arrays: fabrication, evaluation, and application in voltammetric analysis," Electroanalysis, vol. 17, no. 1, pp. 79-84, 2005.

[204] G. Liu, Y. Lin, Y. Tu, and Z. Ren, "Ultrasensitive voltammetric detection of trace heavy metal ions using carbon nanotube nanoelectrode array," Analyst, vol. 130, no. 7, pp. 1098-1101, 2005.

[205] J. Li, H. T. Ng, A. Cassell, et al., "Carbon nanotube nanoelectrode array for ultrasensitive DNA detection," Nano Letters, vol. 3, no. 5, pp. 597-602, 2003.

[206] J. Koehne, J. Li, A. M. Cassell, et al., "The fabrication and electrochemical characterization of carbon nanotube nanoelectrode arrays," Journal of Materials Chemistry, vol. 14, no. 4, pp. 676-684, 2004.

[207] J. E. Koehne, H. Chen, A. M. Cassell, et al., "Miniaturized multiplex label-free electronic chip for rapid nucleic acid analysis based on carbon nanotube nanoelectrode arrays," Clinical Chemistry, vol. 50, no. 10, pp. 1886-1893, 2004.

[208] X.-N. Cao, L. Lin, Y.-Z. Xian, W. Zhang, Y.-F. Xie, and L.T. Jin, "In vivo monitoring of the thiols in rat striatum by liquid chromatography with amperometric detection at a functionalized multi-wall carbon nanotubes modified electrode," Electroanalysis, vol. 15, no. 10, pp. 892-897, 2003.

[209] Y. Xian, Y. Zhou, H. Wang, L. Zhou, F. Liu, and L. Jin, "Nanostructured electrode based on multi-wall carbon nanotubes/Pt microparticles nanocomposite for electrochemical determination of thiols in rat striatum by high performance liquid chromatography separation," Journal of Chromatography B, vol. 817, no. 2, pp. 239-246, 2005.

[210] S. Fei, J. Chen, S. Yao, G. Deng, D. He, and Y. Kuang, "Electrochemical behavior of L-cysteine and its detection at carbon nanotube electrode modified with platinum," Analytical Biochemistry, vol. 339, no. 1, pp. 29-35, 2005.

[211] J. Wang, M. Li, Z. Shi, N. Li, and Z. Gu, "Investigation of the electrocatalytic behavior of single-wall carbon nanotube films on an Au electrode," Microchemical Journal, vol. 73, no. 3, pp. 325-333, 2002.

[212] J. Wang, M. Li, Z. Shi, N. Li, and Z. Gu, "Electrocatalytic oxidation of norepinephrine at a glassy carbon electrode modified with single wall carbon nanotubes," Electroanalysis, vol. 14, no. 3, pp. 225-230, 2002.

[213] G. Zhao, S. Zang, K. Liu, et al., "Determination of trace xanthine by anodic stripping voltammetry with carbon nanotube modified glassy carbon electrode," Analytical Letters, vol. 35, no. 14, pp. 2233-2244, 2002.

[214] W. Zhang, Y. Xie, S. Ai, et al., "Liquid chromatography with amperometric detection using functionalized multi-wall carbon nanotube modified electrode for the determination of monoamine neurotransmitters and their metabolites," Journal of Chromatography B, vol. 791, no. 1-2, pp. 217-225, 2003.

[215] W. Zhang, F. Wan, Y. Xie, et al., "Amperometric determination of $(R)$-salsolinol, $(R)-N$-methylsalsolinol and monoamine neurotransmitters with liquid chromatography using functionalized multi-wall carbon nanotube modified electrode in Parkinson's patients' cerebrospinal fluid," Analytica Chimica Acta, vol. 512, no. 2, pp. 207-214, 2004.

[216] H. Yi, D. Zheng, C. Hu, and S. Hu, "Functionalized multiwalled carbon nanotubes through in situ electropolymerization of brilliant cresyl blue for determination of epinephrine," Electroanalysis, vol. 20, no. 10, pp. 1143-1146, 2008.

[217] J. Xu, Y. Wang, Y. Xian, L. Jin, and K. Tanaka, "Preparation of multiwall carbon nanotubes film modified electrode and its application to simultaneous determination of oxidizable amino acids in ion chromatography," Talanta, vol. 60, no. 6, pp. 1123-1130, 2003.

[218] X.-N. Cao, L. Lin, Y.-Y. Zhou, et al., "Amperometric determination of 6-mercaptopurine on functionalized multi-wall carbon nanotubes modified electrode by liquid chromatography coupled with microdialysis and its application to pharmacokinetics in rabbit," Talanta, vol. 60, no. 5, pp. 10631070, 2003.

[219] G. Zhao, K. Liu, S. Lin, J. Liang, X. Guo, and Z. Zhang, "Application of a carbon nanotube modified electrode in anodic stripping voltammetry for determination of trace amounts of 6-benzylaminopurine," Microchimica Acta, vol. 143, no. 4, pp. 255-260, 2003.

[220] W. Qu, K. Wu, and S. Hu, "Voltammetric determination of pyridoxine (Vitamin $\mathrm{B}_{6}$ ) by use of a chemically-modified glassy carbon electrode," Journal of Pharmaceutical and Biomedical Analysis, vol. 36, no. 3, pp. 631-635, 2004.

[221] J. Wang and M. Musameh, "Electrochemical detection of trace insulin at carbon-nanotube-modified electrodes," Analytica Chimica Acta, vol. 511, no. 1, pp. 33-36, 2004.

[222] C. Yang, "Voltammetric determination of tinidazole using a glassy carbon electrode modified with single-wall carbon nanotubes," Analytical Sciences, vol. 20, no. 5, pp. 821-824, 2004. 
[223] B. Zeng and F. Huang, "Electrochemical behavior and determination of fluphenazine at multi-walled carbon nanotubes/(3-mercaptopropyl)trimethoxysilane bilayer modified gold electrodes," Talanta, vol. 64, no. 2, pp. 380-386, 2004.

[224] S.-F. Wang and Q. Xu, "Square wave voltammetry determination of brucine at multiwall carbon nanotube-modified glassy carbon electrodes," Analytical Letters, vol. 38, no. 4, pp. 657-671, 2005.

[225] F. Zhao, F. Huang, Q. Yan, and B. Zeng, "Characterization of dodecanethiol SAM and multi-walled carbon nanotube modified gold electrodes, and voltammetric determination of prochlorperazine," Microchimica Acta, vol. 150, no. 2, pp. 179-185, 2005.

[226] W. Qu, F. Wang, S. Hu, and D. Cui, "Electrocatalytic properties and voltammetric determination of melatonin at a nanostructured film electrode," Microchimica Acta, vol. 150, no. 2, pp. 109-114, 2005.

[227] X. Yang, F. Wang, and S. Hu, "Enhanced oxidation of diclofenac sodium at a nano-structured electrochemical sensing film constructed by multi-wall carbon nanotubessurfactant composite," Materials Science and Engineering C, vol. 28, no. 1, pp. 188-194, 2008.

[228] Y. Peng, C. Lu, B. Hu, Z. Wang, and S. Hu, "Development of an acetylspiramycin sensor based on a single-walled carbon nanotubes film electrode," Microchimica Acta, vol. 158, no. 1-2, pp. 79-84, 2007.

[229] Y. Wu, S. Ye, and S. Hu, "Electrochemical study of lincomycin on a multi-wall carbon nanotubes modified glassy carbon electrode and its determination in tablets," Journal of Pharmaceutical and Biomedical Analysis, vol. 41, no. 3, pp. 820824, 2006.

[230] A. Callegari, S. Cosnier, M. Marcaccio, et al., "Functionalised single wall carbon nanotubes/polypyrrole composites for the preparation of amperometric glucose biosensors," Journal of Materials Chemistry, vol. 14, no. 5, pp. 807-810, 2004.

[231] Y. Zhu, T. Peng, and J. Li, "A glucose biosensor based on the enzyme electrode with carbon nanotube/platinum nanoparticle," Chinese Journal of Analytical Chemistry, vol. 32, no. 10, pp. 1299-1303, 2004.

[232] H. G. Xue, W. L. Sun, B.-J. He, and Z. Q. Shen, "A new application of carbon nanotubes constructing biosensor," Chinese Chemical Letters, vol. 13, no. 8, pp. 799-800, 2002.

[233] H. G. Xue, W. L. Sun, B.-J. He, and Z. Q. Shen, "Single-wall carbon manotubes as immobilization material for glucose biosensor," Synthetic Metals, vol. 135-136, pp. 831-832, 2003.

[234] M. Musameh, J. Wang, A. Merkoci, and Y. Lin, "Lowpotential stable NADH detection at carbon-nanotubemodified glassy carbon electrodes," Electrochemistry Communications, vol. 4, no. 10, pp. 743-746, 2002.

[235] J. Chen, J. C. Bao, C. X. Cai, and T. H. Lu, "Direct electrochemical oxidation of dihydronicotiamide adenine dinucleotide $(\mathrm{NADH})$ at an ordered carbon nanotubes electrode," Chinese Chemical Letters, vol. 14, no. 11, pp. 11711174, 2003.

[236] M. Zhang and W. Gorski, "Electrochemical sensing platform based on the carbon nanotubes/redox mediators-biopolymer system," Journal of the American Chemical Society, vol. 127, no. 7, pp. 2058-2059, 2005.

[237] J. Wang and M. Musameh, "A reagentless amperometric alcohol biosensor based on carbon-nanotube/teflon composite electrodes," Analytical Letters, vol. 36, no. 9, pp. 2041-2048, 2003.
[238] R. Antiochia, I. Lavagnini, and F. Magno, "Amperometric mediated carbon nanotube paste biosensor for fructose determination," Analytical Letters, vol. 37, no. 8, pp. 16571669, 2004.

[239] J. S. Lenihan, V. G. Gavalas, J. Wang, R. Andrews, and L. G. Bachas, "Protein immobilization on carbon nanotubes through a molecular adapter," Journal of Nanoscience and Nanotechnology, vol. 4, no. 6, pp. 600-604, 2004.

[240] M. Trojanowicz, A. Mulchandani, and M. Mascini, "Carbon nanotubes-modified screen-printed electrodes for chemical sensors and biosensors," Analytical Letters, vol. 37, no. 15, pp. 3185-3204, 2004.

[241] J.-Z. Xu, J.-J. Zhu, Q. Wu, Z. Hu, and H.-Y. Chen, "An amperometric biosensor based on the coimmobilization of horseradish peroxidase and methylene blue on a carbon nanotubes modified electrode," Electroanalysis, vol. 15, no. 3, pp. 219-224, 2003.

[242] Y.-P. Li, H.-B. Cao, and Y. Zhang, "Direct electrochemistry of hemoglobin immobilized on carbon paste electrode modified by carbon nanotubes," Acta Physico-Chimica Sinica, vol. 21, no. 2, pp. 187-191, 2005.

[243] L. Zhang, G.-C. Zhao, X.-W. Wei, and Z.-S. Yang, "Electroreduction of oxygen by myoglobin on multi-walled carbon nanotube-modified glassy carbon electrode," Chemistry Letters, vol. 33, no. 2, pp. 86-87, 2004.

[244] L. Zhang, G.-C. Zhao, X.-W. Wei, and Z.-S. Yang, "A nitric oxide biosensor based on myoglobin adsorbed on multiwalled carbon nanotubes," Electroanalysis, vol. 17, no. 7, pp. 630-634, 2005.

[245] J. Wang, M. Li, Z. Shi, N. Li, and Z. Gu, "Direct electrochemistry of cytochrome $c$ at a glassy carbon electrode modified with single-wall carbon nanotubes," Analytical Chemistry, vol. 74, no. 9, pp. 1993-1997, 2002.

[246] F.-L. Cheng, S. Du, and B.-K. Jin, "Electrochemical studies of cytochrome c on electrodes modified by single-wall carbon nanotubes," Chinese Journal of Chemistry, vol. 21, no. 4, pp. 436-441, 2003.

[247] Y. Wu and S. Hu, "The fabrication of a colloidal goldcarbon nanotubes composite film on a gold electrode and its application for the determination of cytochrome $c$," Colloids and Surfaces B, vol. 41, no. 4, pp. 299-304, 2005.

[248] C. X. Cai and J. Chen, "Direct electrochemistry of horseradish peroxidase at a carbon nanotube electrode," Acta Chimica Sinica, vol. 62, no. 3, pp. 335-340, 2004.

[249] W. Zheng, Q. Li, Y. Yan, L. Su, and L. Mao, "Functionalization of carbon nanotubes for direct electrochemistry of horseradish peroxidase," Indian Journal of Chemistry. Section A, vol. 44, no. 5, pp. 950-955, 2005.

[250] Q. Zhao, L. H. Guan, Z. N. Gu, and Q. K. Zhuang, "Direct electrochemistry of catalase on single wall carbon nanotubes modified glassy carbon electrode," Chinese Chemical Letters, vol. 16, no. 4, pp. 501-504, 2005.

[251] M. Wang, Y. Shen, Y. Liu, et al., "Direct electrochemistry of microperoxidase 11 using carbon nanotube modified electrodes," Journal of Electroanalytical Chemistry, vol. 578, no. 1, pp. 121-127, 2005.

[252] J.-Z. Xu, J.-J. Zhu, Q. Wu, Z. Hu, and H.-Y. Chen, "Direct electron transfer between glucose oxidase and multi-walled carbon nanotubes," Chinese Journal of Chemistry, vol. 21, no. 8, pp. 1088-1091, 2003.

[253] C. X. Cai, J. Chen, and T. Lu, "Direct electron transfer of glucose oxidase on the carbon nanotube electrode," Science in China, Series B, vol. 47, no. 2, pp. 113-119, 2004. 
[254] W. Liang and Y. Zhuobin, "Direct electrochemistry of glucose oxidase at a gold electrode modified with single-wall carbon nanotubes," Sensors, vol. 3, no. 12, pp. 544-554, 2003.

[255] J. H. T. Luong, S. Hrapovic, D. Wang, F. Bensebaa, and B. Simard, "Solubilization of multiwall carbon nanotubes by 3 -aminopropyltriethoxysilane towards the fabrication of electrochemical biosensors with promoted electron transfer," Electroanalysis, vol. 16, no. 1-2, pp. 132-139, 2004.

[256] J.-F. Rochette, E. Sacher, M. Meunier, and J. H. T. Luong, "A mediatorless biosensor for putrescine using multiwalled carbon nanotubes," Analytical Biochemistry, vol. 336, no. 2, pp. 305-311, 2005.

[257] J. H. T. Luong, S. Hrapovic, and D. Wang, "Multiwall carbon nanotube (MWCNT) based electrochemical biosensors for mediatorless detection of putrescine," Electroanalysis, vol. 17, no. 1, pp. 47-53, 2005.

[258] L. Wang and Z. Yuan, "Direct electrochemistry of xanthine oxidase at a gold electrode modified with single-wall carbon nanotubes," Analytical Sciences, vol. 20, no. 4, pp. 635-638, 2004.

[259] Y. Wu and S. Hu, "Direct electron transfer of xanthine oxidase and its catalytic reduction to nitrate," Analytica Chimica Acta, vol. 602, no. 2, pp. 181-186, 2007.

[260] A. Guiseppi-Elie, C. Lei, and R. H. Baughman, "Direct electron transfer of glucose oxidase on carbon nanotubes," Nanotechnology, vol. 13, no. 5, pp. 559-564, 2002.

[261] F. Patolsky, Y. Weizmann, and I. Willner, "Long-range electrical contacting of redox enzymes by SWCNT connectors," Angewandte Chemie International Edition, vol. 43, no. 16, pp. 2113-2117, 2004.

[262] J. Liu, M. N. Paddon-Row, and J. J. Gooding, "Heterogeneous electron-transfer kinetics for flavin adenine dinucleotide and ferrocene through alkanethiol mixed monolayers on gold electrodes," Journal of Physical Chemistry B, vol. 108, no. 24, pp. 8460-8466, 2004.

[263] H. Cai, X. Cao, Y. Jiang, P.-G. He, and Y.-Z. Fang, "Carbon nanotube-enhanced electrochemical DNA biosensor for DNA hybridization detection," Analytical and Bioanalytical Chemistry, vol. 375, no. 2, pp. 287-293, 2003.

[264] H. Cai, Y. Xu, P.-G. He, and Y.-Z. Fang, "Indicator free DNA hybridization detection by impedance measurement based on the DNA-doped conducting polymer film formed on the carbon nanotube modified electrode," Electroanalysis, vol. 15, no. 23-24, pp. 1864-1870, 2003.

[265] Y. Xu, Y. Jiang, H. Cai, P.-G. He, and Y.-Z. Fang, "Electrochemical impedance detection of DNA hybridization based on the formation of M-DNA on polypyrrole/carbon nanotube modified electrode," Analytica Chimica Acta, vol. 516, no. 1-2, pp. 19-27, 2004.

[266] S. G. Wang, R. Wang, P. J. Sellin, and Q. Zhang, "DNA biosensors based on self-assembled carbon nanotubes," Biochemical and Biophysical Research Communications, vol. 325, no. 4, pp. 1433-1437, 2004.

[267] K. Kerman, Y. Morita, Y. Takamura, and E. Tamiya, "Escherichia coli single-strand binding protein-DNA interactions on carbon nanotube-modified electrodes from a labelfree electrochemical hybridization sensor," Analytical and Bioanalytical Chemistry, vol. 381, no. 6, pp. 1114-1121, 2005.

[268] J. Wang, G. Liu, M. R. Jan, and Q. Zhu, "Electrochemical detection of DNA hybridization based on carbon-nanotubes loaded with CdS tags," Electrochemistry Communications, vol. 5, no. 12, pp. 1000-1004, 2003.
[269] J. Wang, M. Li, Z. Shi, N. Li, and Z. Gu, "Electrochemistry of DNA at single-wall carbon nanotubes," Electroanalysis, vol. 16, no. 1-2, pp. 140-144, 2004. 

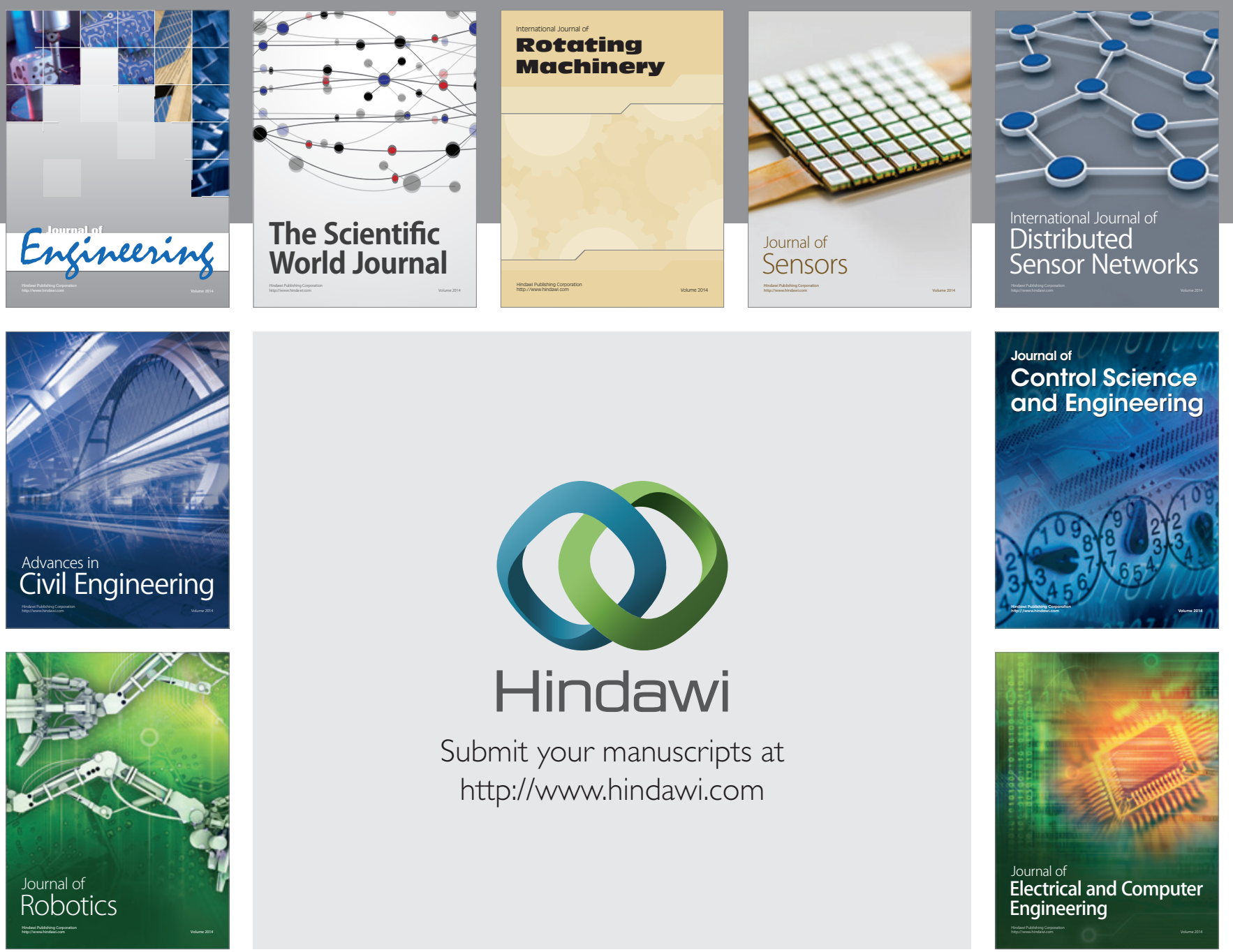

Submit your manuscripts at

http://www.hindawi.com
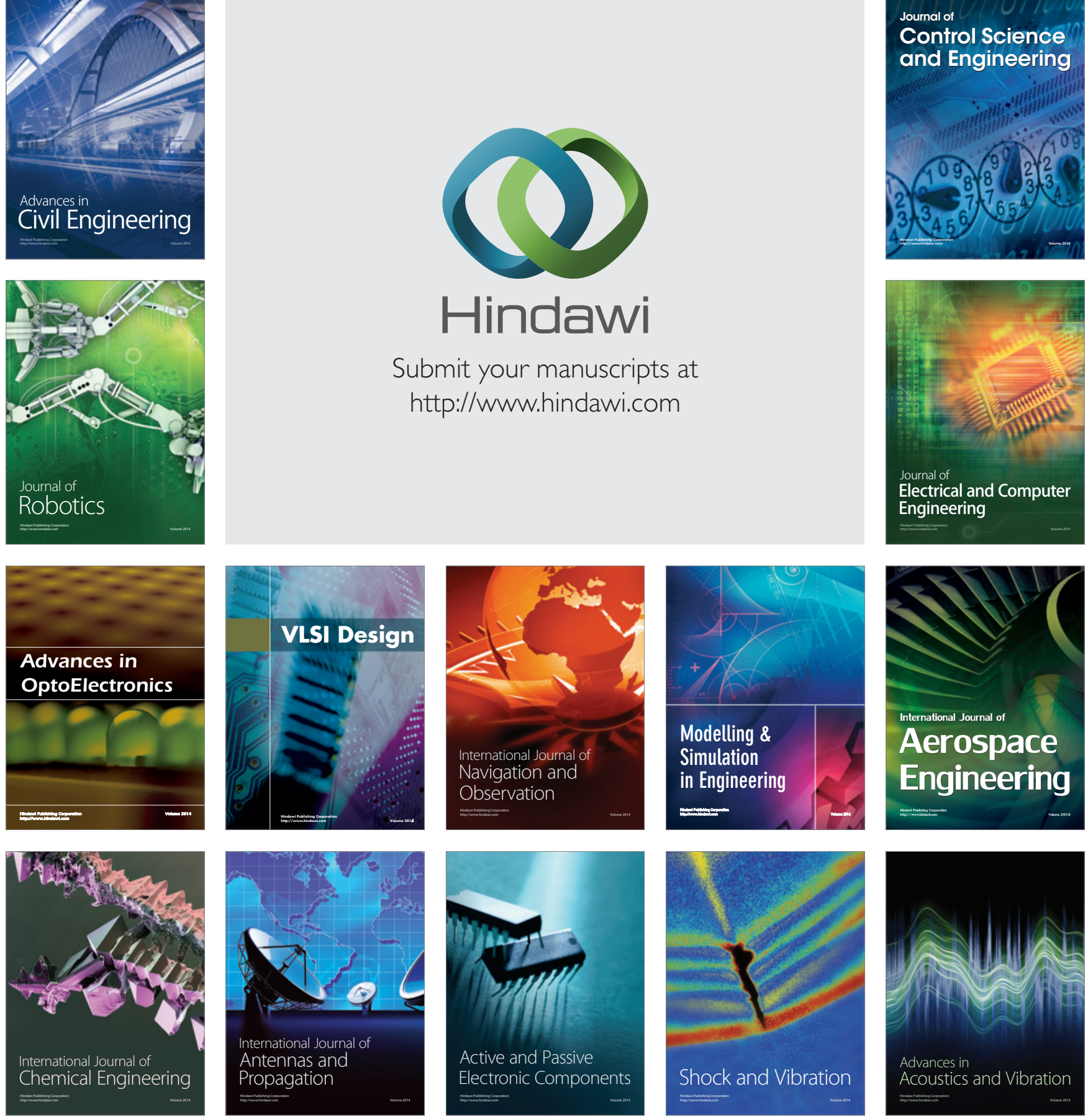